NASA/TM-2008-215415

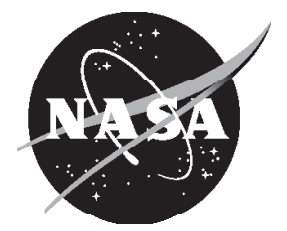

\title{
An Assessment of Current Fan Noise Prediction Capability
}

Edmane Envia

Glenn Research Center, Cleveland, Ohio

Daniel L. Tweedt

AP Solutions, Inc., Solon, Ohio

Richard P. Woodward, David M. Elliott, E. Brian Fite, Christopher E. Hughes, Gary G. Podboy, and Daniel L. Sutliff

Glenn Research Center, Cleveland, Ohio 


\section{NASA STI Program . . . in Profile}

Since its founding, NASA has been dedicated to the advancement of aeronautics and space science. The NASA Scientific and Technical Information (STI) program plays a key part in helping NASA maintain this important role.

The NASA STI Program operates under the auspices of the Agency Chief Information Officer. It collects, organizes, provides for archiving, and disseminates NASA's STI. The NASA STI program provides access to the NASA Aeronautics and Space Database and its public interface, the NASA Technical Reports Server, thus providing one of the largest collections of aeronautical and space science STI in the world. Results are published in both non-NASA channels and by NASA in the NASA STI Report Series, which includes the following report types:

- TECHNICAL PUBLICATION. Reports of completed research or a major significant phase of research that present the results of NASA programs and include extensive data or theoretical analysis. Includes compilations of significant scientific and technical data and information deemed to be of continuing reference value. NASA counterpart of peer-reviewed formal professional papers but has less stringent limitations on manuscript length and extent of graphic presentations.

- TECHNICAL MEMORANDUM. Scientific and technical findings that are preliminary or of specialized interest, e.g., quick release reports, working papers, and bibliographies that contain minimal annotation. Does not contain extensive analysis.

- CONTRACTOR REPORT. Scientific and technical findings by NASA-sponsored contractors and grantees.

- CONFERENCE PUBLICATION. Collected papers from scientific and technical conferences, symposia, seminars, or other meetings sponsored or cosponsored by NASA.

- SPECIAL PUBLICATION. Scientific, technical, or historical information from NASA programs, projects, and missions, often concerned with subjects having substantial public interest.

- TECHNICAL TRANSLATION. Englishlanguage translations of foreign scientific and technical material pertinent to NASA's mission.

Specialized services also include creating custom thesauri, building customized databases, organizing and publishing research results.

For more information about the NASA STI program, see the following:

- Access the NASA STI program home page at http://www.sti.nasa.gov

- E-mail your question via the Internet to help@ sti.nasa.gov

- Fax your question to the NASA STI Help Desk at 301-621-0134

- Telephone the NASA STI Help Desk at 301-621-0390

- Write to: NASA Center for AeroSpace Information (CASI) 7115 Standard Drive Hanover, MD 21076-1320 
NASA/TM-2008-215415

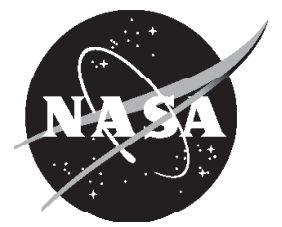

\section{An Assessment of Current Fan Noise Prediction Capability}

Edmane Envia

Glenn Research Center, Cleveland, Ohio

Daniel L. Tweedt

AP Solutions, Inc., Solon, Ohio

Richard P. Woodward, David M. Elliott, E. Brian Fite, Christopher E. Hughes, Gary G. Podboy, and Daniel L. Sutliff

Glenn Research Center, Cleveland, Ohio

Prepared for the

14th Aeroacoustics Conference

cosponsored by American Institute of Aeronautics and Astronautics (AIAA) and Council of European Aerospace Societies (CEAS)

Vancouver, British Columbia, Canada, May 5-7, 2008

National Aeronautics and

Space Administration

Glenn Research Center

Cleveland, Ohio 44135 


\section{Acknowledgments}

E. Envia thanks Dr. Christopher J. Miller for his invaluable suggestions for improving the quality of the mean flow solutions used in the LINFLUX assessment studies.

This report is a formal draft or working paper, intended to solicit comments and ideas from a technical peer group.

This report contains preliminary findings, subject to revision as analysis proceeds.

This work was sponsored by the Fundamental Aeronautics Program at the NASA Glenn Research Center.

Level of Review: This material has been technically reviewed by technical management.

Available from

NASA Center for Aerospace Information 7115 Standard Drive

Hanover, MD 21076-1320
National Technical Information Service 5285 Port Royal Road Springfield, VA 22161 


\title{
An Assessment of Current Fan Noise Prediction Capability
}

\author{
Edmane Envia \\ National Aeronautics and Space Administration \\ Glenn Research Center \\ Cleveland, Ohio 44135 \\ Daniel L. Tweedt \\ AP Solutions, Inc. \\ Solon, Ohio 44139 \\ Richard P. Woodward, David M. Elliott, E. Brian Fite, Christopher E. Hughes, \\ Gary G. Podboy, and Daniel L. Sutliff \\ National Aeronautics and Space Administration \\ Glenn Research Center \\ Cleveland, Ohio 44135
}

\begin{abstract}
In this paper the results of an extensive assessment exercise carried out to establish the current state of the art for predicting fan noise at NASA are presented. Representative codes in the empirical, analytical and computational categories were exercised and assessed against a set of benchmark acoustic data obtained from wind tunnel tests of three model scale fans. The chosen codes were ANOPP representing an empirical capability, RSI representing an analytical capability, and LINFLUX representing a computational aeroacoustics capability. The selected benchmark fans cover a wide range of fan pressure ratios and fan tip speeds, and are representative of modern turbofan engine designs. The assessment results indicate that the ANOPP code can predict fan noise spectrum to within $4 \mathrm{~dB}$ of the measurement uncertainty band on a third-octave basis for the low and moderate tip speed fans except at extreme aft emission angles. The RSI code can predict fan broadband noise spectrum to within $1.5 \mathrm{~dB}$ of experimental uncertainty band provided the rotor-only contribution is taken into account. The LINFLUX code can predict interaction tone power levels to within experimental uncertainties at low and moderate fan tip speeds, but could deviate by as much as $6.5 \mathrm{~dB}$ outside the experimental uncertainty band at the highest tip speeds in some case.
\end{abstract}

\section{Nomenclature}

$\begin{array}{ll}c_{0} & \text { ambient speed of sound } \\ M_{D} & \text { duct Mach number } \\ p & \text { duct acoustic mode pressure } \\ \bar{P} & \text { duct acoustic mode power } \\ R & \text { duct radius } \\ \rho_{0} & \text { ambient density } \\ \sigma & \text { hub-to-tip radius ratio } \\ \zeta & \text { duct acoustic cut-off ratio }\end{array}$

\section{Introduction}

The fan is a significant source of noise in modern aircraft engines and, as such, it is important to establish the ability of aircraft designers to predict its noise contribution accurately. There are a variety of fan noise prediction methods in existence, but in general, these methods can be grouped into three main categories; empirical, analytical and computational.

In the first category, experimental data are used to construct correlations between appropriate fan noise metrics and operating parameters. The correlations are often constructed for overall fan noise levels (i.e., contributions from 
all sources combined) since it is often not possible to conclusively isolate contributions of various noise sources from the total measured noise signature. These methods are widely used, principally as part of system level prediction codes for engine design evaluation studies. While it takes significant experience and skill to discern the appropriate correlation relationships from the mass of available information, once constructed, these methods are relatively easy to use requiring a readily available set of input parameters. Codes based on empirical models tend to require minimal computer resources and run times, typically producing answers on a third-octave spectral basis in a matter of seconds.

As the name suggests, the methods in the second category are analytical in nature relying on first principles as well as phenomenological considerations of the noise generation and propagation processes. Most of the methods in this category are based on the acoustic analogy theory developed by Lighthill. In the acoustic analogy theory, the aerodynamic and acoustic aspects of the problem are treated separately. Mathematically, this is done by a rearrangement of the exact equations of the motion so that a linear wave equation is obtained whose left hand side describes the propagation of sound and its right hand side represents a "known" aerodynamic source that generates the sound. The aerodynamic source is to be measured, computed or otherwise modeled independently. The solution to the wave equation is given formally in terms of integrals that describe convolution of the source distribution and propagation characteristics. Depending on the level of approximations involved in the description of the fan geometry and/or flow conditions, the solution can be expressed either in closed form or may require the use of quadrature schemes to evaluate the solution integrals. Such models have been developed for a number of fan noise sources, but most have been developed to predict the so-called rotor stator interaction noise, which is the tone or broadband noise produced as a result of the interaction between the fan wakes and fan exit guide vanes. The level of expertise needed to use this class of codes is more than the empirical models often requiring access to, or knowledge of, fairly detailed aerodynamic and geometric input parameters from independent measurements or computations. As such, codes based on analytical methods tend to require more computer resources and run times, typically producing answers in a matter of a few minutes for tone noise prediction and a few hours for broadband noise prediction.

The third category of fan noise prediction methods encompasses those approaches that, like the analytical methods start with the equations of motion, but require little or no approximations regarding the fan geometry or flowfield. The resulting coupled system of unsteady flow equations, therefore, retain their complexity and can only be solved numerically through the use of appropriate computational algorithms. These methods, generically called computational aeroacoustics (CAA) methods, include linearized frequency-domain methods as well as nonlinear time-domain methods. With recent advances in computing power and computational algorithms, CAA codes are beginning to gain a place in the toolbox of fan noise prediction methods. The use of CAA tools typically requires a high level of expertise and familiarity with the tools themselves, and with computer hardware and software. Depending on the particular code and application, these codes require significant computer resources, typically requiring tens of hours of computation time for tone noise prediction and several days for broadband noise prediction.

In this paper, a representative code in each category that is available in the public domain will be discussed and assessed against a set of benchmark fan noise data. In each case, a brief description of the code will be given including a discussion of the input parameters and the output produced by the code. It should be emphasized that the list of codes considered here is representative, not exhaustive. Each selected code typifies the current state of the art at NASA in each category, and represents the capabilities of similar codes in that category.

\section{Benchmark Test Cases}

The selected test cases for this study include an ultra high bypass ratio fan stage called the NASA/PW Advanced Ducted Propulsor (ADP) Fan 1, a high bypass ratio fan stage called the NASA/GE Source Diagnostic Test (SDT) fan, and a moderate bypass ratio fan stage called the NASA/Honeywell Quiet High Speed Fan 2 (QHSF2). Again, the test cases selected are not meant to be exhaustive, but representative. All three fans were tested in the NASA Glenn 9-Foot by 15-Foot (9-ft by 15-ft) acoustic wind tunnel over the last decade. In all cases, sideline as well as induct acoustic measurements were acquired for these fan, and have been used for the comparison purposes in this study. Owing to the limitations of the codes, only measured acoustic data from the so-called hard-wall configurations, which do not include acoustic treatment inside the fan duct, have been considered. Table 1 shows select design parameters for these three model fans. The fan design conditions represent a significant value range. The ADP fan has a subsonic design tip speed in contrast to the supersonic design tip speeds for the SDT and QHSF2 fans. Note the change in the fan bypass ratio, pressure ratio and tip speed for the three selected fans. The design 
point corrected inlet weight flows are similar for all three, although the lower flow for the ADP fan is partly due to the higher rotor hub/tip ratio and consequent reduced flow area for that fan. All three fans have a 22-in. diameter rotor and were tested at a number of fan tip speeds. For the purposes of this study, five fan tip speed conditions have been considered which include speeds that are representative of the three certification points, namely, approach, cutback and takeoff, and two intermediate tip speeds. The fan tip speeds investigated in this study are listed in table 2 .

TABLE 1.-MODEL FAN STAGE DESIGN PARAMETERS

\begin{tabular}{|l|c|c|c|}
\hline Parameter & ADP & SDT & QHSF2 \\
\hline Corrected tip speed (ft/sec) & 840 & 1,215 & 1,474 \\
\hline Stage pressure ratio & 1.29 & 1.47 & 1.82 \\
\hline Rotor hub-to-tip-radius-ratio & 0.43 & 0.30 & 0.35 \\
\hline Bypass ratio & 13.3 & 8.9 & 3.8 \\
\hline Corrected weight flow $\left(\mathrm{lbm} / \mathrm{ft}^{2}-\mathrm{sec}\right)$ & 36.9 & 41.8 & 43.7 \\
\hline Inlet corrected weight flow $(\mathrm{lbm} / \mathrm{sec})$ & 85.7 & 100.5 & 98.9 \\
\hline Rotor blade count & 18 & 22 & 22 \\
\hline Bypass duct stator vane count & 45 & 54 & 50 \\
\hline Core duct stator vane count & 63 & None & 10 \\
\hline Bypass duct support struts & None & None & 10 \\
\hline
\end{tabular}

TABLE 2.-MODEL FAN TIP SPEED CONDITIONS USED IN THIS STUDY

\begin{tabular}{|c|c|c|c|}
\hline Fan & Condition & $\begin{array}{c}\text { Corrected, } \\
\text { rpm }\end{array}$ & $\begin{array}{c}\text { Design speed, } \\
\%\end{array}$ \\
\hline \multirow{4}{*}{ ADP } & Approach & 5,425 & 62.0 \\
\cline { 2 - 4 } & - & 6,700 & 76.6 \\
\cline { 2 - 4 } & Cutback & 7,525 & 86.0 \\
\cline { 2 - 4 } & - & 8,345 & 95.4 \\
\cline { 2 - 4 } & Takeoff & 8,750 & 100.0 \\
\hline \multirow{4}{*}{ SDT } & Approach & 7,809 & 61.7 \\
\cline { 2 - 4 } & - & 9,493 & 75.0 \\
\cline { 2 - 4 } & Cutback & 11,075 & 87.5 \\
\cline { 2 - 4 } & - & 11,771 & 93.0 \\
\cline { 2 - 4 } & Takeoff & 12,657 & 100.0 \\
\cline { 2 - 4 } & Approach & 9,840 & 63.0 \\
\cline { 2 - 4 } & - & 10,935 & 70.0 \\
\cline { 2 - 4 } & Cutback & 12,500 & 80.0 \\
\cline { 2 - 4 } & - & 13,280 & 85.0 \\
\cline { 2 - 4 } & Takeoff & 14,060 & 90.0 \\
\hline
\end{tabular}

The ADP fan (refs. 1 and 2) (see the photograph in fig. 1) has a relatively low stage pressure ratio of 1.29 and a subsonic design corrected tip speed of $840 \mathrm{ft} / \mathrm{sec}$. The cross-section of the fan stage is shown in figure 2 . The fan stage has 45 radial bypass vanes and 63 radial core stator vanes. This fan has the highest design bypass ratio (13.3) of the three fans considered in this paper. Its subsonic design tip speed avoids the generation of multiple pure tones. Figures 3 shows a photograph of the SDT fan installed in the 9-ft by $15-\mathrm{ft}$ wind tunnel (refs. 3 and 4 ). A crosssectional sketch is also shown in figure 4 for the SDT fan with the R4 rotor and 54 radial stator vanes. The SDT fan has a design corrected tip speed of $1,215 \mathrm{ft} / \mathrm{sec}$ and a stage pressure ratio of 1.47 . Figure 5 is a photograph of the QHSF2 model installed in the 9-ft by 15-ft low speed acoustic wind tunnel. This fan has the highest design tip speed $(1,474 \mathrm{ft} / \mathrm{sec})$ of the three model fans in this study (refs. 5 and 6). The QHSF2 has a swept, cut-off bypass stator with 50 vanes. The bypass rotor-stator spacing is fairly close for this fan stage (see fig. 6) compared with the other two fans. This fan also has a passive core flow with 10 support struts. Its bypass ratio of 3.8, well below that of the other two model fans, is considered moderate. 


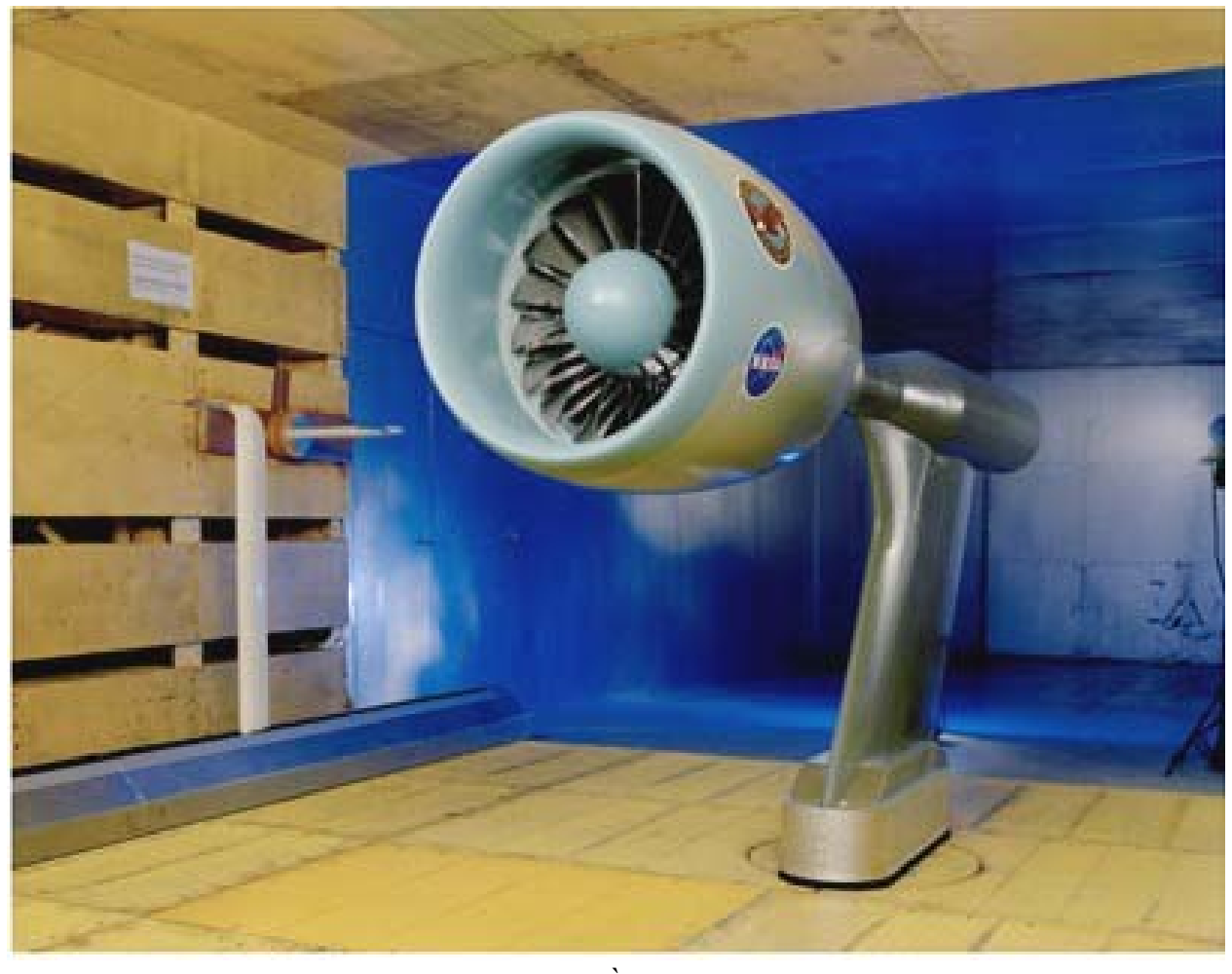

Figure 1.-22-in. scale model of the Advanced Ducted Propulsor (ADP) Fan 1 installed in the 9 -ft by $15-\mathrm{ft}$ LSWT.

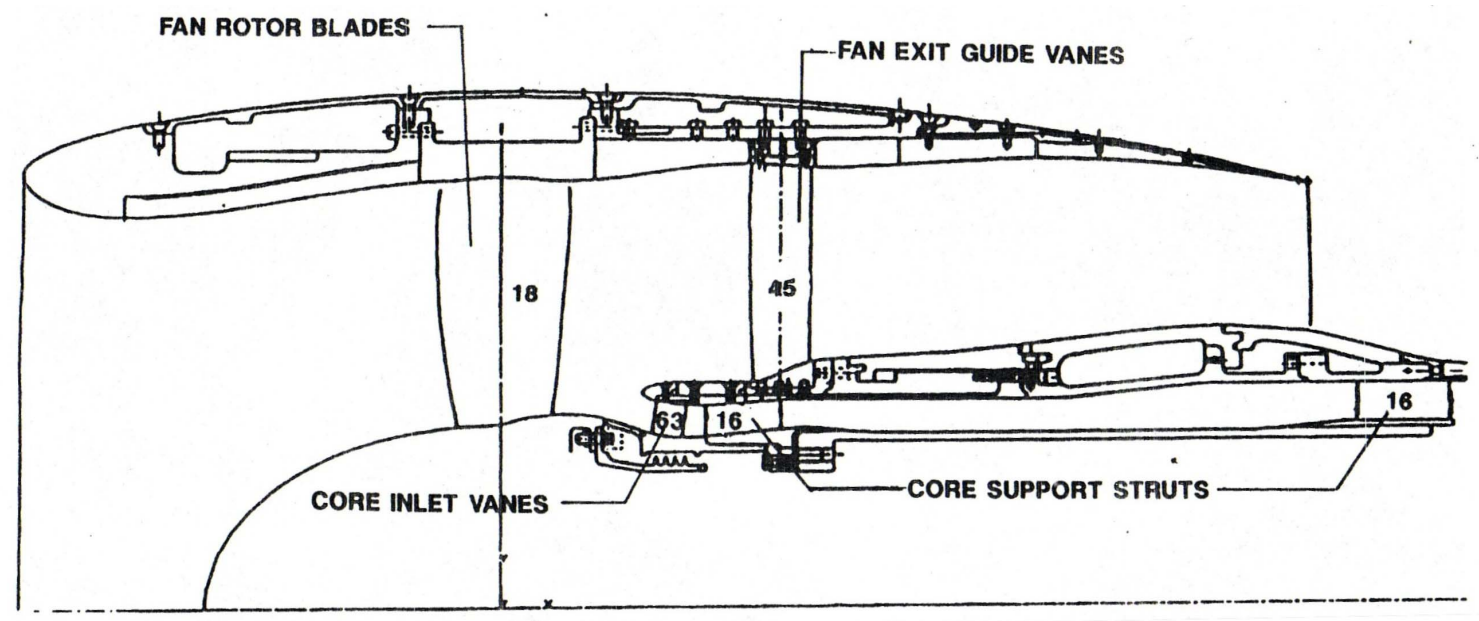

Figure 2.-Cross-sectional sketch of the ADP Fan1 model fan stage. 


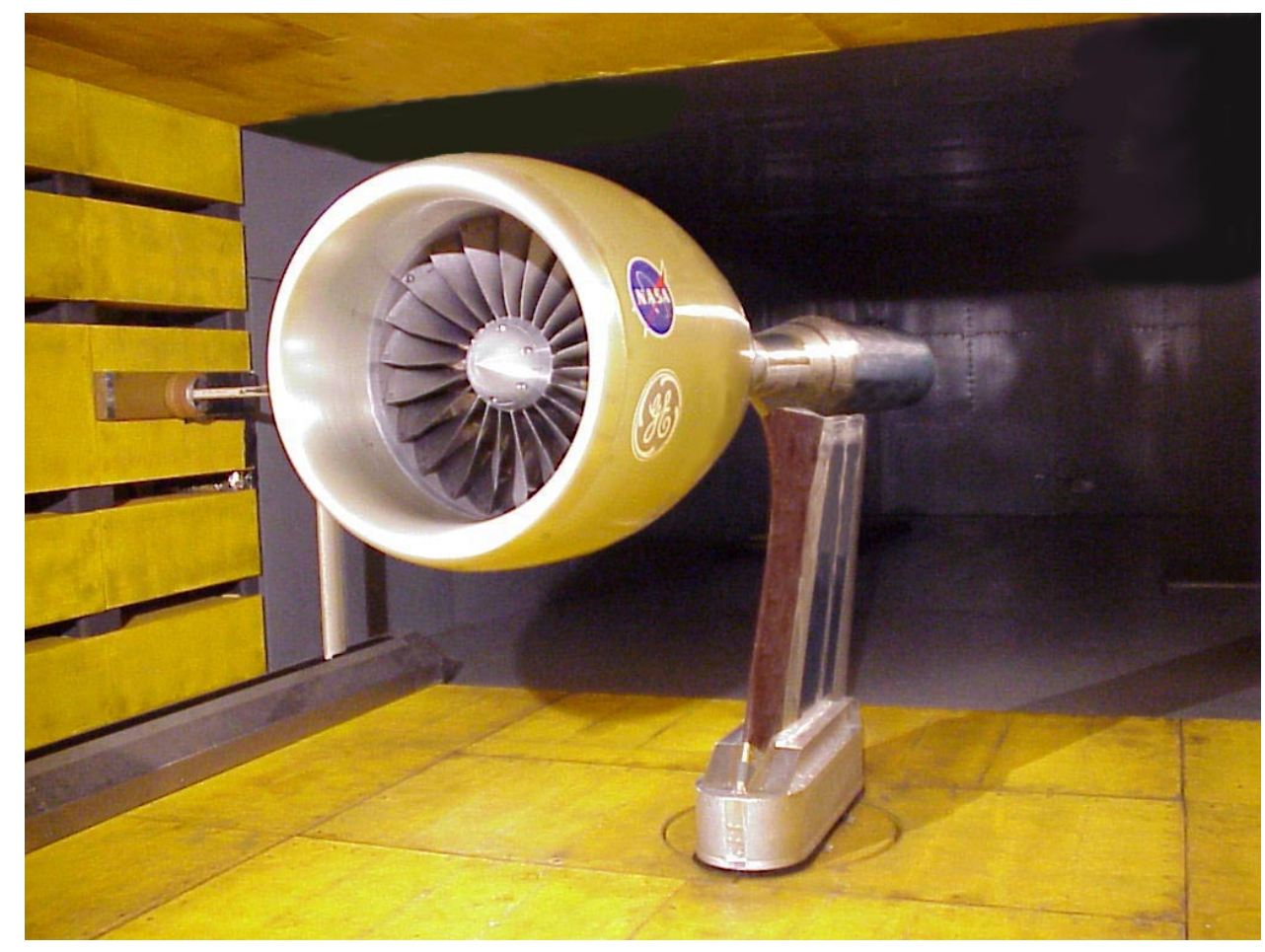

Figure 3.-22-in. scale model of the Source Diagnostic Test (SDT) model fan installed in the $9-\mathrm{ft}$ by $15-\mathrm{ft}$ LSWT.

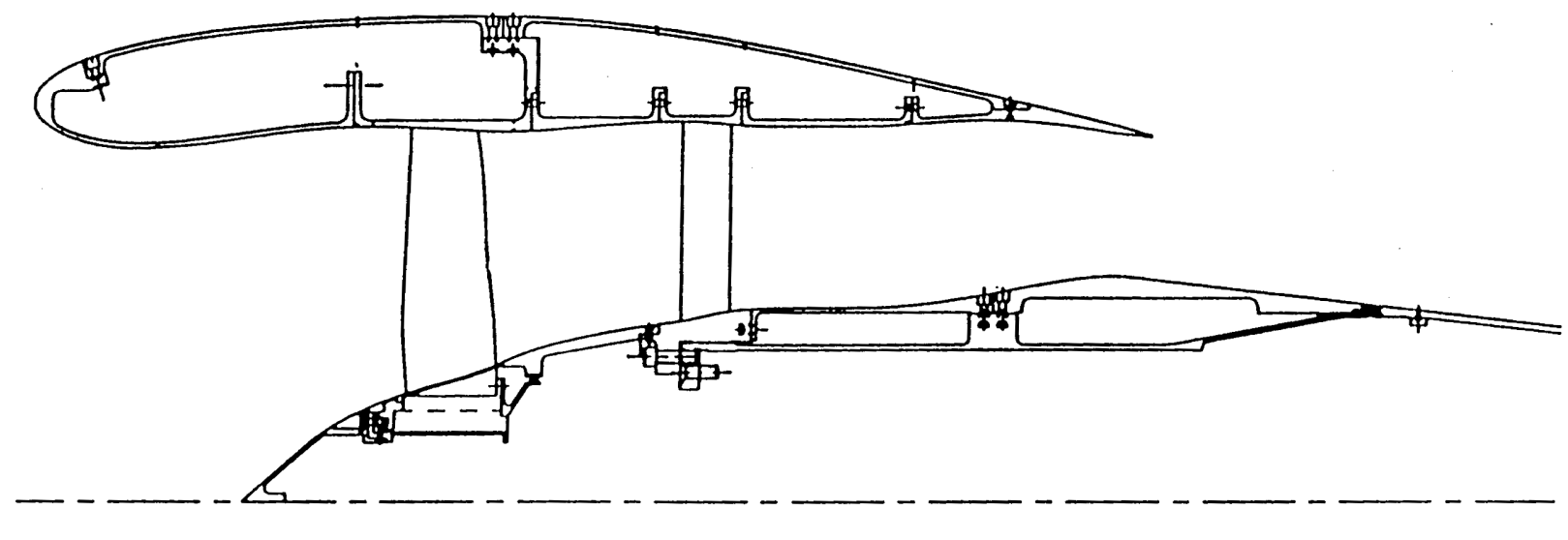

Figure 4.-Cross-sectional sketch of the SDT model fan stage. 


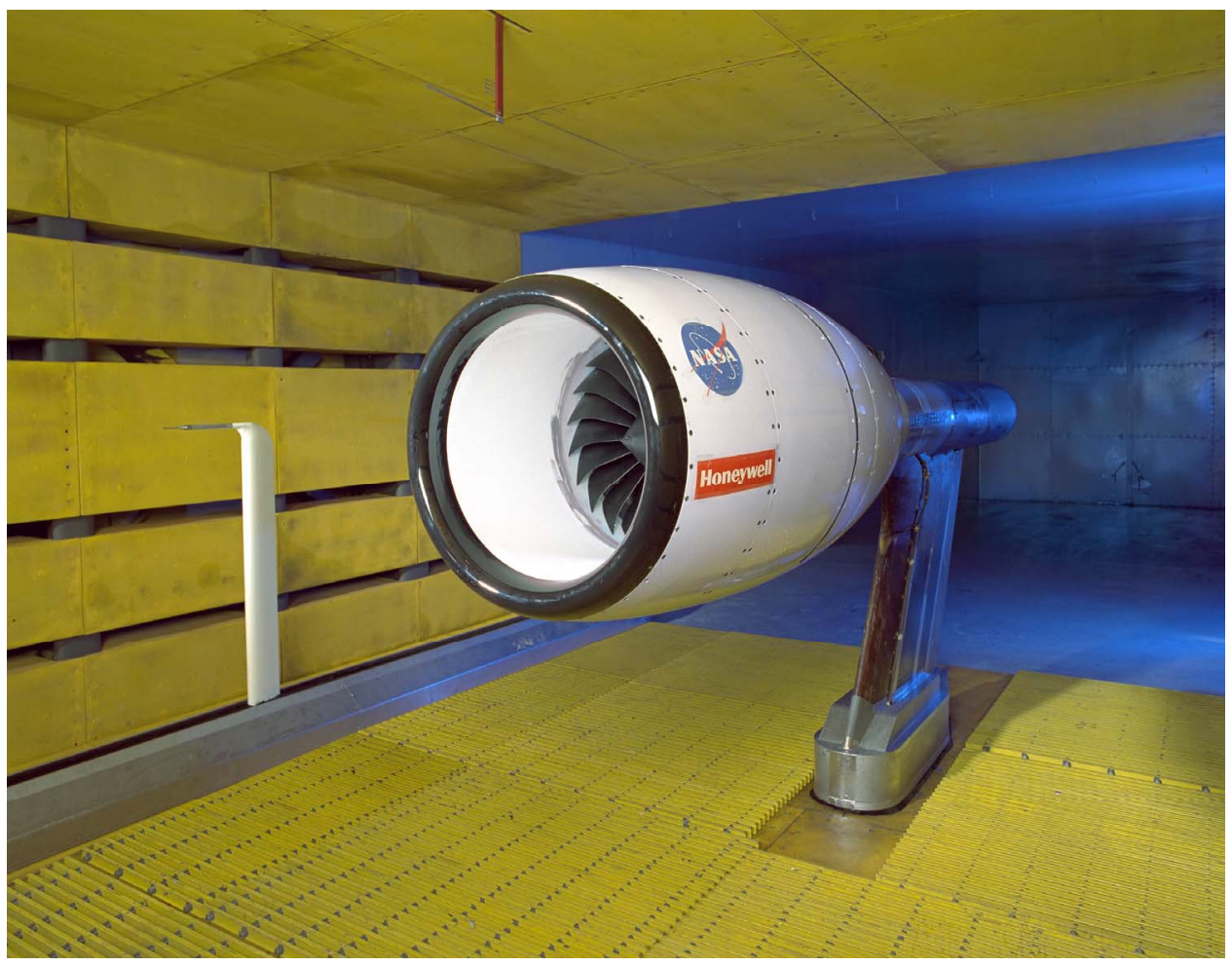

Figure 5.-22-in. scale model of the Quiet High Speed Fan 2 (QHSF2) installed in the 9 -ft by $15-\mathrm{ft}$ LSWT.

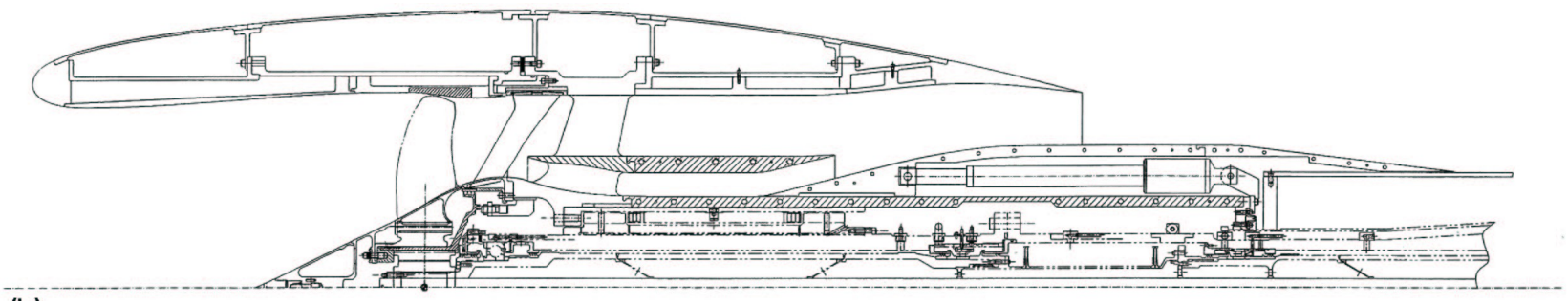

Figure 6.-Cross-sectional sketch of the QHSF2 model fan stage.

\section{Test Facility and Data Acquisition Systems}

The 9-ft by 15-ft Low Speed Wind Tunnel is an open-loop, continuous-flow, anechoic wind tunnel facility located at NASA Glenn Research Center (ref. 7), and is part of the 8-Foot by 6-Foot Supersonic Wind Tunnel complex. The $9-\mathrm{ft}$ by $15-\mathrm{ft}$ wind tunnel is capable of producing test section Mach numbers up to 0.23 , as well as being used for static propulsion system performance testing. Treatment-filled boxes are installed on the test section flow surfaces making the test section anechoic down to $250 \mathrm{~Hz}$ (refs. 8 to 11). Flow conditioning systems upstream of the test section reduce incoming turbulence and velocity distortions levels to very low values, making this facility ideally suited for establishing baseline acoustic levels and noise source isolation testing of simulated propulsion systems. Figure 7 is a schematic showing an overhead view of the 9 - $\mathrm{ft}$ by $15-\mathrm{ft}$ test section and the location of the scale model turbofan research hardware installed and the sideline acoustic measurement system. The fan models were powered by the NASA Glenn Ultra High Bypass (UHB) Drive Rig propulsion simulator. A four-stage air turbine driven by high pressure, high temperature air through tubes in the support strut generates the power that is supplied to the fan model through a common shaft connection. The UHB Drive Rig can deliver a maximum of 5,050 shaft horsepower at $16,850 \mathrm{rpm}$ with air supplied at $230 \mathrm{psia}$ and $500^{\circ} \mathrm{F}$. 


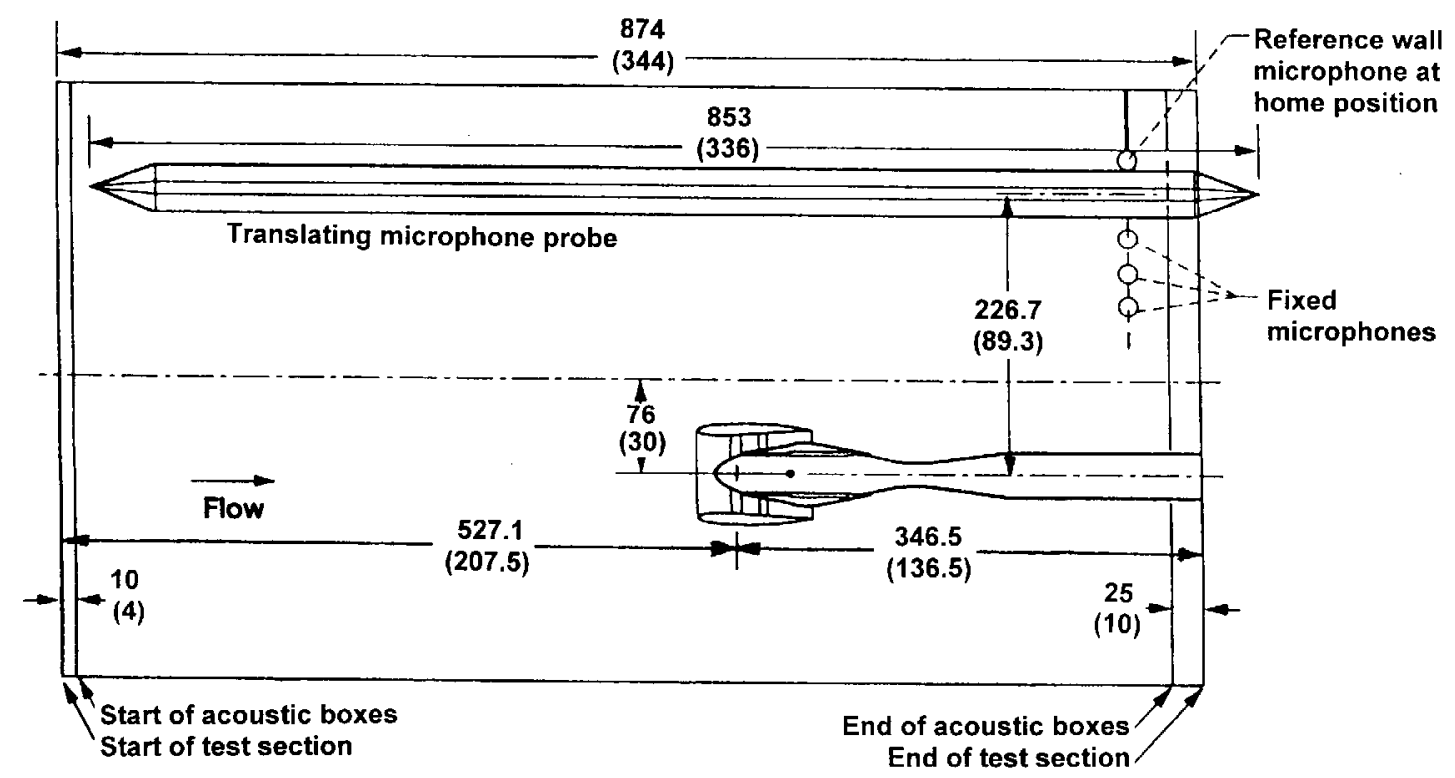

Figure 7.-Top view schematic of the 9 -ft by 15 -ft test section showing scale model fan acoustic installation and sideline traversing microphone and fixed aft microphones. All dimensions are in $\mathrm{cm}$ and (in.).

\section{A. Wind Tunnel Acoustic Measurements}

Model fan acoustic sideline measurements in the 9 -ft by $15-\mathrm{ft}$ wind tunnel are acquired using a traversing microphone probe at an 89-in. sideline distance to the fan axis (see fig. 7). Data is taken at 48 positions at $2.5^{\circ}$ intervals. Additionally, to obtain more angular coverage in the aft quadrant, three fixed microphone probes are placed in the rear of the test section. Together, the traversing probe and the fixed microphones cover 51 measurement locations. All acoustic data is obtained at 0.1 tunnel Mach number which is sufficient to establish acoustic flight effects (ref. 12). The emitted angles corresponding to the 51 microphone locations at 0.1 Mach number range from $25^{\circ}$ to $158^{\circ}$ from the fan axis with $0^{\circ}$ being the forward position upstream of the fan. The microphones used in the measurements are all $1 / 4$-in. in diameter.

Data in the $9-\mathrm{ft}$ by $15-\mathrm{ft}$ wind tunnel is taken in two bursts at different sampling rates in order to obtain 0 to $8 \mathrm{kHz}$ and 0 to $80 \mathrm{kHz}$ spectra. The bandwidth of the 0 to $8 \mathrm{kHz}$ spectra is $5.9 \mathrm{~Hz}$ and the bandwidth of the 0 to $80 \mathrm{kHz}$ spectra is $59 \mathrm{~Hz}$. Corrections to the data have been made for microphone response, cable response, bullet nose receptivity, filter response, atmospheric attenuation, and spherical spreading. Finally, for the purposes of comparison with predictions, the measured spectra shown in this paper are presented on a 1-ft lossless basis.

\section{B. Rotating Rake Acoustic Measurements}

An experimental measurement system was developed and implemented by NASA Glenn Research Center in the 1990 s to measure turbofan duct acoustic modes. The system is a continuously rotating radial microphone rake that is inserted into the duct (see fig. 8). The Rotating Rake (refs. 13 and 14) provides a complete map of the acoustic duct modes present in a ducted fan and has been used on a variety of test articles: from a low-speed, concept test rig, high-speed, scaled, wind tunnel models, to a full-scale production turbofan engine. The Rotating Rake has been critical in developing and evaluating a number of noise reduction concepts as well as providing experimental databases for verification of several aero-acoustic codes.

The key concept of the Rotating Rake is that by slowly rotating in a manner locked to the fan shaft (e.g., 1:200 speed ratio), a Doppler shift is imparted to the duct spinning modes that is uniquely based on the mode physics. This separates the pressure profile into circumferential modes. The radial modes are obtained by solving a least-squarescurve fit to these circumferential modes using the hard-wall cylindrical Bessel functions as the basis functions. The acoustic power level (PWL) for each mode is computed based on physical conditions directly from the mode pressure (see eq. (1)). Strictly speaking, this is valid only for a hard-wall cylindrical flow path with constant, plug flow, and has implications for the accuracy of the solution. The theory and implementation of the Rotating Rake with historical examples is documented in reference 13. 

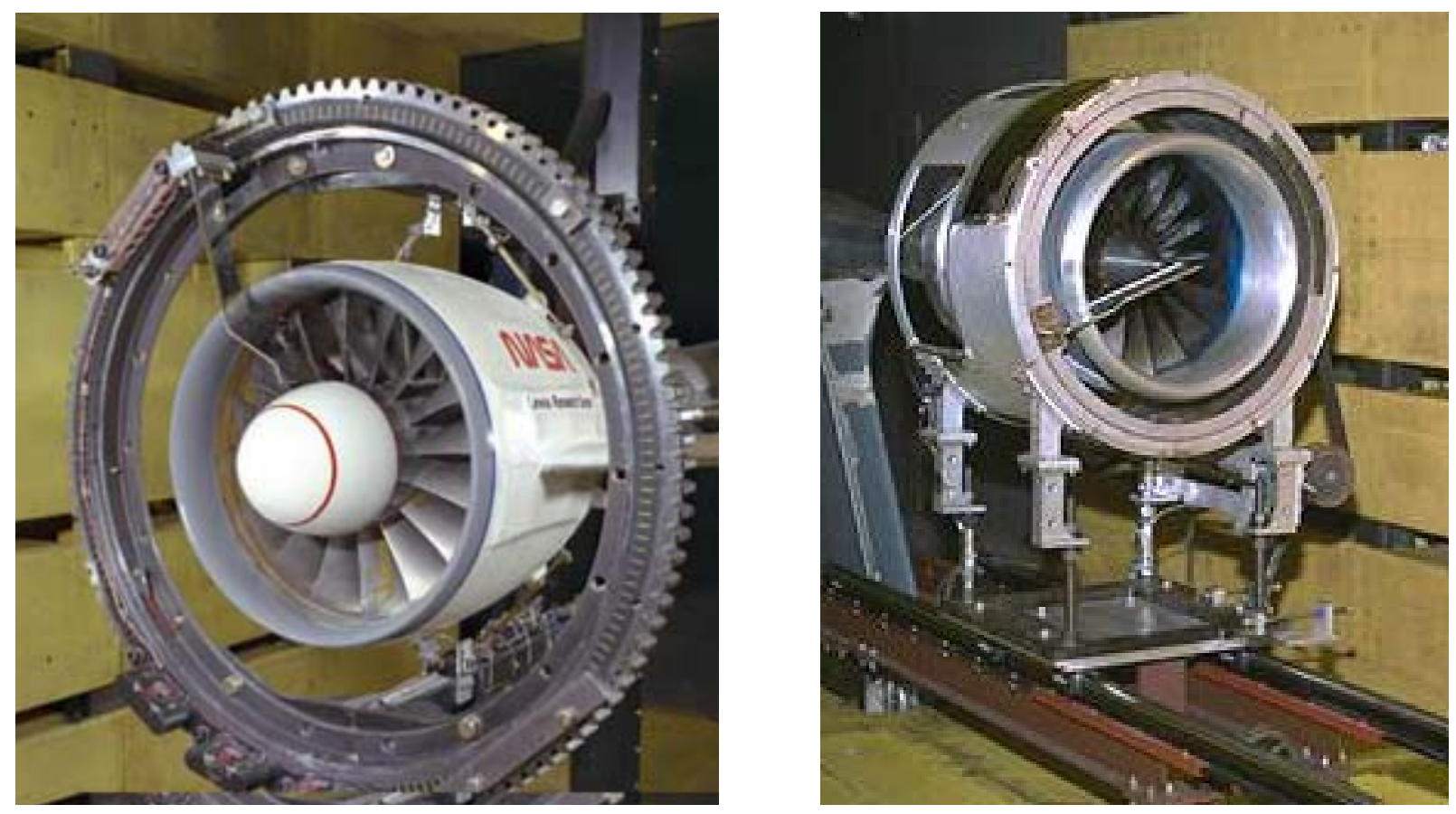

Figure 8.--Rotating Rake Ring Assembly on Advanced Ducted Propulsor (ADP) in 9-ft by 15-ft wind tunnel. First generation system is shown in the left and current generation system is shown on the right.

Rotating Rake data is obtained from radially distributed high response transducers mounted on a rake. Transducers used are 0.062 in. in diameter with a 5-psi delta dynamic range. For inlet measurements, 12 to 14 transducers are typically distributed in equal radial increments starting near the outer-wall to the duct centerline at the throat. For exhaust measurements, 6 to 8 transducers are typically distributed in equal radial increments starting near the outer-wall to the near inner wall at the duct exit plane.

\section{Uncertainty in Measurements}

\section{A. Wind Tunnel Aerodynamic Data Uncertainty Analysis}

An error analysis using the standard ASME measurement analysis techniques (refs. 15 to 17) was conducted on the aerodynamic values used for reducing experimental farfield and Rotating Rake acoustic data. The measurement uncertainties of the data were identified, which included random and bias errors. A confidence level of 95 percent was used corresponding to two standard deviations in a Gaussian error distribution with the number of degrees of freedom at least equal to 30 . The random and bias errors from the uncorrelated sources were combined either linearly or in quadrature to produce an overall characterization for each variable. The computed uncertainties for aerodynamic variables important for acoustic data reduction are shown in the table 3.

\section{B. Wind Tunnel Sideline Acoustic Data Uncertainty Analysis}

The acoustic data system in the 9 -ft by $15-\mathrm{ft}$ wind tunnel consists of the following hardware from end to end: Bruel \& Kjaer (B\&K) Type 4939 1/4-in. microphones, B\&K 1/4- to 1/2-in. adapter, cabling, B\&K Type 2807 power supply, Stewart High Pass Filters, DSP Technology A/D and low pass filter boards, and a Concurrent/Masscomp Unix computer. The primary component, the B\&K Type 4939 microphone, is calibrated by $\mathrm{B} \& \mathrm{~K}$ before use and has an uncertainty shown in table 4 . This uncertainty is broken into three frequency groups corresponding to 20 to $30 \mathrm{~Hz}$ (low), 30 to $20,000 \mathrm{~Hz}$ (medium), and 20,000 to $80,000 \mathrm{~Hz}$ (high). This frequency grouping is due to the uncertainty assigned by $\mathrm{B} \& \mathrm{~K}$. While every component introduces an amplitude uncertainty, this is effectively calibrated out at the beginning of every run by using a known source and generating a calibration factor for the entire system. The calibration source is a B\&K $4220124 \mathrm{~dB}, 250 \mathrm{~Hz}$ pistonphone. The B\&K pistonphone computed uncertainty is also shown in table 4. 
For atmospheric attenuation, the ANSI S1.26-1995 Method for Calculation of the Absorption of Sound by the Atmosphere claims an uncertainty of \pm 10 percent for the regime in which data is acquired in the 9 - $\mathrm{ft}$ by 15 - $\mathrm{ft}$ wind tunnel. The uncertainty levels for the ambient conditions of temperature and humidity were determined as $\pm 1.25^{\circ} \mathrm{F}$ and 0.022 percent relative humidity (based on the instrument manufacturer's specifications) respectively. Other errors in measurement include distance to the microphone from the assumed source and the uncertainty of the fan model corrected rpm, which is the controlling model set point. These uncertainty values are \pm 0.5 in. per 100 in. and $\pm 5 \mathrm{rpm}$ corrected respectively.

TABLE 3.-AERODYNAMIC DATA UNCERTAINTY ANALYSIS RESULTS

\begin{tabular}{|l|c|c|}
\hline Variable name & Uncertainty, & Units \\
\hline Tunnel total pressure, $\mathrm{Pt}_{0}$ & \pm & psia \\
\hline Tunnel total temperature, $\mathrm{Tt}_{0}$ & 0.0074 & deg. \\
\hline Tunnel static pressure, $\mathrm{Ps}_{0}$ & 1.25 & $\mathrm{psia}$ \\
\hline Tunnel Mach number, $\mathrm{M}_{0}$ & 1.25 & $\mathrm{~N} / \mathrm{A}$ \\
\hline Tunnel percent humidity & 0.0016 & $\%$ \\
\hline Fan speed & 0.022 & $\mathrm{rpm}$ \\
\hline Corrected fan speed & 4 & $\mathrm{rpm}$ \\
\hline Inlet/exit duct mach number & 5 & $\mathrm{~N} / \mathrm{A}$ \\
\hline Fan exit temperature, $\mathrm{Tt}_{\text {fan }}$ & 0.0004 & ${ }^{\circ} \mathrm{R}$ \\
\hline
\end{tabular}

TABLE 4.-ABSOLUTE EXPERIMENTAL SPECTRA UNCERTAINTY ANALYSIS

\begin{tabular}{|c|c|c|c|c|}
\hline Source & $\begin{array}{c}\text { Low } \\
\text { frequency, } \\
\mathrm{dB}\end{array}$ & $\begin{array}{c}\text { Medium } \\
\text { frequency, } \\
\mathrm{dB}\end{array}$ & $\begin{array}{c}\text { High } \\
\text { frequency, } \\
\mathrm{dB}\end{array}$ & Basis \\
\hline Atmospheric attenuation & 0.00001 & 0.001 & 0.1 & $\pm 1.25^{\circ} \mathrm{F}, \pm 0.022 \% \mathrm{RH}$, hot humid day \\
\hline Distance & 0.04 & 0.04 & 0.04 & \pm 0.5 in. error in 100 in. \\
\hline Set point & 0.1 & 0.1 & 0.1 & $> \pm 0.25 \%$ error in $\mathrm{rpm}$ \\
\hline Pistonphone & 0.15 & 0.15 & 0.15 & B\&K $4220124 \mathrm{~dB} 250 \mathrm{~Hz}$ pistonphone \\
\hline Spectral response calibration & 0.27 & 0.17 & 0.27 & Certified by B\&K calibration facility \\
\hline Third-octave band averaging & 0.33 & 0.1 & 0.1 & $\begin{array}{l}\chi^{2} \text { analysis of third-octave integration ( } 5 \\
\text { narrowbands minimum) at } 90 \% \text { confidence }\end{array}$ \\
\hline \multicolumn{5}{|c|}{- or -} \\
\hline Narrowband averaging & 0.61 & 0.61 & 0.61 & $\begin{array}{l}\chi^{2} \text { analysis of } 194-\text { average narrowband at } \\
90 \% \text { confidence }\end{array}$ \\
\hline \multirow{2}{*}{ Total } & 0.83 & 0.54 & 0.63 & Third-octave spectra \\
\hline & 1.08 & 1.00 & 1.16 & Narrowband spectra \\
\hline
\end{tabular}

Lastly, an error uncertainty is determined for the integration of the acquired data for averaging analysis purposes for both narrowband and third-octave band analysis. A $\chi^{2}$ analysis was done for 194-average narrow bands at a 90 percent confidence for the narrow band uncertainty. A $\chi^{2}$ analysis was also done for a minimum of 5 narrow bands at 90 percent confidence for the third-octave band uncertainty. The uncertainty varies in the third-octave band analysis according to frequency due to the fact that fewer narrow bands are used in the lower frequencies, and the number of narrow bands combined together to form single third-octave bands increases as frequency increases. All uncertainty values are shown in table 4.

In order to determine the overall data measurement uncertainty, each uncertainty level in decibels was first expressed as a percentage on the linear basis (i.e., anti-logs were used), before they were summed. Finally the total was converted back to $\mathrm{dB}$ by taking $10 \log _{10}(1+\mathrm{SUM})$. The results are shown in table 4 for three different frequency ranges and two noise band-averaging methods.

The above analysis deals with the uncertainty in measured amplitude of the data. The measured frequency uncertainty is based on the uncertainty in the rpm of the fan model in the 9 - $\mathrm{ft}$ by 15 - $\mathrm{ft}$ wind tunnel. The calculated uncertainty of the fan model in the 9 -ft by $15-\mathrm{ft}$ wind tunnel is \pm 5 corrected rpm. The highest uncertainty can be 
calculated for the lowest speed of interest here which is 5,425 rpm. This gives an uncertainty in the measured frequency of $\sim 0.09$ percent.

\section{Rotating Rate Acoustic Data Uncertainty Analysis}

The uncertainty in the mode acoustic power level (PWL) computed from the Rotating Rake mode measurements arise from three basic components: instrumentation/calibration, data reduction, and modeling error.

The instrumentation error arises from the errors associated transducer and the telemetry transmission. The transducer uncertainty was determined by referencing to a piston-phone that was calibrated to a known transducer and the uncertainty assumed to be that of the piston phone. The uncertainty induced by transmission through the telemetry system was obtained by placing a known signal across the telemetry and comparing this known signal to the telemetry output, concentrating on the differences between channels.

The data reduction uncertainty arises from uncertainty in the inputs to the equation used for computation of mode power (eq. (1)). Propagation of uncertainty through this equation is calculated by partial derivative of the power equation with respect to the term under consideration (eq. (2)). The parameters that have a significant effect on mode PWL are mode pressure, duct Mach number and cut-off ratio based on the corrected rpm. Errors in geometry are assumed to have an insignificant effect on mode PWL. The resulting equations for each parameter are presented in equation (3). Uncertainties arising in rotor-stator interactions modes measurements that would arise for the SDT fan at three certification points are shown in table 5 .

$$
\begin{gathered}
\frac{\Delta \bar{P}}{\bar{P}}=\frac{2 \Delta p}{p} ; \quad \frac{\Delta \bar{P}}{\bar{P}}=\frac{2\left(\psi \pm M_{D}\right)}{\left(M_{D} \psi \pm 1\right)\left(M_{D}^{2}-1\right)} \Delta M_{D} ; \quad \frac{\Delta \bar{P}}{\bar{P}}=\frac{1-M_{D} \psi}{\zeta\left(\zeta^{2}-1\right)\left(1+M_{D} \psi\right)} \Delta \zeta \\
\bar{P}=\mp \frac{\pi R^{2}\left(1-\sigma^{2}\right)\left(1-M_{D}^{2}\right)^{2}}{\rho_{0} c_{0}} \operatorname{Re}\left\{\frac{\psi}{\left|1 \pm M_{D} \psi\right|^{2}}\right\}|p|^{2} ; \quad \psi=\sqrt{1-\frac{1}{\zeta^{2}}} \\
\Delta \bar{P}=\left(\frac{\partial \bar{P}}{\partial \Theta}\right) \Delta \Theta ; \quad \frac{\Delta \bar{P}}{\bar{P}} \propto \frac{\left(\frac{\partial \bar{P}}{\partial \Theta}\right) \Delta \Theta}{\bar{P}}
\end{gathered}
$$

$\begin{array}{ll}\text { Where } & \\ R & \text { duct radius } \\ M_{D} & \text { duct Mach number } \\ p & \text { duct mode acoustic pressure } \\ \bar{P} & \text { duct mode acoustic power } \\ c_{0} & \text { speed of sound } \\ \rho_{0} & \text { density } \\ \sigma & \text { hub-to-tip radius ratio } \\ \zeta & \text { duct mode cut-off ratio }\end{array}$

The uncertainty in modeling error is a result of using basis functions assuming hard-wall, plug flow boundary conditions when a better fit would be to use the basis functions for shear flow in the duct. These can be computed using the methodology described in reference 18. If done for a typical case, an uncertainty can be computed by obtaining the solution for a desired mode and comparing it to the solution obtained from the analytical plug flow. Table 6 shows an error that would result in fitting a hard-wall, plug-flow, basis function to a mode shape arising in shear flow.

The overall uncertainty is then the root-mean-square of the component errors as shown in table 7.

$$
\text { R.M.S. Error } \equiv \sqrt{(\text { Instumentation Error })^{2}+(\text { Equation Error })^{2}+\left({\text { Modeling Error })^{2}}^{2}\right.}
$$


Thus for each fan, and operating point, an uncertainty can be computed for all modes at each harmonic. This uncertainty can be expected to vary. In the absence of actual data for each mode it is proposed that the number obtained here in for the worst case analyzed for SDT be applied to the other fans. As such, this will encompass the uncertainty in mode PWL for a "random" mode.

TABLE 5.-TYPICAL UNCERTAINTY IN MODE PWL DUE TO DATA REDUCTION (E.G., FOR SDT)

\begin{tabular}{|l|c|c|c|}
\hline \multicolumn{1}{|c|}{ Inlet } & \multicolumn{3}{c|}{ Mode R.M.S. uncertainty, } \\
& \multicolumn{3}{c|}{ dB } \\
\hline 2BPF Modes & -8 & 18 & -10 \\
\hline Uncertainty at Approach & 1.26 & 1.10 & 1.47 \\
\hline Uncertainty at Cutback & 0.27 & 0.51 & 0.91 \\
\hline Uncertainty at Takeoff & 0.21 & 0.87 & 0.34 \\
\hline
\end{tabular}

TABLE 6.-MODELING ERROR FROM USING HARD-WALL PLUG-FLOW BASIS FUNCTIONS FOR DATA FROM SHEAR-FLOW

\begin{tabular}{|c|c|c|c|c|c|c|}
\hline \multirow{2}{*}{$\begin{array}{l}\text { Location, } \\
\mathrm{r} / \mathrm{R}_{\text {tip }}\end{array}$} & \multirow{2}{*}{\multicolumn{3}{|c|}{ Measured }} & \multicolumn{3}{|c|}{$n=0$ curve fit } \\
\hline & & & & \multicolumn{2}{|c|}{$\mathrm{Pa}$} & $\%$ error \\
\hline 0.000 & \multicolumn{3}{|c|}{0.000} & \multicolumn{2}{|c|}{0.000} & 0.0 \\
\hline 0.040 & \multicolumn{3}{|c|}{0.000} & \multicolumn{2}{|c|}{0.000} & 0.0 \\
\hline 0.106 & \multicolumn{3}{|c|}{0.002} & \multicolumn{2}{|c|}{0.001} & 0.1 \\
\hline 0.206 & \multicolumn{3}{|c|}{0.029} & \multicolumn{2}{|c|}{0.010} & 1.4 \\
\hline 0.341 & \multicolumn{3}{|c|}{0.196} & \multicolumn{2}{|c|}{0.069} & 9.7 \\
\hline 0.500 & \multicolumn{3}{|c|}{0.691} & \multicolumn{2}{|c|}{0.260} & 32.9 \\
\hline 0.659 & \multicolumn{3}{|c|}{1.260} & \multicolumn{2}{|c|}{0.590} & 51.1 \\
\hline 0.794 & \multicolumn{3}{|c|}{1.310} & \multicolumn{2}{|c|}{0.901} & 31.2 \\
\hline 0.894 & \multicolumn{3}{|c|}{0.925} & \multicolumn{2}{|c|}{1.077} & 11.6 \\
\hline 0.960 & \multicolumn{3}{|c|}{0.507} & \multicolumn{2}{|c|}{1.140} & 48.2 \\
\hline & & & & \multicolumn{3}{|c|}{ Average error: $\frac{1}{n} \sum_{n} \%$ error $=18.6 \%$} \\
\hline & \multicolumn{3}{|c|}{ Mode amplitude } & \multicolumn{3}{|c|}{ Mode amplitude } \\
\hline & $n$ & $\mathrm{~Pa}$ & $\mathrm{~dB}$ & $n$ & $\mathrm{~Pa}$ & $\mathrm{~dB}$ \\
\hline & 0 & 0.909 & 91.8 & 0 & 0.536 & 88.6 \\
\hline
\end{tabular}

TABLE 7.-TYPICAL UNCERTAINTIES IN MODE PWL (dB) FROM ALL SOURCES

\begin{tabular}{|l|c|c|}
\hline \multicolumn{1}{|c|}{ Inlet } & $\begin{array}{c}\text { Delta PWL, } \\
\mathrm{dB}\end{array}$ & Error \\
\hline Calibration & 0.5 & 1.122 \\
\hline Telemetry & 0.4 & 1.096 \\
\hline Data Reduction & 1.5 & 1.413 \\
\hline Modeling & 3.2 & 2.089 \\
\hline R.M.S. Error $\left(\mathrm{E}_{\text {R.M.S. }}\right)$ & --- & 2.205 \\
\hline & Uncertainty & $\mathbf{1 0} \mathbf{L o g}_{\mathbf{1 0}}\left(\mathbf{E}_{\text {R.M.S. }}\right)=\mathbf{3 . 4}$ \\
\hline
\end{tabular}

\section{Prediction and Assessment}

In this section the results of the assessment exercise are presented. The presentation is organized according to categorization discussed earlier, namely, that we begin with the empirical results, followed by the analytical result and conclude with the computational aeroacoustics results. In each case, comparisons of the predicted levels with the measured levels are presented. All comparisons include the calculated uncertainty of the experimental measurements as appropriate. In the interest of brevity, only typical sample prediction results are presented here (most are included in the appendix). However, all computed data-theory errors obtained in this effort are shown for the sake of completeness. The complete details of this assessment exercise will be included in an forthcoming 
NASA Technical Publication, which will cover not only fan noise prediction, but also an assessment of the prediction capability for all other sources of aircraft noise. Depending on the particular fan noise code evaluated, the results are presented in terms of sound pressure level (SPL) or sound power level (PWL). The input requirements of each code are listed and discussed as appropriate.

\section{A. Empirical Methods}

As a representative code in the empirical methods category, the version (i.e., Level) 25 of the Aircraft Noise Prediction Program (ANOPP) was chosen to assess the accuracy of the empirical methods for predicting fan noise. ANOPP represents the state of the art at NASA as far as empirical methods for aircraft noise prediction are concerned. It can be used to predict the noise on the component basis as well as at the system level. Much literature has been devoted to describing the inner workings of ANOPP (see refs. 19 to 24 for an in-depth understanding of ANOPP), so no details will be given about the code here. For the purposes of this study, the fan noise module in ANOPP, called HDNFAN (ref. 25), was used to predict the sideline noise radiation for the test-bed fans. The HDNFAN fan noise prediction module, designated Level 25, version 3 (L25v3), was developed using data from a number of fans, but this database does not include data from the model fans used in this study. HDNFAN predicts fan noise spectrum on a third-octave level basis and for the aggregate noise signature of the fan, inclusive of all fan noise sources and for both inlet and exhaust, and including the effects of acoustic transmission through the blade rows, scattering from the inlet and exhaust lips, and shear layer refraction in the exhaust stream.

ANOPP requires a host of geometric, environmental and operational parameters as input. Table 8 lists these input parameters for each fan under consideration here. The ANOPP calculations for each of the three fans were carried out at the three fan tip speeds corresponding to the nominal approach, cutback and take off conditions listed in table 2. These are: $5,425,7,525$, and 8,750 rpm for ADP; 7,809, 11,075, and 12,657 rpm for the SDT; and 9,840, 12,500 , and 14,060 rpm for the QHSF2. The calculations and comparisons with the data were carried out for all emission angles as "lossless" on a 1-ft radius centered on the fan pitch axis.

A sampling of the data-theory comparisons is presented in figures A.1 to A.18 in the appendix for typical inlet and exhaust quadrant emission angles, namely $46^{\circ}$ and $136^{\circ}$. The figures are organized as a function of fan tip speed for ADP, SDT and QHSF2, respectively. As shown in table 4, the measured acoustic sound pressure level (SPL) data have a frequency-dependant third-octave uncertainty level of less than $1 \mathrm{~dB}$ over the entire range of frequencies of interest. However, for the sake of simplicity the uncertainty level is assumed to be a constant $\pm 1 \mathrm{~dB}$ band for the entire frequency range as indicated by the error bars on the measured levels shown in these figures. It should be noted that the microphone measurements for both inlet and exhaust below about $1.6 \mathrm{kHz}$ are contaminated by jet noise from the bypass and core ducts as well as the scrubbing noise of the exhaust flow over the drive rig assembly. This extraneous "drive rig" noise has been robustly characterized and documented in a recent investigation whose results will be presented in a paper by Brown \& Schifer (ref. 26). As a result, the portion of the data below $1.6 \mathrm{kHz}$ is shown as a dotted line in figures A.1 to A.18. In addition, at the cutback condition, the entire range of data in the inlet quadrant is suspect due to the presence of extraneous tones that are inconsistent with the known mechanisms of noise generation in fans. As such the inlet data at this speed are also shown as a dotted line.

In figures 9 to 17 the results for all sideline (emission) angles have been summarized in the form of the $\mathrm{dB}$ error in predicting the measured levels. Therefore, each point represents the difference between the measured and predicted SPL on a third-octave basis. The gray band spanning the $\pm 1 \mathrm{~dB}$ range represents the experimental uncertainty. As in the previous set, results below $1.6 \mathrm{kHz}$ band are not shown due to drive rig noise contamination.

On average, the data-theory agreement falls well outside of the experimental uncertainties. In particular, there is no discernable trend, quantitative or qualitative, for the QHSF2 fan predictions when compared with the data. However, the picture improves for both the ADP and SDT fans (see, for example, figs. A.4 to A.6, A.8 to A.12, 11, 12 , and 14). The exception here is the inlet sector for the cutback condition for ADP, which as was mentioned earlier, is contaminated with extraneous tones. Where there is good agreement, the levels are reasonably well predicted, say, to within $\pm 5 \mathrm{~dB}$ with respect to the mean of the measured levels over a wide range of emission angles and third-octave frequency bands. The agreement is worse than that for high emission angles (say, greater than $140^{\circ}$ ) in the exhaust for ADP.

In summary, the data-theory comparisons indicate that ANOPP predictions are reasonably good for most fan tip speed, third-octave frequency band and emission angle combinations for the ADP and SDT fans. In fact, accounting for the experimental uncertainty level, the ANOPP predictions are usually within $\pm 4 \mathrm{~dB}$ outside the measurement uncertainty band. However, the agreement is significantly worse for the QHSF2 fan. 
TABLE 8.-ANOPP L25v3 HDNFAN INPUT PARAMETERS

\begin{tabular}{|c|c|c|c|c|c|c|c|c|c|}
\hline \multirow{2}{*}{ Input Parameter } & \multicolumn{3}{|c|}{ ADP } & \multicolumn{3}{|c|}{ SDT } & \multicolumn{3}{|c|}{ QHSF2 } \\
\hline & AP & $\mathrm{CB}$ & TO & AP & $\mathrm{CB}$ & TO & AP & $\mathrm{CB}$ & TO \\
\hline Ambient temperature, $\mathrm{R}$ & 535.2 & 533.48 & 534.8 & 532.2 & 531.9 & 531.5 & 535.3 & 534.9 & 536.3 \\
\hline Ambient pressure (psfa) & 2039.9 & 2039.0 & 2038.3 & 2056.0 & 2053.1 & 2052.0 & 2077.2 & 2075.0 & 2074.3 \\
\hline Ambient speed of sound ( $\mathrm{ft} / \mathrm{s})$ & 1134.1 & 1132.2 & 1133.6 & 1116.4 & 1116.4 & 1116.4 & 1134.1 & 1133.7 & 1135.2 \\
\hline Ambient density $\left(\mathrm{slug} / \mathrm{ft}^{3}\right)$ & 0.00229 & 0.00229 & 0.00229 & 0.00226 & 0.00226 & 0.00226 & 0.00233 & 0.00233 & 0.00233 \\
\hline Blade count & 18 & 18 & 18 & 22 & 22 & 22 & 22 & 22 & 22 \\
\hline Vane count & 45 & 45 & 45 & 54 & 54 & 54 & $52^{3}$ & $52^{3}$ & $52^{3}$ \\
\hline rpm (actual) & 5,510 & 7,630 & 8,885 & 7,910 & 11,205 & 12,810 & 9,995 & 12,690 & 14,295 \\
\hline Source to observer distance $(\mathrm{ft})$ & 1 & 1 & 1 & 1 & 1 & 1 & 1 & 1 & 1 \\
\hline Inlet cross-sectional area $\left(\mathrm{ft}^{2}\right)$ & 2.15 & 2.15 & 2.15 & 2.39 & 2.39 & 2.39 & 2.32 & 2.32 & 2.32 \\
\hline Fan reference diameter $\left(\mathrm{ft}^{2}\right)$ & 1.83 & 1.83 & 1.83 & 1.83 & 1.83 & 1.83 & 1.83 & 1.83 & 1.83 \\
\hline Design area relative tip Mach no. & 0.86 & 0.86 & 0.86 & 1.20 & 1.20 & 1.20 & 1.52 & 1.52 & 1.52 \\
\hline $\begin{array}{l}\text { Axial rotor-stator spacing } \\
\text { (in rotor tip chords) }\end{array}$ & 1.42 & 1.42 & 1.42 & 3.14 & 3.14 & 3.14 & 2.32 & 2.32 & 2.32 \\
\hline Fan inlet flow (lb/s) & 24.60 & 39.02 & 45.54 & 56.14 & 81.17 & 94.24 & 59.60 & 76.8 & 88.1 \\
\hline Flight Mach number ${ }^{1}$ & 0.0 & 0.0 & 0.0 & 0.0 & 0.0 & 0.0 & 0.0 & 0.0 & 0.0 \\
\hline Fan inlet total temperature (R) & 535.2 & 533.5 & 534.8 & 532.2 & 531.9 & 531.5 & 535.3 & 534.9 & 536.3 \\
\hline Fan exit total temperature (R) & 550.8 & 564.3 & 576.7 & 558.6 & 586.1 & 604.0 & 577.3 & 605.8 & 628.4 \\
\hline $\begin{array}{l}\text { Prediction method flag } \\
\text { 2: Allied Signal small fan method } \\
\text { 3: GE revised method }\end{array}$ & 3 & 3 & 3 & 3 & 3 & 3 & 2 & 2 & 2 \\
\hline $\begin{array}{l}\text { Inlet guide vane index } \\
(1=\text { no vanes })\end{array}$ & 1 & 1 & 1 & 1 & 1 & 1 & 1 & 1 & 1 \\
\hline $\begin{array}{l}\text { Inlet flow distortion } \\
(1=\text { no distortion })\end{array}$ & 1 & 1 & 1 & 1 & 1 & 1 & 1 & 1 & 1 \\
\hline $\begin{array}{l}\text { GE flight cleanup } \\
(\mathrm{TO} \& \mathrm{CB}=1, \mathrm{AP}=2)\end{array}$ & 2 & 1 & 1 & 2 & 1 & 1 & 2 & 1 & 1 \\
\hline Fan inlet broadband switch & true. & true. & true. & true. & true. & true. & true. & true. & true. \\
\hline Fan inlet R/S discrete tone switch & true. & true. & true. & true. & true. & true. & true. & true. & true. \\
\hline Fan inlet combination tone switch ${ }^{2}$ & true. & true. & true. & true. & true. & true. & true. & true. & true. \\
\hline $\begin{array}{l}\text { Fan inlet distortion tone switch } \\
\text { (off) }\end{array}$ & false. & false. & false. & false. & false. & false. & false. & false. & false. \\
\hline Fan inlet broadband switch & true. & true. & true. & true. & true. & true. & true. & true. & true. \\
\hline Fan discharge $\mathrm{R} / \mathrm{S}$ discrete tone & true. & true. & true. & true. & true. & true. & true. & true. & true. \\
\hline
\end{tabular}

1. Flight Mach set to 0.0 to avoid "flyover" Doppler frequency shift in output spectra.

2. Fan inlet combination tone switch turned off due to over predictive nature of method and counterintuitive results.

3. The vane count for QHSF2 was mistakenly set at 52 instead of the 50 during the ANOPP calculations. However, the impact on the ANOPP results and associated conclusions is minimal and, as a result, the calculations were not repeated for vane count of 50 in this paper.

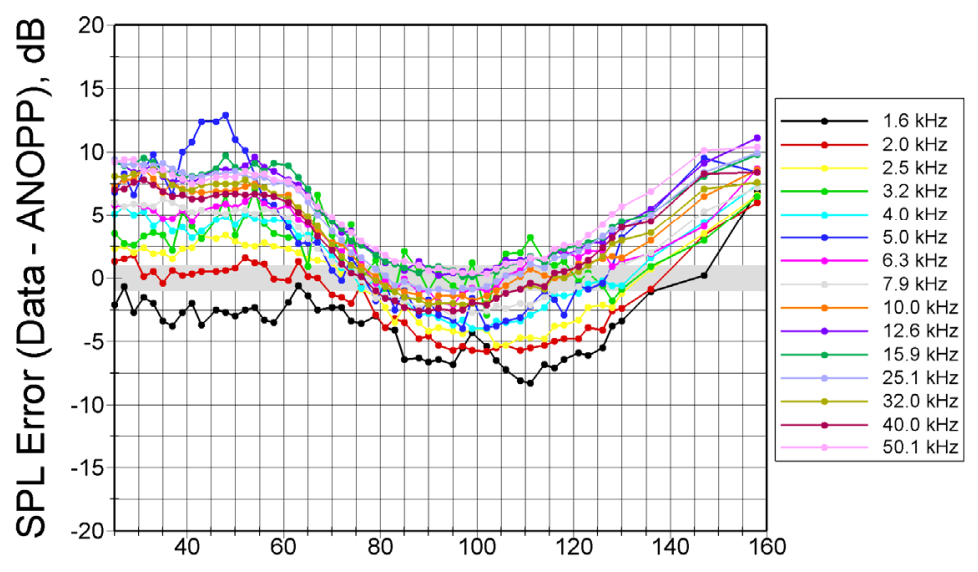

Sideline Angle, deg.

Figure 9.-ANOPP prediction error for all emission angles. ADP results at 5,425 rpm are shown. Bands below $1.6 \mathrm{kHz}$ are not shown owing to data contamination. 


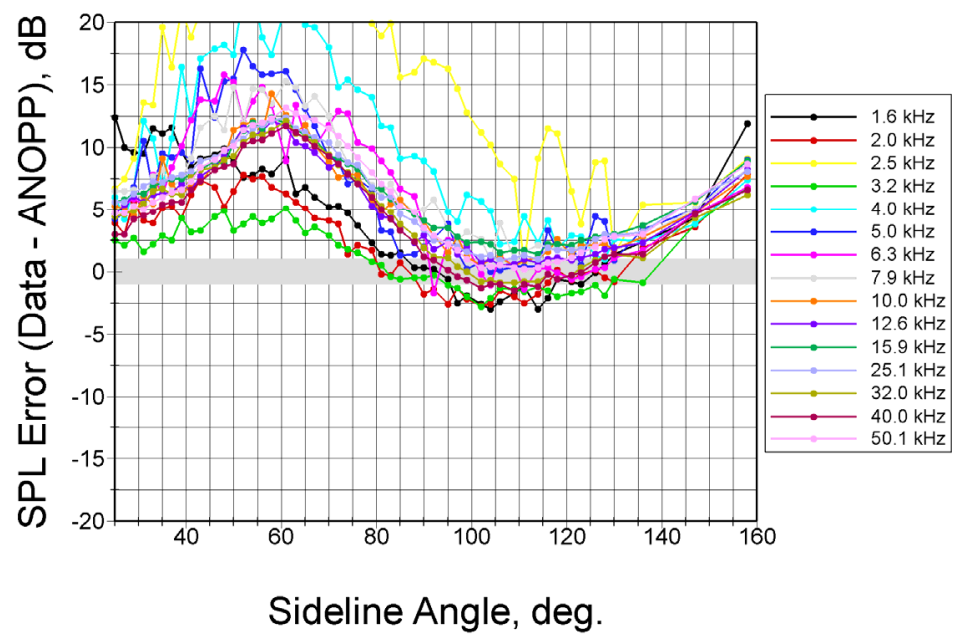

Figure 10.-ANOPP prediction error for all emission angles. ADP results at 7,525 rpm are shown. Bands below $1.6 \mathrm{kHz}$ are not shown owing to data contamination.

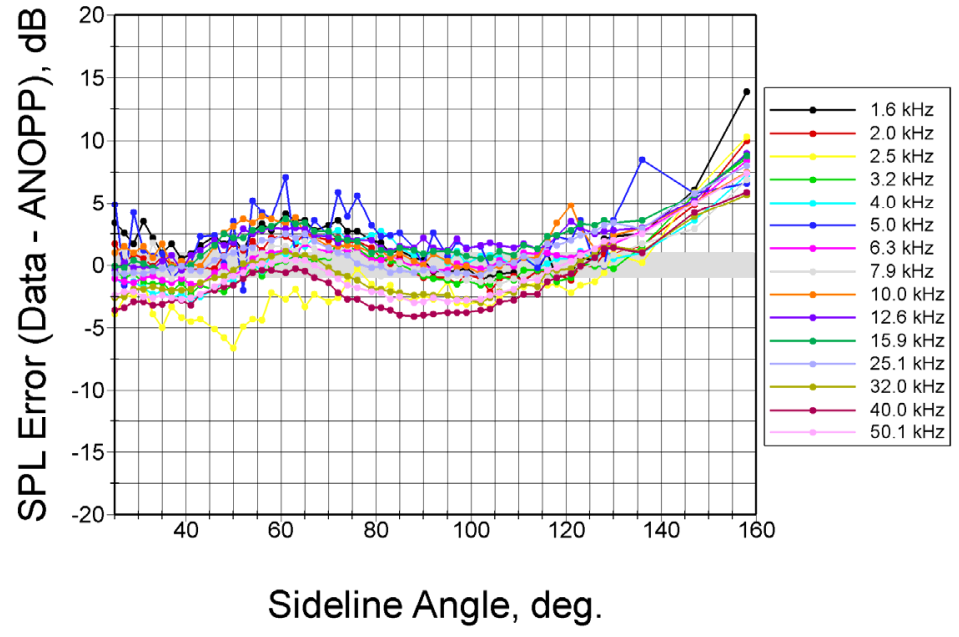

Figure 11.-ANOPP prediction error for all emission angles. ADP results at $8,750 \mathrm{rpm}$ are shown. Bands below $1.6 \mathrm{kHz}$ are not shown owing to data contamination. 


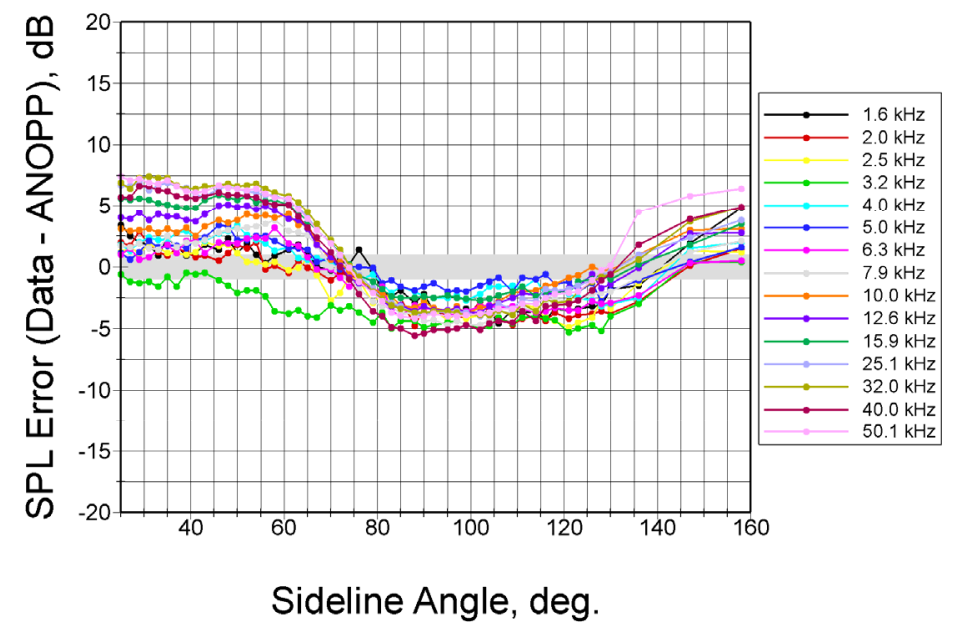

Figure 12.-ANOPP prediction error for all emission angles. SDT results at 7,809 rpm are shown. Bands below $1.6 \mathrm{kHz}$ are not shown owing to data contamination.

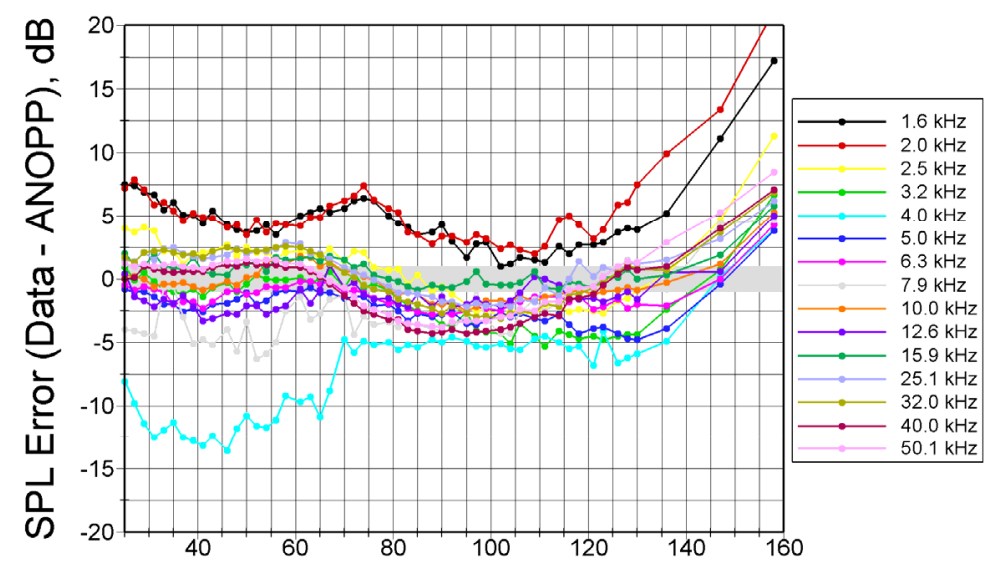

Sideline Angle, deg.

Figure 13.-ANOPP prediction error for all emission angles. SDT results at $11,075 \mathrm{rpm}$ are shown. Bands below $1.6 \mathrm{kHz}$ are not shown owing to data contamination. 


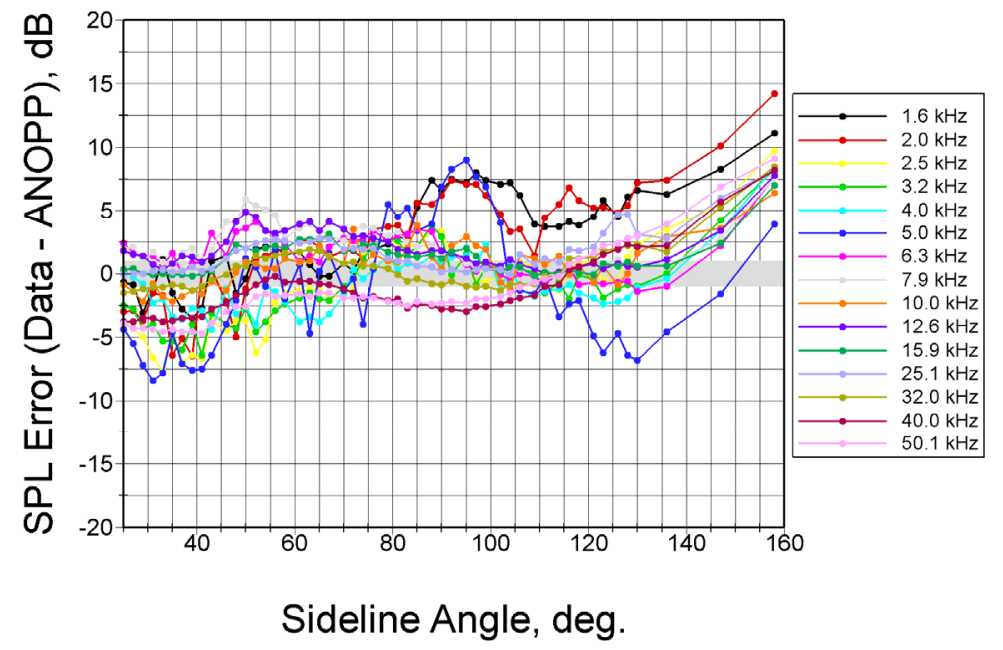

Figure 14.-ANOPP prediction error for all emission angles. SDT results at $12,657 \mathrm{rpm}$ are shown. Bands below $1.6 \mathrm{kHz}$ are not shown owing to data contamination.

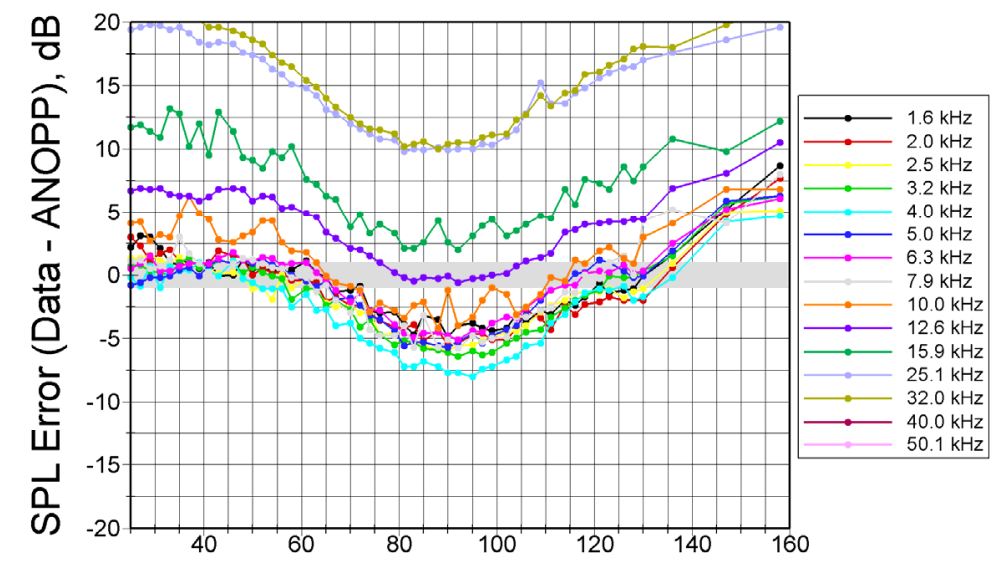

Sideline Angle, deg.

Figure 15.-ANOPP prediction error for all emission angles. QHSF2 results at 9,840 rpm are shown. Bands below $1.6 \mathrm{kHz}$ are not shown owing to data contamination. (Note: 40.0 and $50.1 \mathrm{kHz}$ bands are off the graph.) 


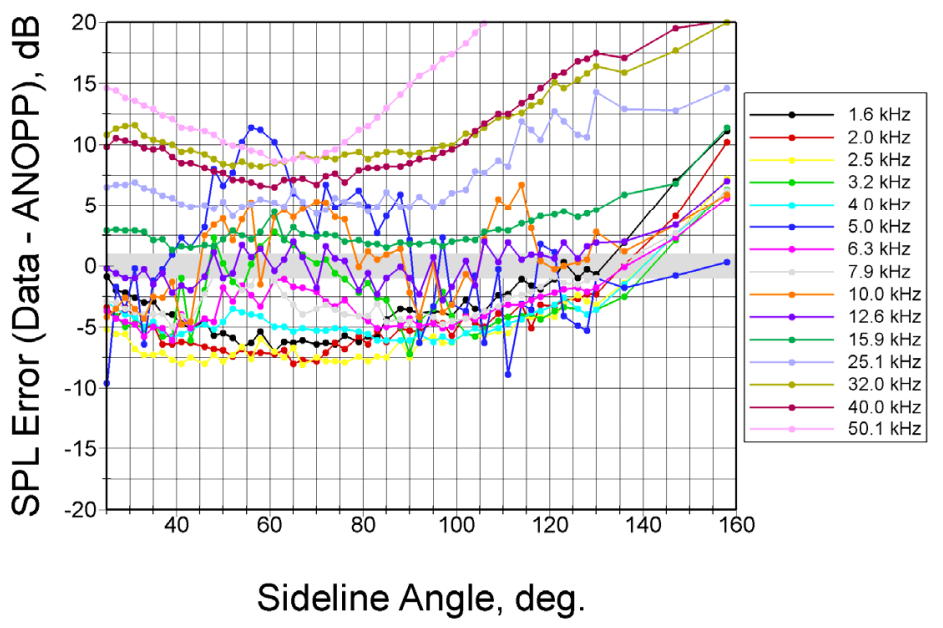

Figure 16.-ANOPP prediction error for all emission angles. QHSF2 results at 12,500 rpm are shown. Bands below $1.6 \mathrm{kHz}$ are not shown owing to data contamination.

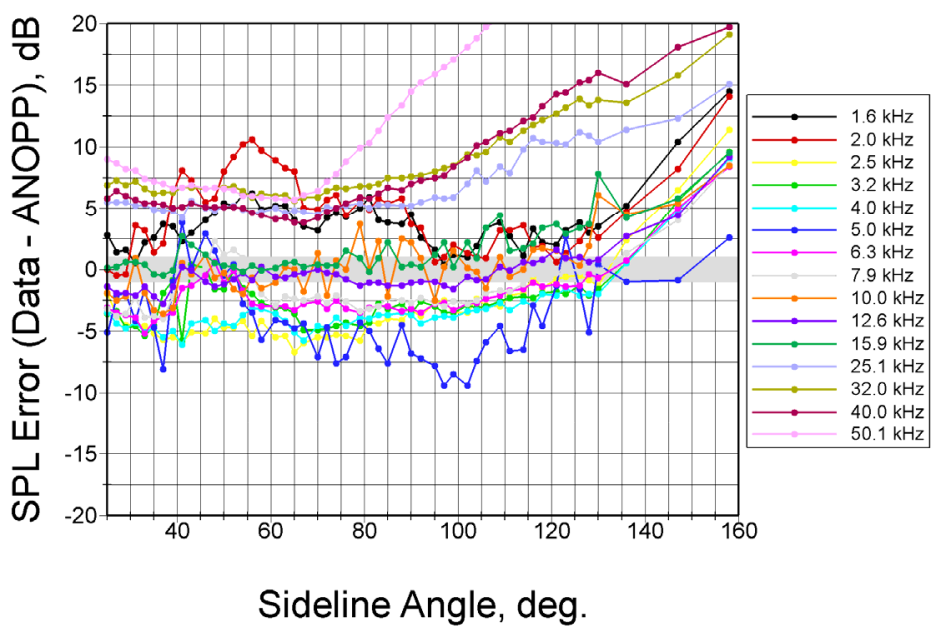

Figure 17.-ANOPP prediction error for all emission angles. QHSF2 results at $14,060 \mathrm{rpm}$ are shown. Bands below $1.6 \mathrm{kHz}$ are not shown owing to data contamination.

\section{B. Analytical Methods}

As a representative code in the analytical methods category, the most recent version of the RSI (i.e., rotor-stator interaction) code was chosen to predict broadband noise generated by the interaction of rotor turbulence impinging on the downstream stator in the bypass duct. The underlying theory for this code has been described in detail in reference 27 and will not be repeated here. The RSI code computes in-duct narrowband distribution of acoustic power as a function of frequency. It computes acoustic power levels upstream and downstream of the stator. The upstream portion contributes to the fan inlet noise and the downstream portion is the main source of the fan exhaust noise. It should be noted here that the measured power level, which is calculated by integrating the measured sideline sound pressure level over a sphere enclosing the fan model, includes contributions from the rotor-stator interaction source as well as the rotor-only sources (i.e., the contribution of the rotor by itself). As such, it is expected that the RSI code will under-predict the measure data. However, if the rotor-only contribution can be quantified and/or modeled, and combined with the RSI prediction, the data-theory comparisons should be more favorable. We shall come back to this point later in this section. 
Like similar codes, RSI requires a description of the basic blade row geometry, mean flow quantities and impinging turbulence characteristics as input for computing broadband noise spectra. Specifically, RSI requires the radial variations of the vane chord and stagger angle; radial distributions of the axial and tangential components of the mean flow; radial distributions of the R.M.S. turbulence intensity and the integral length scales of turbulence. Turbulence information is sometimes available from experiments or more typically is heuristically modeled to provide the best fit of the predicted noise spectra to the measured levels. An alternative approach is to compute the turbulence characteristics using a Reynolds Averaged Navier-Stokes (RANS) type calculations, since measuring turbulence integral length scales is not an easy task especially in a high-speed flow environment. The RANS code utilized in this study is TSWIFT, which is derivative of a code developed at NASA Glenn Research Center over the past several years (see ref. 28). For each fan under consideration in this study, the TSWIFT code was used to compute the flowfield at all tip speeds of interest. This represents a large and detailed investigation of the fan aerodynamics for the three fans used in this study and served as an invaluable resource for generating the input for the assessment.

Shown in figure 18 are the 3D computational blocks for the rotor and stator (in this case for the ADP fan). The full simulation includes additional blocks enclosing not only the two blade rows, but also the entire flow path inside the nacelle as well as the external flowfield. The blocks are a mix of axisymmetric and full 3D flowfield volumes. In figure 19 axisymmetric Mach number contours computed using the TSWIFT code for the ADP fan at the takeoff condition (i.e., 8,750 rpm) are shown. All geometric, mean flow and turbulence information needed to run the RSI code was obtained by interrogating the rotor, stator and the rotor/stator intermediate blocks. As described in reference 27 the turbulence and kinetic energy information are used to construct both an analytic description of the R.M.S. turbulence intensity across the blade pitch and to estimate the integral length scales of turbulence using the isotropic assumption. In the RSI code a distinction is made between the distributions of the turbulence intensity within the background flow and within the rotor wake flow (see ref. 27). Background turbulence refers to that portion of turbulence that was not generated by the rotor blades, but originated ahead of the fan and was drawn into the fan disc. It should be noted that we define the background turbulence region as spanning the entire blade pitch and that its level is uniform across the blade pitch. Any excess level downstream of the fan blade is considered to be the wake turbulence contribution. Since the RSI predictions are sensitive to the input turbulence information, it is desirable to check the accuracy of the computed turbulence characteristics from the TSWIFT code by comparing them with the experimental data.
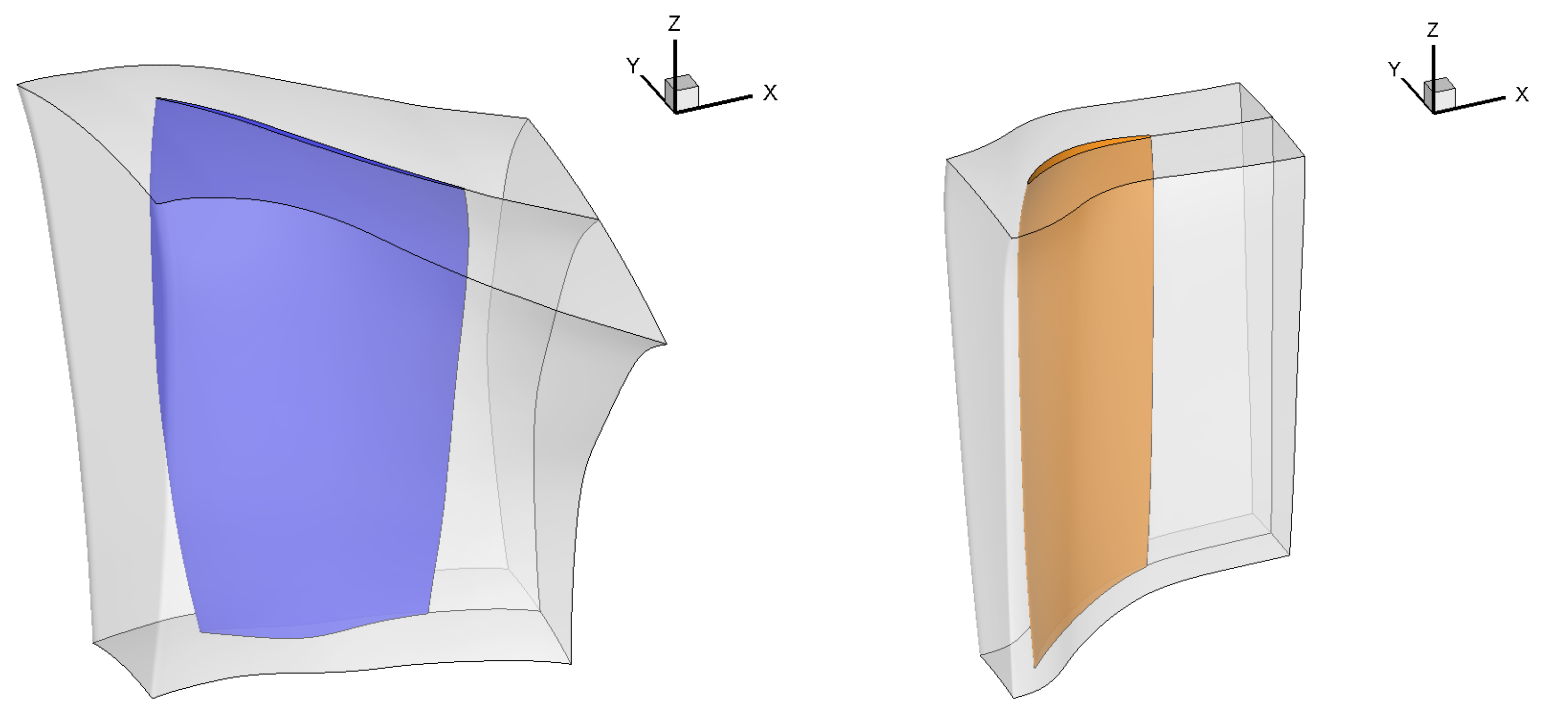

Figure 18.-Computational domains for the rotor (left) and stator (right) are shown for the ADP fan. 


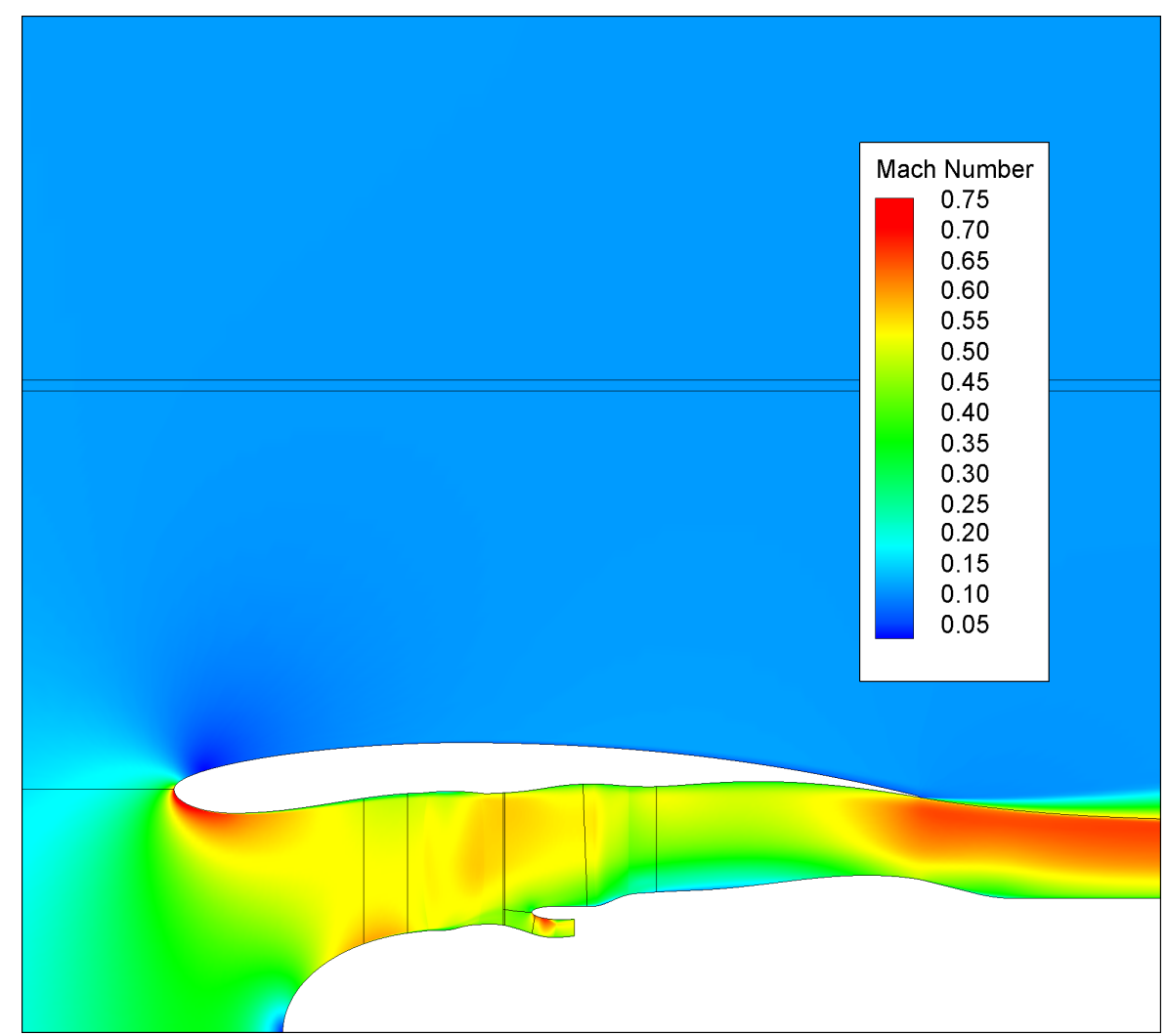

Figure 19.-Axisymmetric Mach number contours for the ADP fan at 8,750 rpm computed using the TSWIFT code. The thin black lines indicate the block boundaries. The simulation includes external as well as the internal flow. Note that the core flow is accounted for also.

In figure 20 comparisons of the predicted and measured total turbulence intensity 2.5 in. downstream of the fan rotor are plotted at three spanwise stations. The results correspond to the approach condition $(7,809 \mathrm{rpm})$ for the SDT fan and are the most reliable available data for this purpose. The comparisons are for an outboard station (88 percent span) shown in the top plot, the midspan station (71 percent span) shown in the middle plot, and an inboard station (56 percent span) shown in the bottom plot. Note that the inboard and outboard stations are outside of the highly disturbed flow regions near the inner and outer walls where it is hard to make a distinction between the background and wake turbulence. While the TSWIFT code seems to predict reasonable levels of turbulence within the wake region, it predicts much lower levels for the background turbulence. The cause of this shortfall is not entirely clear at this point and warrants further investigation. In the meantime, for the purposes of this study, the measured background turbulence level, which turns out to be $\sim 5 \mathrm{ft} / \mathrm{s}$ at all spanwise stations and all the measured conditions, was used as the input for the background turbulence level for all RSI test cases. Otherwise, the RANS results were used "as is" meaning that the distribution of the wake turbulence intensity as well as the integral length scale were used from the RANS simulation results without any change. It should emphasized that in the TSWIFT code, the background turbulence level is set a priori on the outer boundaries of the computational domain ${ }^{1}$ and remains essentially unaffected by the flow through the fan rotor. Therefore, the computed wake turbulence level (as we have defined it here) would have not changed had a $5 \mathrm{ft} / \mathrm{s}$ background level been used in TSWIFT simulations in the first place.

The predictions of the RSI code for all cases considered in this paper are compared with the measured sound power levels and are presented in figures A.19 to A.33 in the appendix. It should be noted that the predicted spectra shown here include both inlet and exhaust contribution since the measured data includes both of these contributions too. Per information in table 4 , an error band of $\pm 1 \mathrm{~dB}$ is assigned to the measured acoustic sound power levels. The reader is reminded that the measurements below about $1.6 \mathrm{kHz}$ are contaminated by the extraneous "drive rig" noise mentioned in the previous section. Clearly, the RSI predictions fall short of the measured data in all cases. As was

\footnotetext{
${ }^{1} 1990$ s vintage measurements reported 0.25 percent freestream turbulence level at Mach 0.1 (i.e., $\sim 0.28 \mathrm{ft} / \mathrm{s}$ ).
} 
alluded to earlier, this is mainly due to the rotor-only contribution not being accounted for in the predictions. To demonstrate this assertion we have plotted in figure 21 the measured rotor-only acoustic power level data for the SDT fan at the approach condition (i.e., 7,809 rpm) shown in green. This data was acquired during a wind tunnel test of the SDT fan where the stators were removed and the nacelle and the centerbody were independently supported (see ref. 29). The acoustic data was acquired for a number of fan tip speeds, but due to excess noise produced by the high-speed swirling flow exiting the duct and impinging on the drive rig, data for speeds higher than the approach condition are suspect since the measured rotor-only noise levels turn out to be higher than the measured fan stage levels in some cases and the discrepancy gets worse as the tip speed increases.
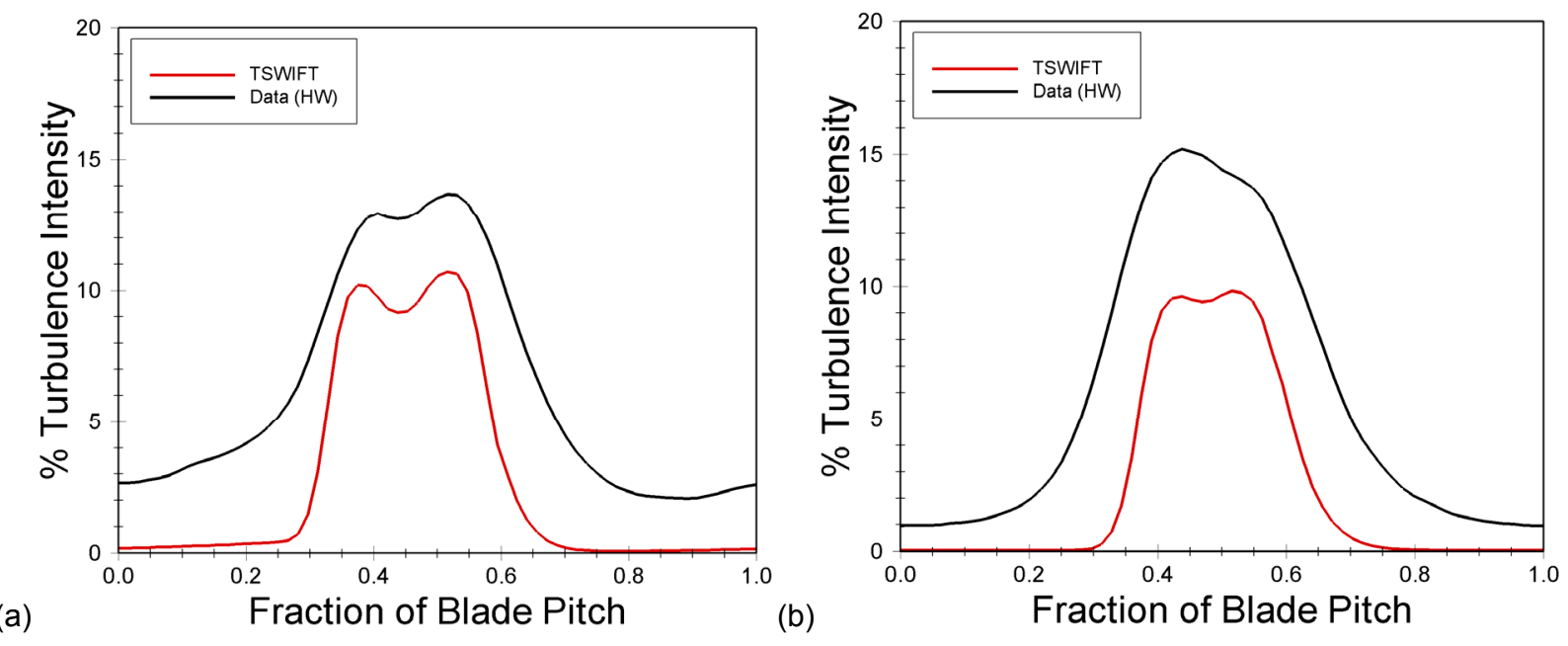

(a)

(b)

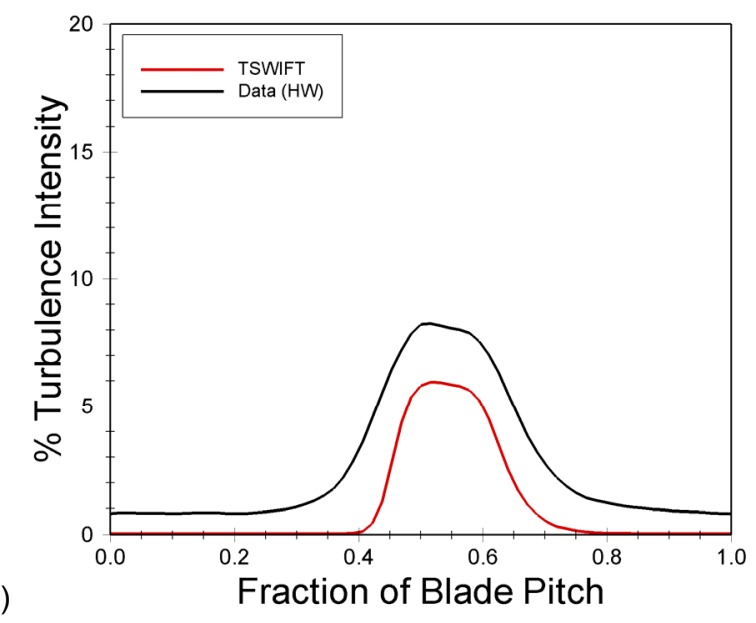

Figure 20.-Comparisons of predicted and measured turbulence intensity downstream of the fan rotor for SDT at the approach condition $(7,809 \mathrm{rpm})$. (a) Plot is for the outboard region (88 percent span), (b) plot for the midspan region (71 percent), and (c) plot for the inboard region (56 percent span). 


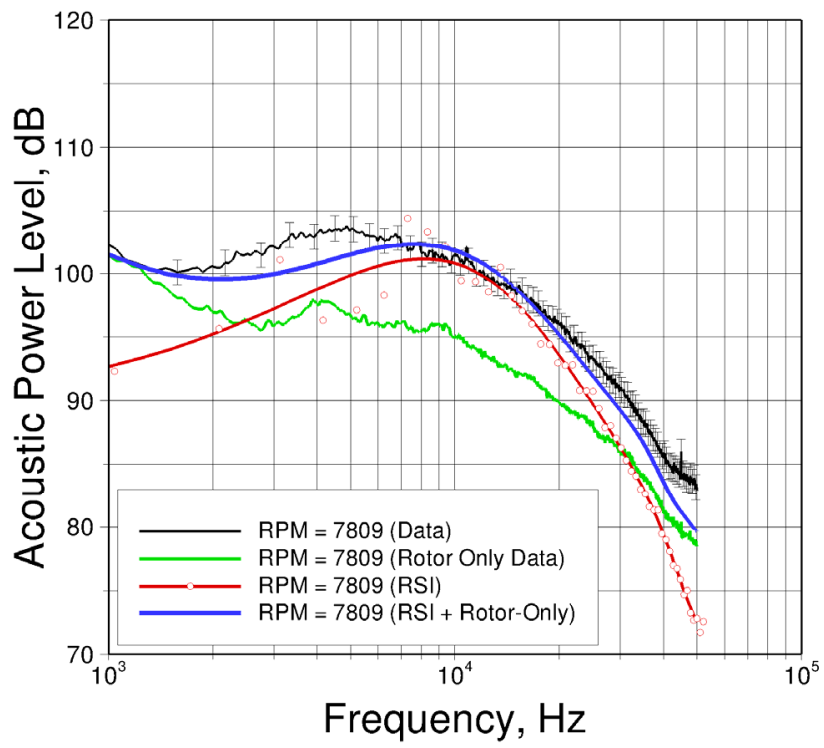

Figure 21.-Comparison of predicted (RSI) and measured narrowband sound power level for SDT at 7,809 rpm without and with the rotor-only contribution. The rotor-only data is shown in green, RSI prediction for stator generated power level is shown in red, and RSI prediction combined with rotor-only data is shown in blue. The measured data for the fan stage is shown in black inclusive of experimental uncertainties.

Returning to figure 21, when the RSI prediction (shown in red) is combined (i.e., anti-logarithmically summed) with the rotor-only contribution, this "augmented" prediction agrees quite favorably with the measured fan stage data. This is especially true in the frequency ranges below ${ }^{2} 5 \mathrm{kHz}$ and above $20 \mathrm{kHz}$ where the agreement with the RSI predictions that include only the stator levels was quite poor. To explore whether this hypothesis applies to the higher fan tip speeds, the rotor-only noise was assumed to follow the (tip speed) ${ }^{6}$ scaling law commonly associated with fan noise. Therefore, we have estimated the rotor-only noise as following the $\left(\mathrm{V}_{\text {tip }} / 7809\right)^{6}$ profile meaning that the rotor-only spectrum of the acoustic power is raised by $60 \times \log _{10}\left(\mathrm{~V}_{\text {tip }} / 7809\right)$ as a function of fan tip speed for SDT. The resulting rotor-only noise power level estimates were added to the RSI predictions for the stator contribution and the augmented predictions were compared with the fan stage data. The results are shown in figures 22 to 25 . Clearly, there is now much better agreement between the predictions and measured data across the frequency range and throughout the fan tip speed range indicating the importance of including the rotor-only contribution. Unfortunately, since rotor-only configurations have not been tested for ADP and QHSF2 it is not possible to make similar comparisons for these two fans at this time. Therefore, for the purposes of this paper we shall estimate the data-theory error margin using the SDT fan results only. A rigorous investigation of the datatheory discrepancy must, therefore, be deferred until a reliable rotor noise model can be employed.

The results of the data-theory comparisons for SDT are summarized in figure 26. With the rotor-only contributions taken into account, there is good agreement between the predicted and measured levels throughout the frequency and tip speed ranges. In fact, the data-theory discrepancy, while still larger than the experimental uncertainty, is well within a $\pm 2.5 \mathrm{~dB}$ margin especially when frequencies below $1.6 \mathrm{kHz}$ are ignored owing to excess rig noise contamination. Therefore, relative to the $\pm 1 \mathrm{~dB}$ experimental uncertainty, the predictions are less than $\pm 1.5 \mathrm{~dB}$ outside the experimental uncertainty band. Of course, there is no guarantee that this conclusion would necessarily apply to the ADP and QHSF2 fans. Nevertheless, these results are an indicator of how robust analytical methods can be in modeling fan broadband noise especially given the level of geometric and flowfield simplifications usually employed in these types of models. A corollary conclusion is that the $\left(\mathrm{V}_{\text {tip }}\right)^{6}$ scaling law

\footnotetext{
${ }^{2}$ Note that there is drive rig noise contamination below $1.6 \mathrm{kHz}$ in the rotor-only noise levels as well.
} 
appears to be a good indicator of the change in the level of the rotor-only noise for the SDT fan as a function of tip speed. Again, whether this scaling law applies to the other two fans is only speculation at this point and a more rigorous conclusion must await modeling work or direct measurements in the future.

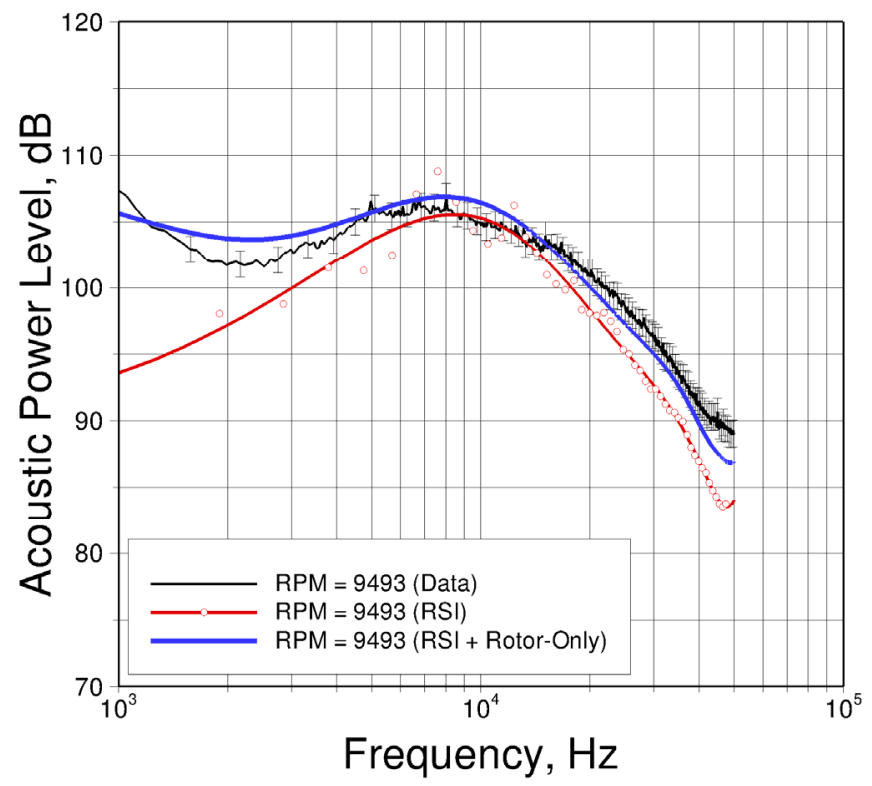

Figure 22.-Comparison of augmented RSI prediction and measured narrowband PWL for SDT at 9,493 rpm.

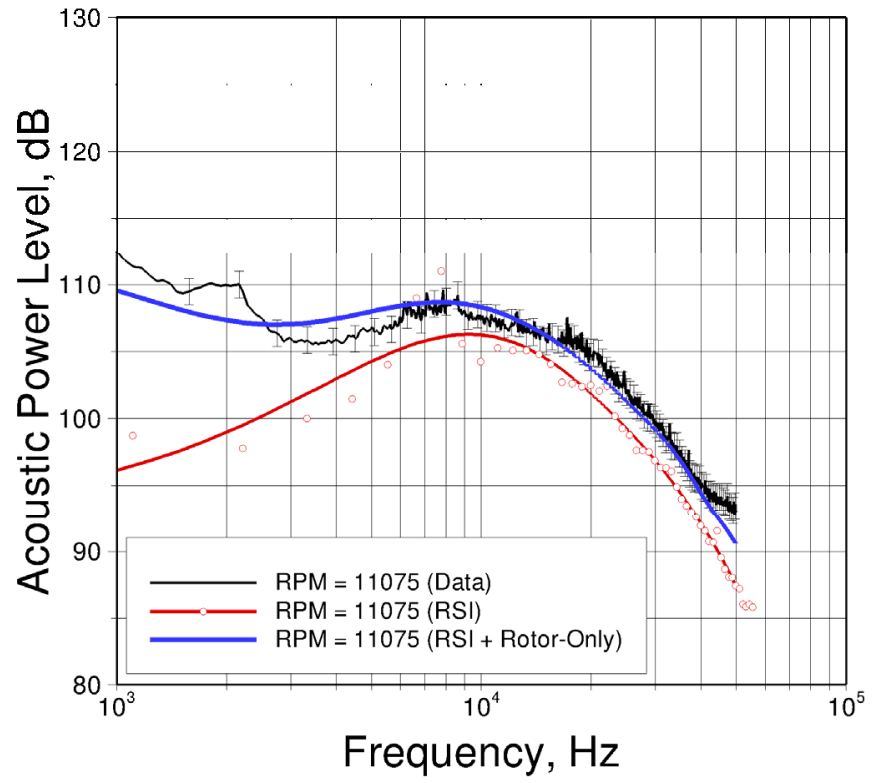

Figure 23.-Comparison of augmented RSI prediction and measured narrowband PWL for SDT at 11,075 rpm. 


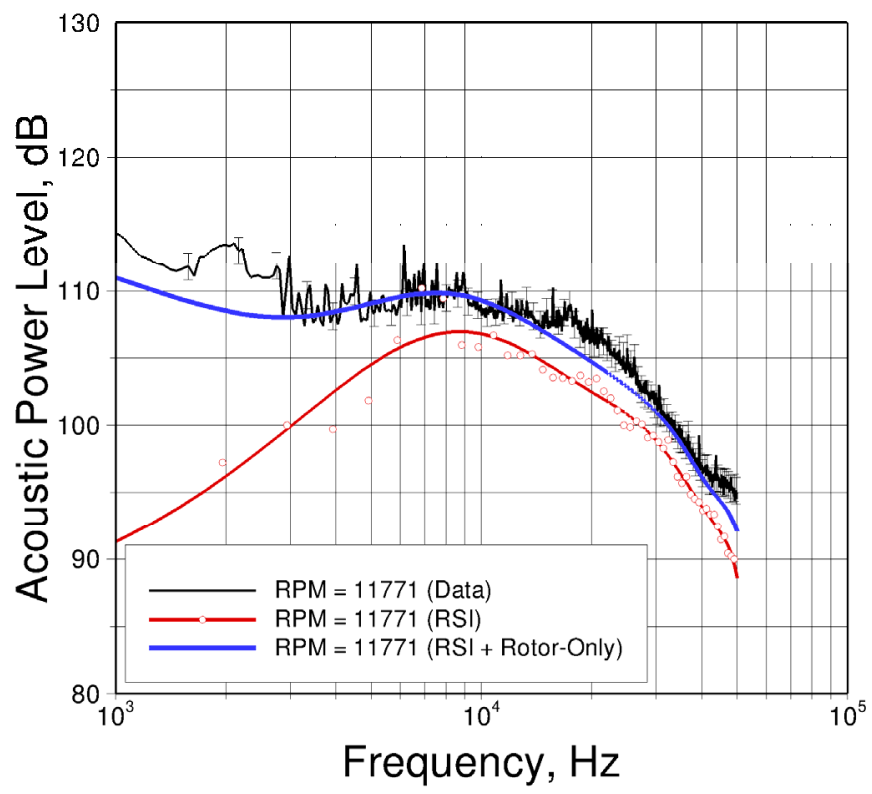

Figure 24.-Comparison of augmented RSI prediction and measured narrowband PWL for SDT at 11,771 rpm.

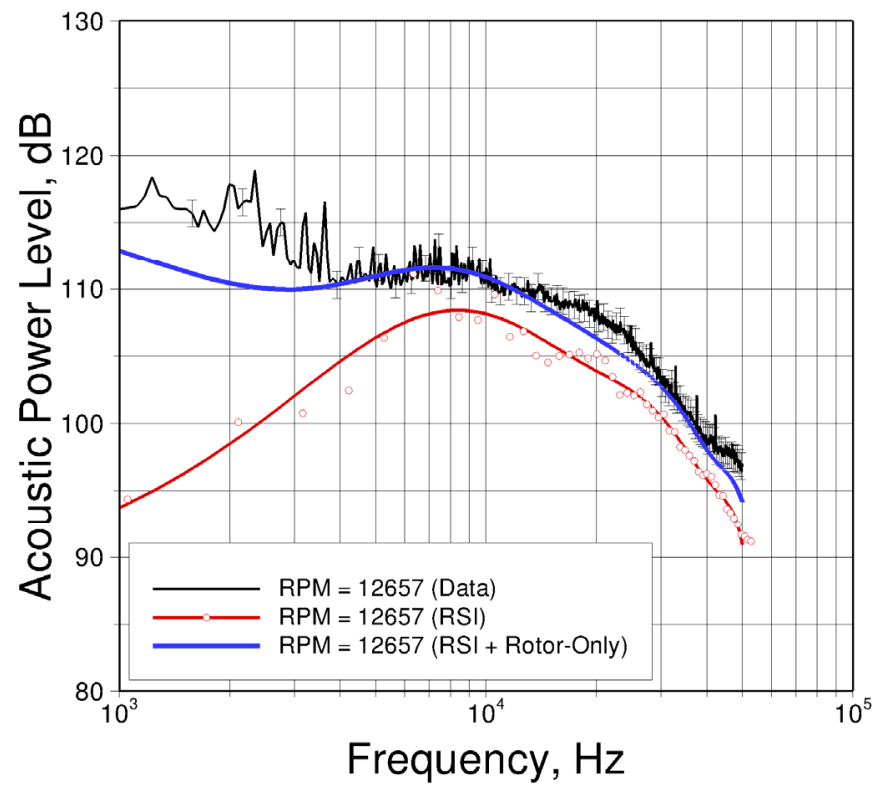

Figure 25.-Comparison of augmented RSI prediction and measured narrowband PWL for SDT at 12,657 rpm. 


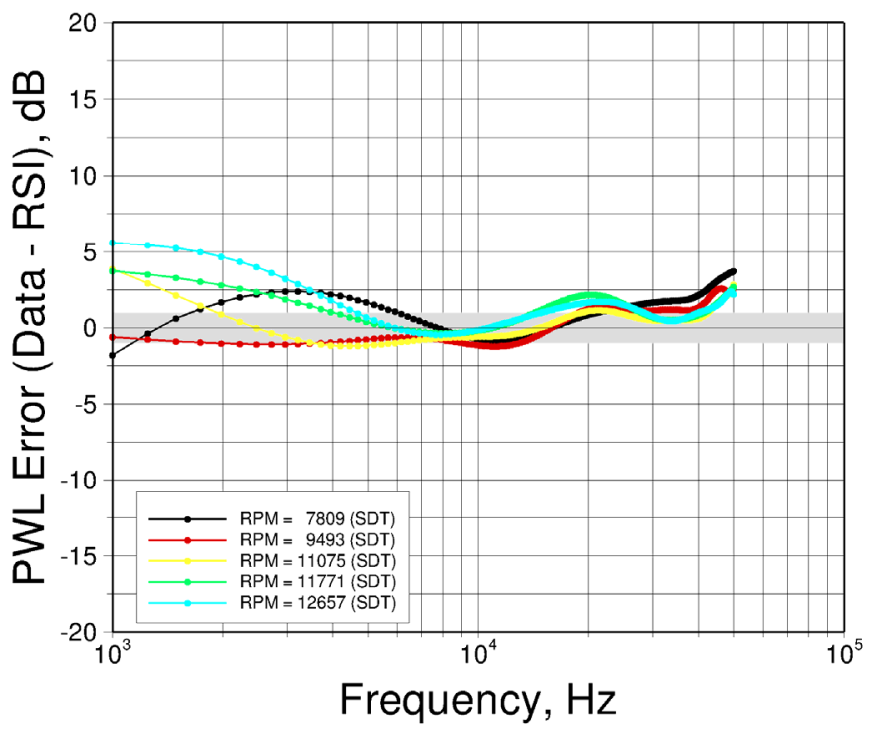

Figure 26.-RSI prediction error for all three fans. Results below $1.6 \mathrm{kHz}$ are suspect due to data contamination.

\section{Computational Methods}

As an example of computationally intensive methods, the LINFLUX code (see ref. 30) was selected for this assessment exercise. The choice was dictated for two main reasons. First, LINFLUX has been in use since the late 1990s and has been rigorously exercised and even used in design work. Second, computational codes tend to require significant user experience to be reliably used for analysis and design purposes. At NASA, LINFLUX has been extensively used and is the tool of choice when high-fidelity predictions are required. NASA has been developing a more advanced code in this category, but it is still in the late development stages and not yet ready for routine use.

LINFLUX is a frequency-domain, three-dimensional, linearized inviscid description of the unsteady flow. In this study it was used to compute the rotor-stator interaction tones generated as a result of the mean perturbations in the fan rotor wake impinging on the stator. The underlying mean flow (also three-dimensional and inviscid) is representative of the flow through a realistic stator. The required nonlinear mean flow can be computed using any suitable inviscid code, but for the purposes of this study a serial version of the TURBO steady aerodynamic code was used. Both LINFLUX and TURBO use an implicit and finite-volume description of the flow, which makes for consistency in describing and analyzing both the mean and perturbation components of the flow. A detailed description of the LINFLUX code (and to some extent the version of the TURBO code used here) can be found in reference 30 and other works cited in that document. LINFLUX code calculates perturbation density, momenta and internal energy everywhere in the domain subject to specified wake perturbation input, which are supplied in the terms of the fan blade-passing harmonic content. In this study, these were generated from the TSWIFT simulations discussed earlier. The TSWIFT simulations were also used to supply the inflow conditions for the mean flow calculations. These include the radial profiles of the circumferentially averaged total pressure, total temperature and the swirl angle at the inflow plane of the computational domain for TURBO.

In addition to the field solution, LINFLUX also calculates the tone sound pressure level and acoustic power level upstream and downstream of the stator. Since the computational inflow/outflow boundaries fall well short of the Rotating Rake measurement stations, the data-theory comparisons shown here are on the acoustic power level basis, which is thought to be conserved, at least for the non-swirling flow downstream of the stator.

Both the mean and perturbation flows are discretized on a regular H-mesh topology, which needs to be dense enough to resolve the perturbations of interest. Therefore, the size of the grid depends on the frequency content under consideration. In this study, the goal was to resolve rigorously the second ${ }^{3}$ harmonic of the blade passing frequency (i.e., $2 \times B P F$ ) tone. The rule of thumb suggested in the documentation for the LINFLUX code calls for a minimum of 40 grid points per wavelength to adequately resolve the perturbations. Each grid extents axially one

\footnotetext{
${ }^{3}$ Blade passing frequency tone is cut-off for all three fans given their blade/vane ratios.
} 
vane chord upstream and one vane chord downstream to allow the mean flow to become axisymmetric at the inflow and outflow planes. In the radial direction the same number of grid points were used in all cases since the vane span (measured vertically) is the nearly the same for all three stators. In the tangential direction, the grid spans one blade passage, since LINFLUX uses the known inter-blade phase angle as a means of relating the boundary conditions on one side of the passage to those on the other side. The grid sizes used for the three fans in this study are listed in table 9. The larger axial grid size for QHSF2 is a consequence of the swept geometry of the stator for this fan, which necessitates a larger axial domain if one vane chord upstream and downstream "rule" was to be enforced. Finally, the differences in the tangential direction are due to differences in the vane counts. In the interest of reducing the number of grids that had to be generated and the mean flowfields that had to be computed for each fan, the gird corresponding to the highest fan tip speed (and hence highest frequency) was chosen as a the common grid for all speeds for that fan.

TABLE 9.-TURBO/LINFLUX GRID SIZES

\begin{tabular}{|l|c|c|c|}
\hline \multicolumn{1}{|c|}{ Fan } & Axial & Radial & Tangential \\
\hline ADP & 181 & 51 & 43 \\
\hline SDT & 181 & 51 & 37 \\
\hline QHSF2 & 211 & 51 & 39 \\
\hline
\end{tabular}

In all cases, the TURBO and LINFLUX calculations were run to convergence (i.e., at least four orders of magnitude reduction in the residual). This involved running the TURBO simulations at least 12,000 iterations and the LINFLUX calculations a minimum of 5,000 iterations unless the solution converged sooner. The characteristics of the converged mean flowfields were closely examined in each case to ensure that the flow was well behaved especially near the blade surface. This turned out to be possible only for the ADP and SDT fans, but not the QHSF2 fan. For the latter fan, the flow develops small recirculation zone near the leading edge on the pressure side and/or near the trailing edge on the suction side of the vane. An examination of the TSWIFT simulation results indicates that the same phenomena are present in the viscous solutions and, hence, they are not an artifact of the inviscid calculations. When such recirculation zones are present in the mean flow, the perturbation calculation do not behave well and sometimes do not even converge. As a result, the QHSF2 results are not included in this paper, but might be included in the NASA TP if they can be converged through reasonable changes in the inflow conditions.

The results of the data-theory comparisons for the 2xBPF tone of the ADP and SDT fans are shown in figures 27 and $28^{4}$. The comparisons shown here are only for the downstream-radiated noise (i.e., the exhaust noise), since the three-dimensional rotor acoustic transmission loss through the fan rotor cannot be accounted for at the present time. Figure 27 shows the variations in the level of the acoustic power at the 2 XPPF as a function of the tip speed for the ADP fan, and figure 28 shows the results for the SDT fan. As indicated in table 7, the uncertainty margin in measuring tone power level is $\pm 3.4 \mathrm{~dB}$, which is indicated by the errors on the experimental data in these figures. The results of the prediction error analysis are presented in figure 29 where the gray bar signifies the experimental uncertainty. For both fans, the predictions agree with the measurements to within the experimental uncertainty band at lower fan tip speeds but they deviate from the measurements at higher fan tip speeds. In fact, the agreement is quite good up to the cutback tip speed, but is off by as much as $6.5 \mathrm{~dB}$ at the takeoff speed for the ADP fan when experimental uncertainties are taken into account. Where there is discrepancy, it is typically smaller for SDT than ADP. Additional studies have been carried out to investigate the dependence of the LINFLUX predictions on the grid size. The results of these studies indicate that the solutions presented here are grid-independent in that halving the grid size for the ADP fan $(181 \times 25 \times 43)$ changed the predictions by only a fraction of $1 \mathrm{~dB}$.

\footnotetext{
${ }^{4}$ The measured mode acoustic power level data presented here are $12 \mathrm{~dB}$ lower than those reported previously for the ADP and SDT fans. Recently, an error was discovered in the Rotating Rake data reduction routine and the mode acoustic power data was corrected retroactively. It was also discovered that the LINFLUX sound pressure level and acoustic power level calculations contained an error related to inconsistent use of flowfield variable normalizations. In particular, the correct acoustic power is given by the expression $\mathrm{PWL}_{\text {corrected }}=\mathrm{PWL} \mathrm{L}_{\text {Linflux }}+10 \log _{10}\left(\rho_{\text {ref }} V_{\text {ref }}^{3}\right)$ where $\rho_{\text {ref }}$ and $V_{\text {ref }}$ are LINFLUX flowfield normalization factors. These depend on the particular fan operating condition and, hence, vary with tip the fan speed.
} 


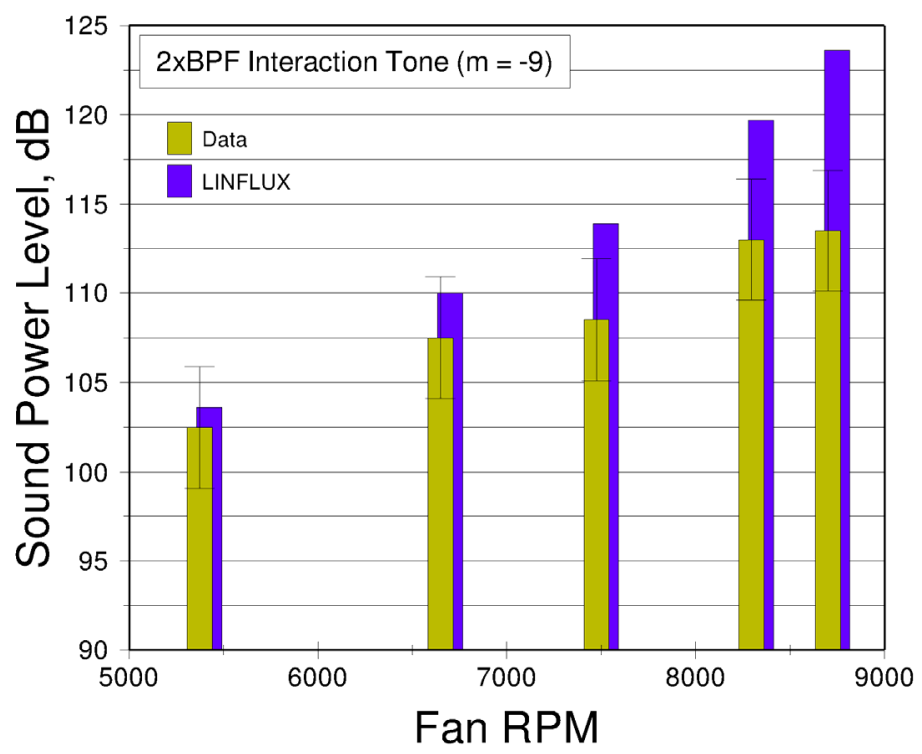

Figure 26.-Comparisons of predicted (LINFLUX) and measured rotor-stator interaction tone for ADP. The results are for the 2xBPF tone for which one circumferential mode, namely, $m=-9$ propagates.

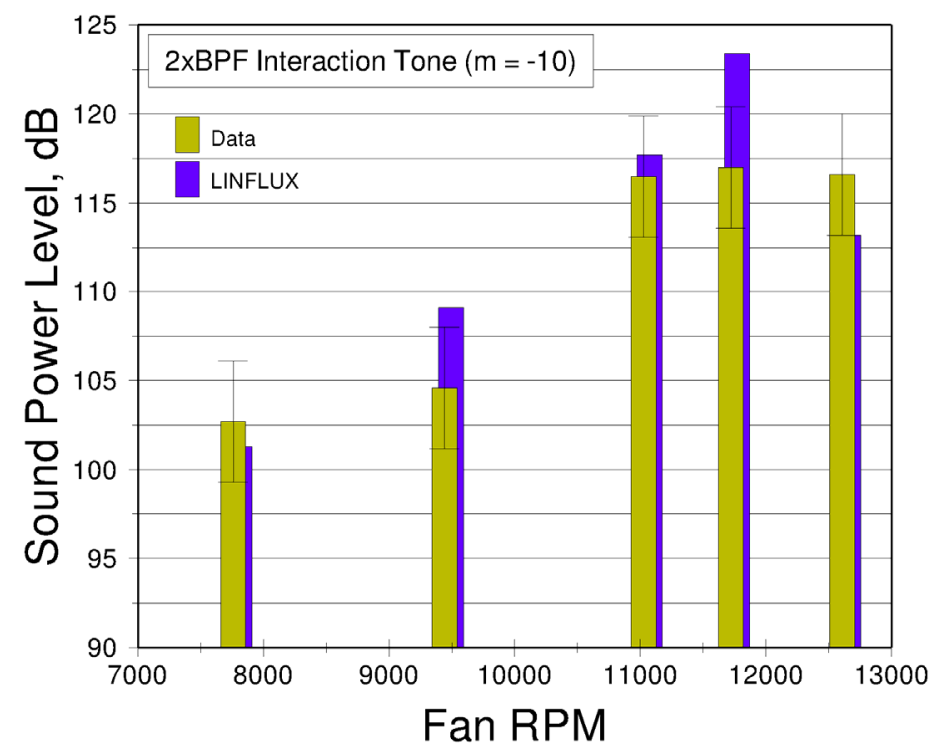

Figure 27.-Comparisons of predicted (LINFLUX) and measured rotor-stator interaction tone for SDT. The results are for the 2xBPF tone for which one circumferential mode, namely, $m=-10$ propagates. 


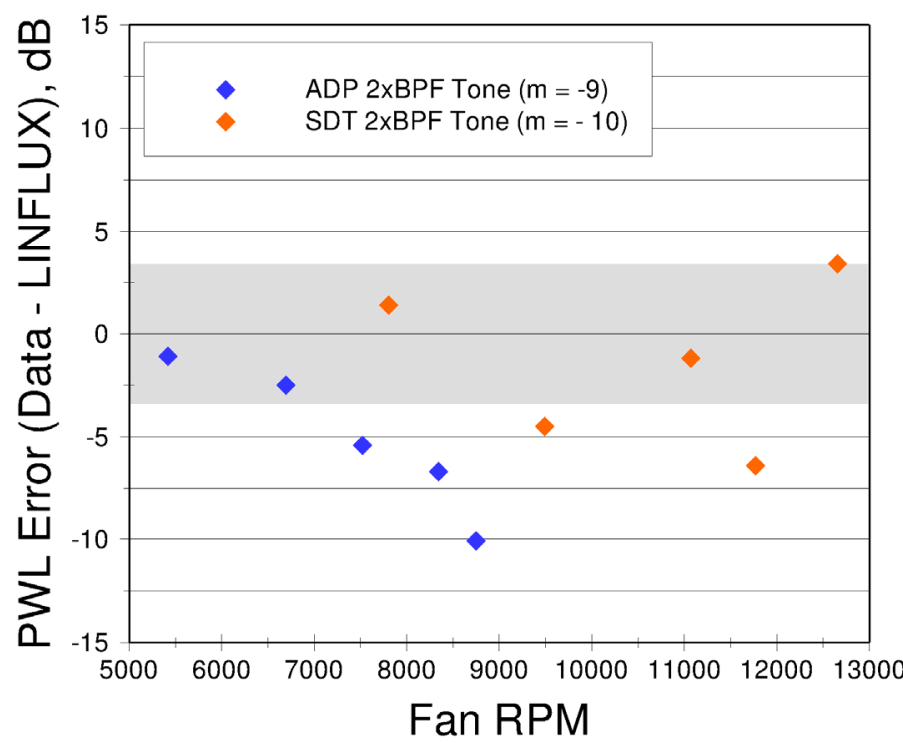

Figure 28.-LINFLUX 2xBPF tone power level prediction errors for ADP and SDT fans at all five tip speeds. The LINFLUX results for the QHSF2 fan could not be converged and are not shown here.

\section{Conclusions}

NASA fan prediction codes in the empirical, analytical and computational categories were exercised and assessed against a set of benchmark fan acoustic data. The codes included ANOPP (an empirical code), RSI (an analytical code), and LINFLUX (a computational aeroacoustics code). The benchmark fans cover a wide range of fan pressure ratios and tip speeds. The assessment results indicate that the ANOPP code can predict the fan noise spectrum to within $4 \mathrm{~dB}$ of the measurement uncertainty band on a third-octave basis for the low and moderate pressure ratio fans. The RSI code can predict fan broadband noise spectrum to within $1.5 \mathrm{~dB}$ of experimental uncertainty band provided the rotor-only contribution is taken into account. The LINFLUX code can predict interaction tone power levels to within experimental uncertainties at low and moderate fan tip speeds, but could deviate by as much as $6.5 \mathrm{~dB}$ outside the experimental uncertainty band at the highest tip speeds in some cases. Full details of this assessment effort will be documented in an forthcoming NASA Technical Publication (TP). This report will guide the course of the future developments in the area of fan noise modeling and prediction at NASA. 


\section{Appendix}

In order to streamline the presentation of the material in this paper additional data-theory comparisons are included in this appendix for all cases that were run using the ANOPP and RSI codes. The figures begin on the next page.

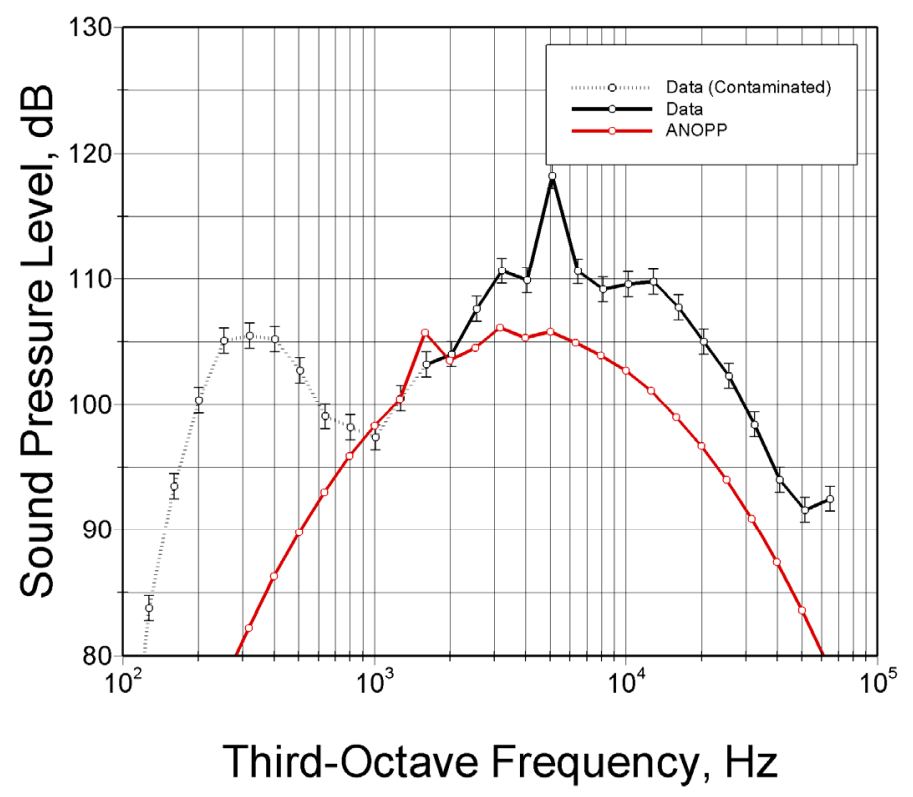

Figure A.1.-Comparison of predicted (ANOPP) and measured SPL for ADP at 5,425 rpm. Results for a position in the inlet quadrant are shown (emission angle of $46^{\circ}$ at Mach 0.1).

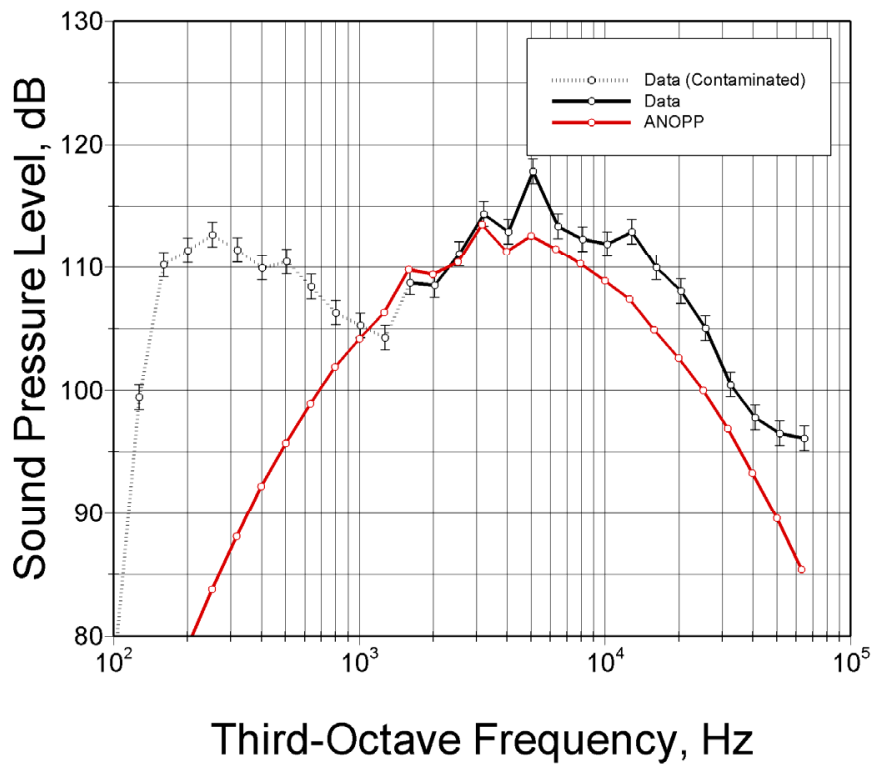

Figure A.2-Comparison of predicted (ANOPP) and measured SPL for ADP at 5,425 rpm. Results for a position in the exhaust quadrant are shown (emission angle of $136^{\circ}$ at Mach 0.1 ). 


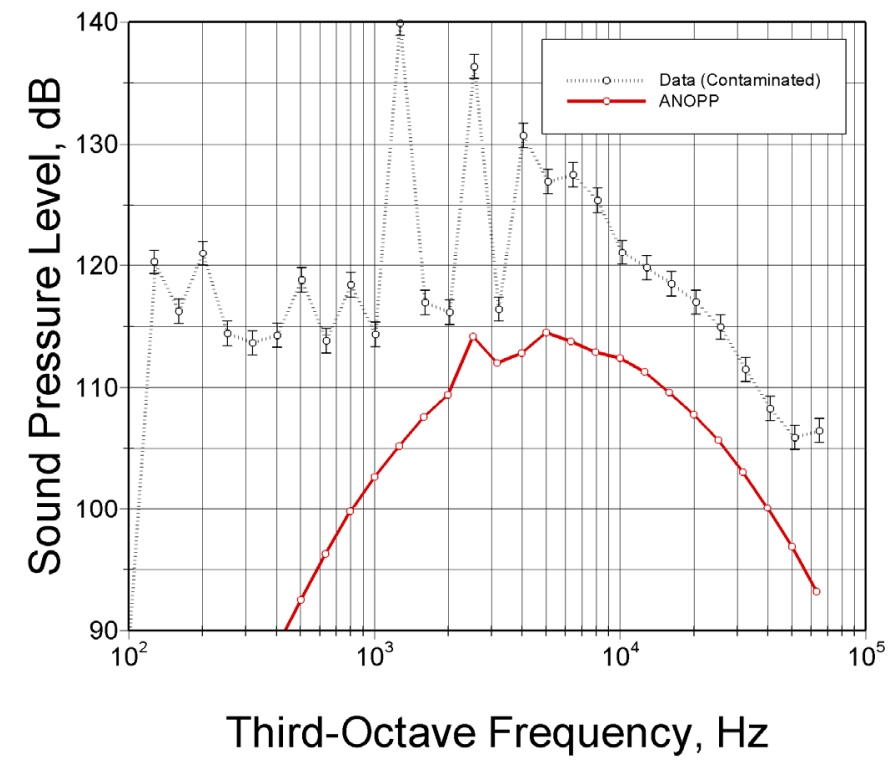

Figure A.3.-Comparison of predicted (ANOPP) and measured SPL for ADP at 7,525 rpm. Results for a position in the inlet quadrant are shown (emission angle of $46^{\circ}$ at Mach 0.1).

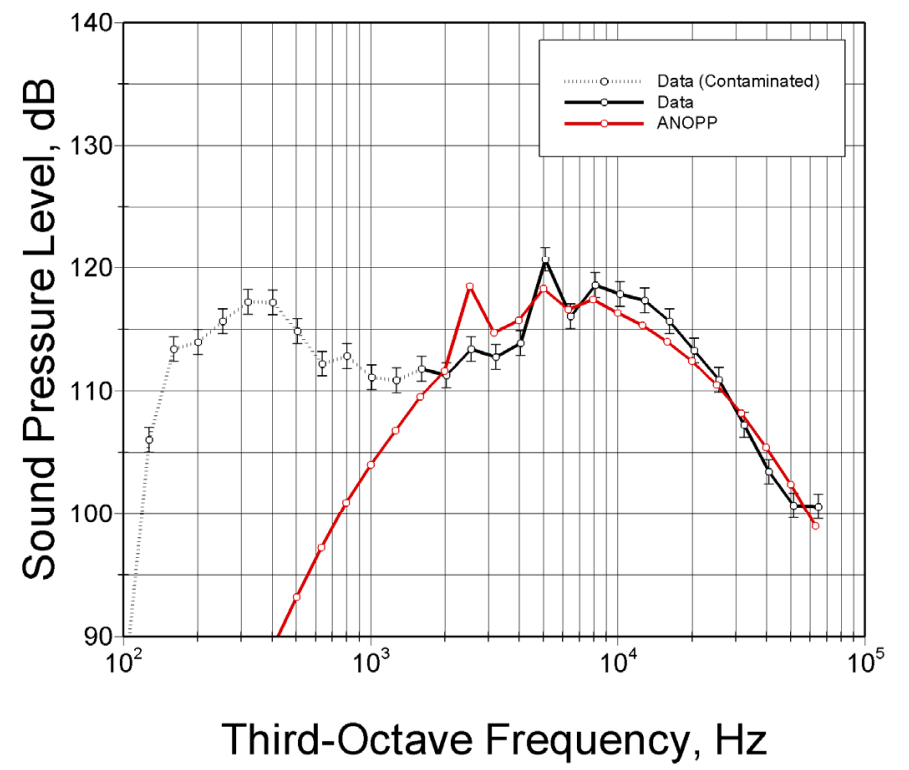

Figure A.4.-Comparison of predicted (ANOPP) and measured SPL for ADP at 7,525 rpm. Results for a position in the exhaust quadrant are shown (emission angle of $136^{\circ}$ at Mach 0.1). 


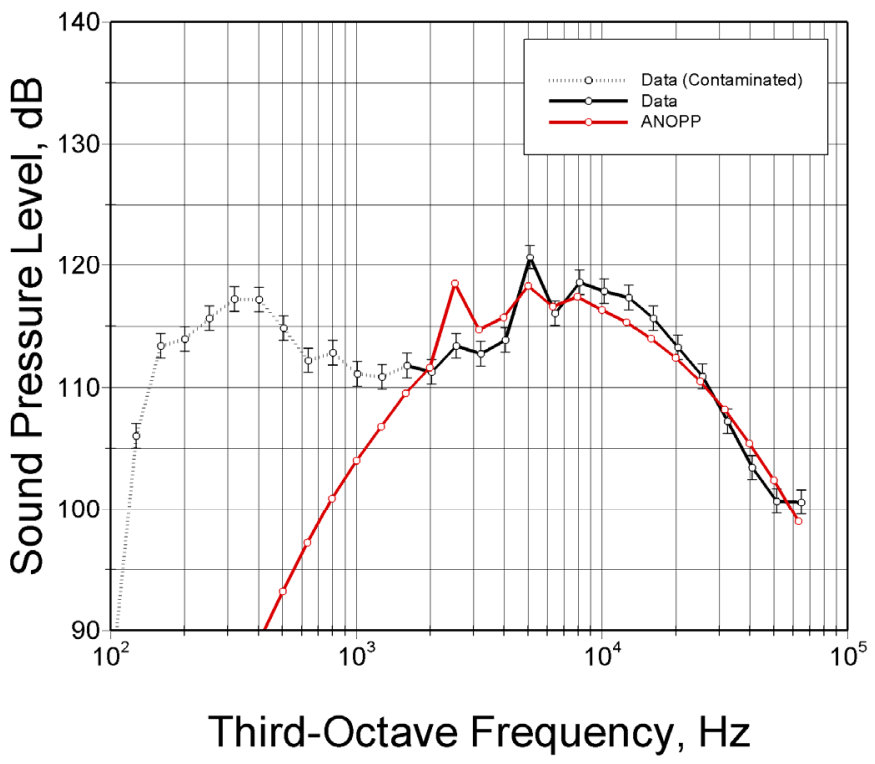

Figure A.5.-Comparison of predicted (ANOPP) and measured SPL for ADP at 8,750 rpm. Results for a position in the inlet quadrant are shown (emission angle of $46^{\circ}$ at Mach 0.1 ).

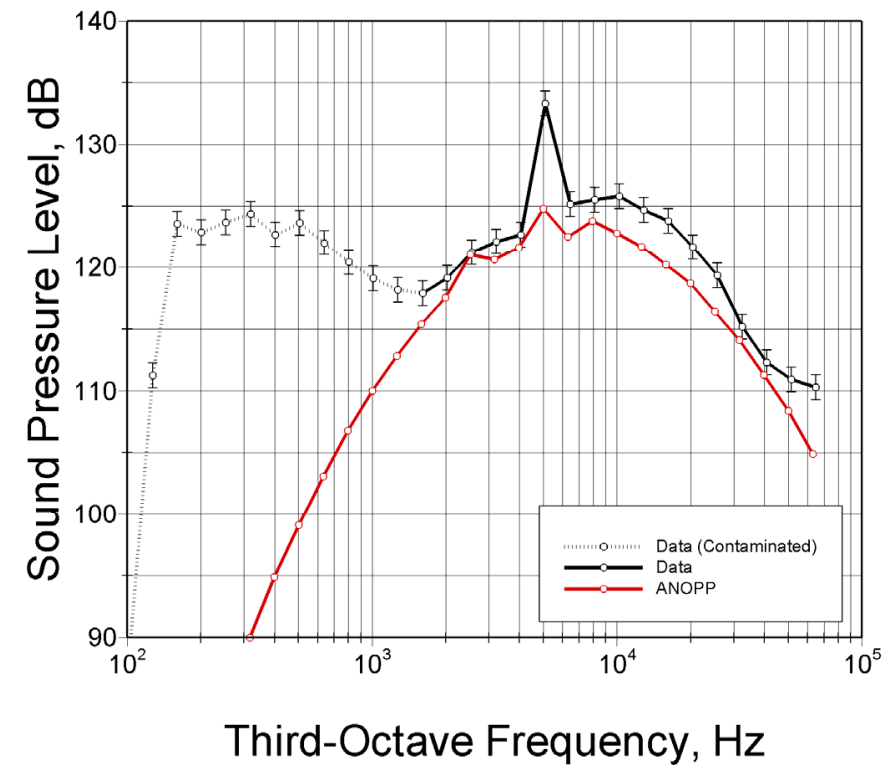

Figure A.6.-Comparison of predicted (ANOPP) and measured SPL for ADP at 8,750 rpm. Results for a position in the exhaust quadrant are shown (emission angle of $136^{\circ}$ at Mach 0.1). 


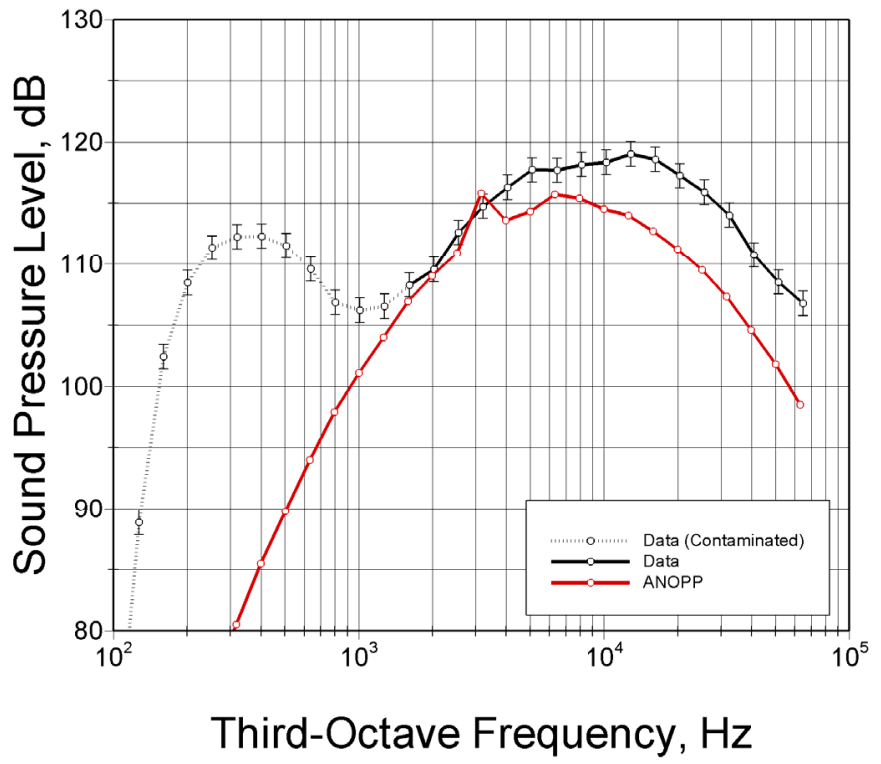

Figure A.7.-Comparison of predicted (ANOPP) and measured SPL for SDT at 7,809 rpm. Results for a position in the inlet quadrant are shown (emission angle of $46^{\circ}$ at Mach 0.1 ).

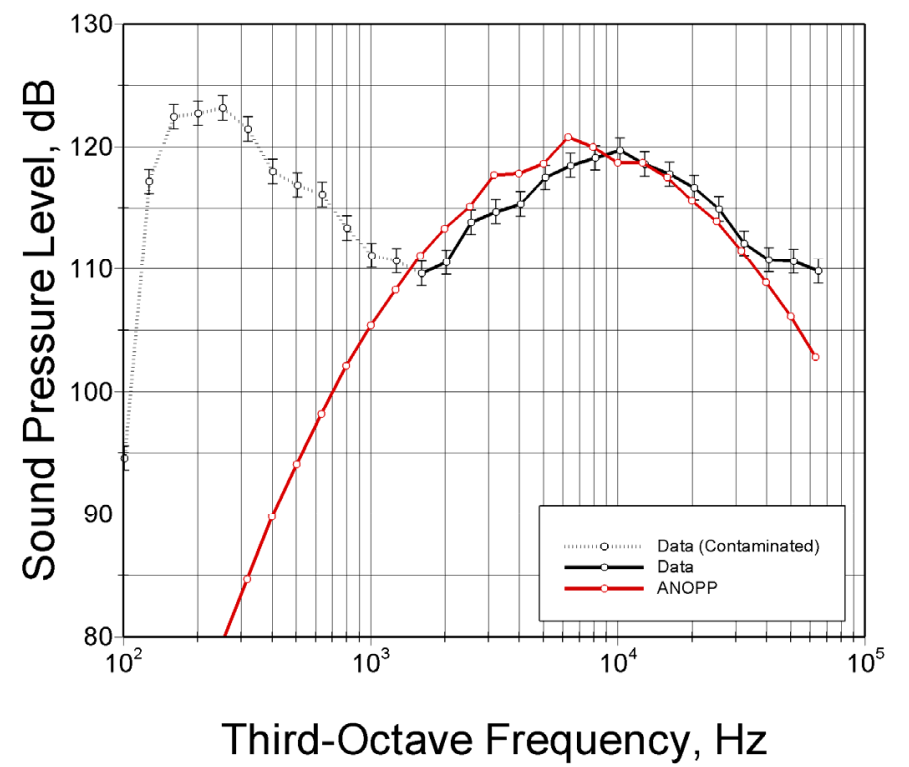

Figure A.8.-Comparison of predicted (ANOPP) and measured SPL for SDT at 7,809 rpm. Results for a position in the exhaust quadrant are shown (emission angle of $136^{\circ}$ at Mach 0.1). 


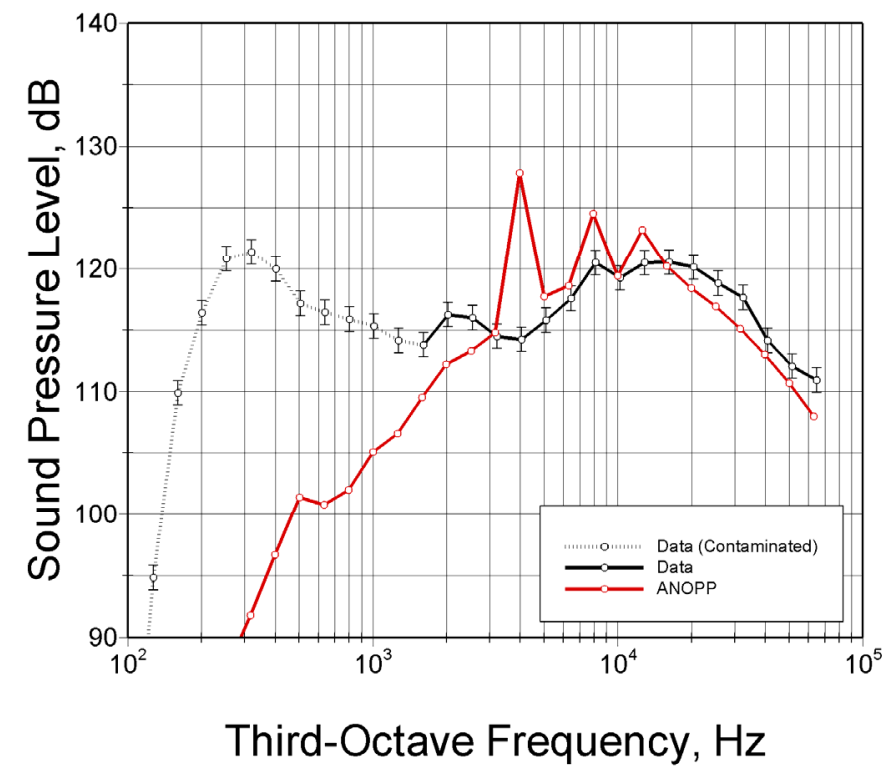

Figure A.9.-Comparison of predicted (ANOPP) and measured SPL for SDT at 11,075 rpm. Results for a position in the inlet quadrant are shown (emission angle of $46^{\circ}$ at Mach 0.1).

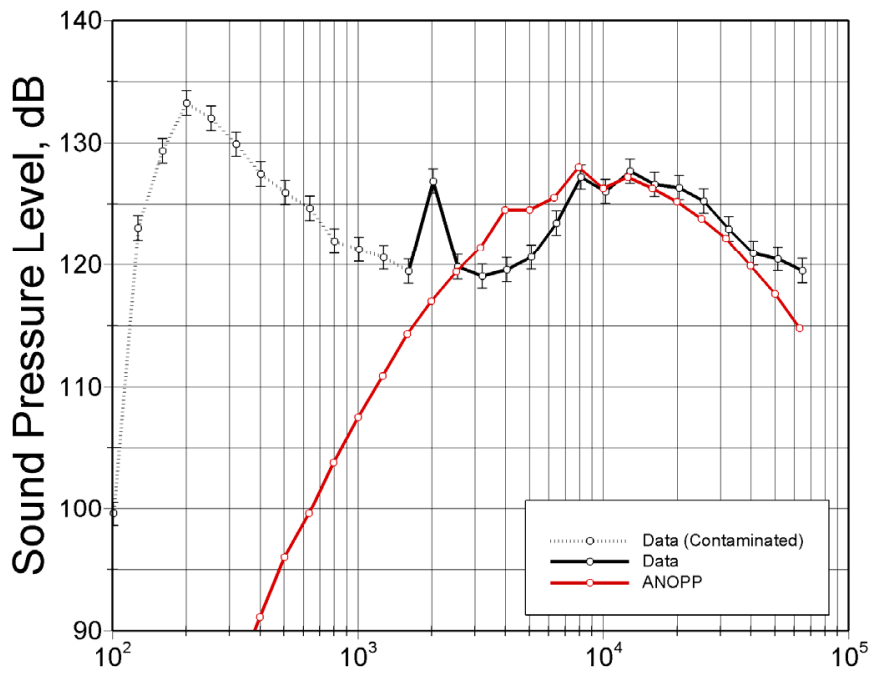

Third-Octave Frequency, $\mathrm{Hz}$

Figure A.10.-Comparison of predicted (ANOPP) and measured SPL for SDT at 11,075 rpm. Results for a position in the exhaust quadrant are shown (emission angle of $136^{\circ}$ at Mach 0.1). 


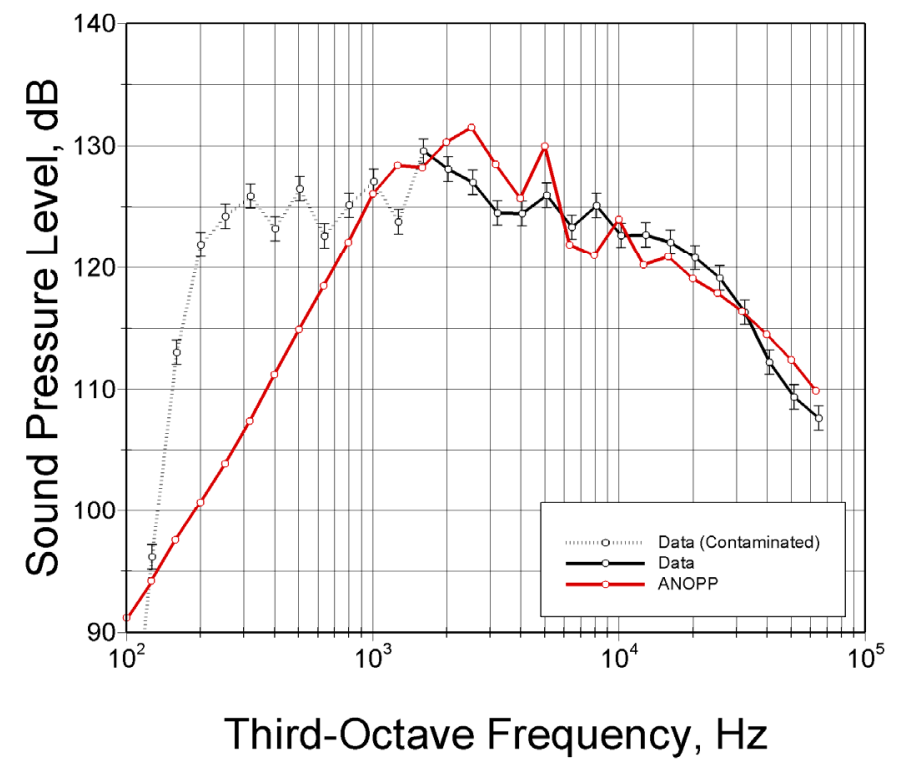

Figure A.11.-Comparison of predicted (ANOPP) and measured SPL for SDT at 12,657 rpm. Results for a position in the inlet quadrant are shown (emission angle of $46^{\circ}$ at Mach 0.1).

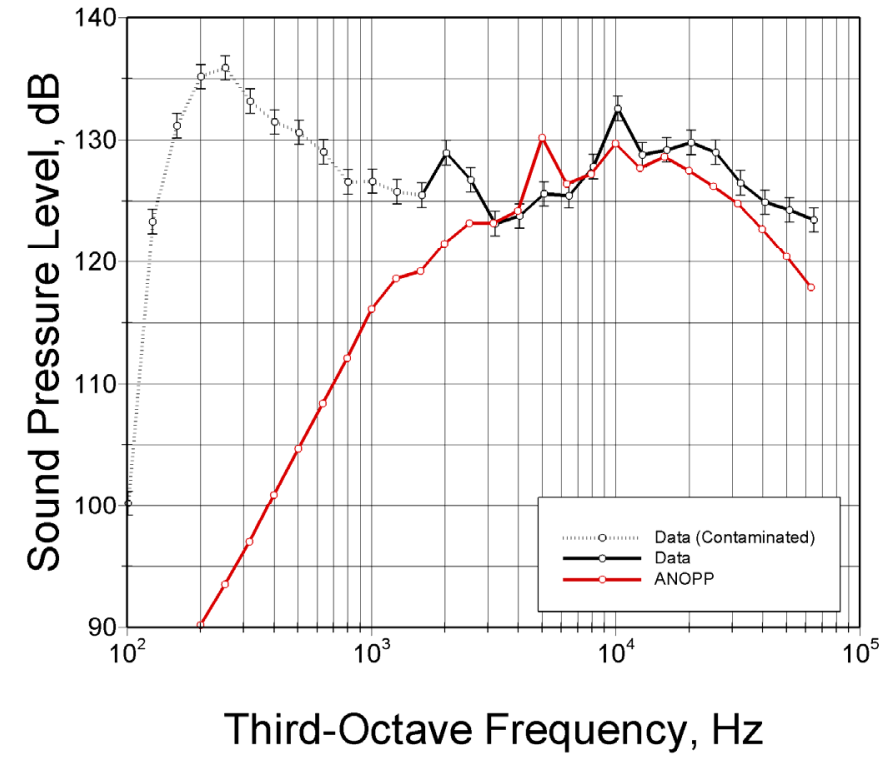

Figure A.12.-Comparison of predicted (ANOPP) and measured SPL for SDT at 12,657 rpm. Results for a position in the exhaust quadrant are shown (emission angle of $136^{\circ}$ at Mach 0.1). 


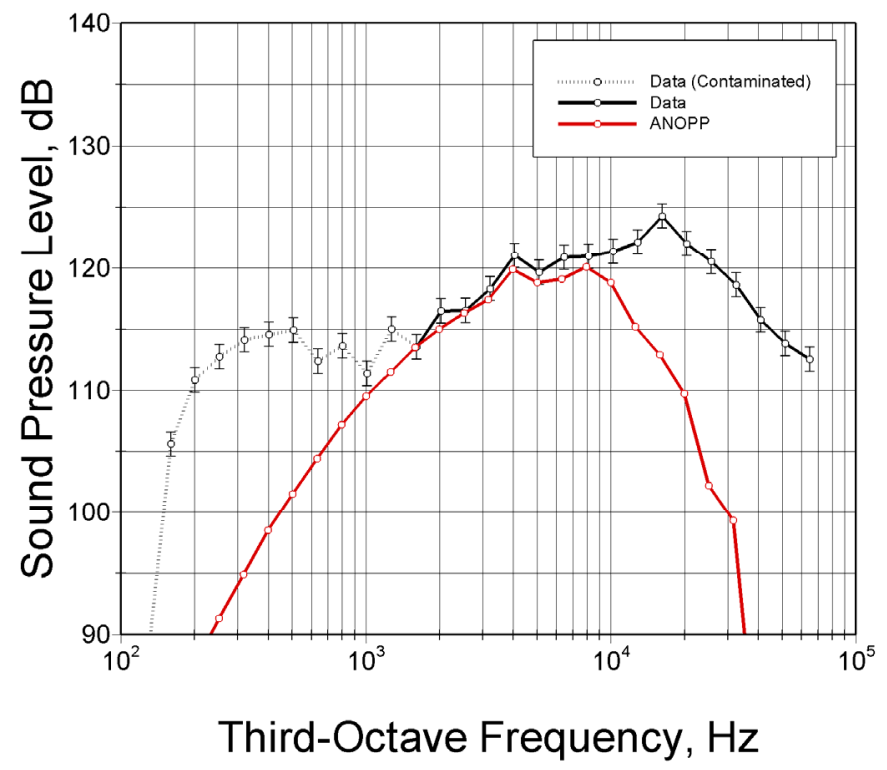

Figure A.13.-Comparison of predicted (ANOPP) and measured SPL for QHSF2 at 9,840 rpm. Results for a position in the inlet quadrant are shown (emission angle of $46^{\circ}$ at Mach 0.1).

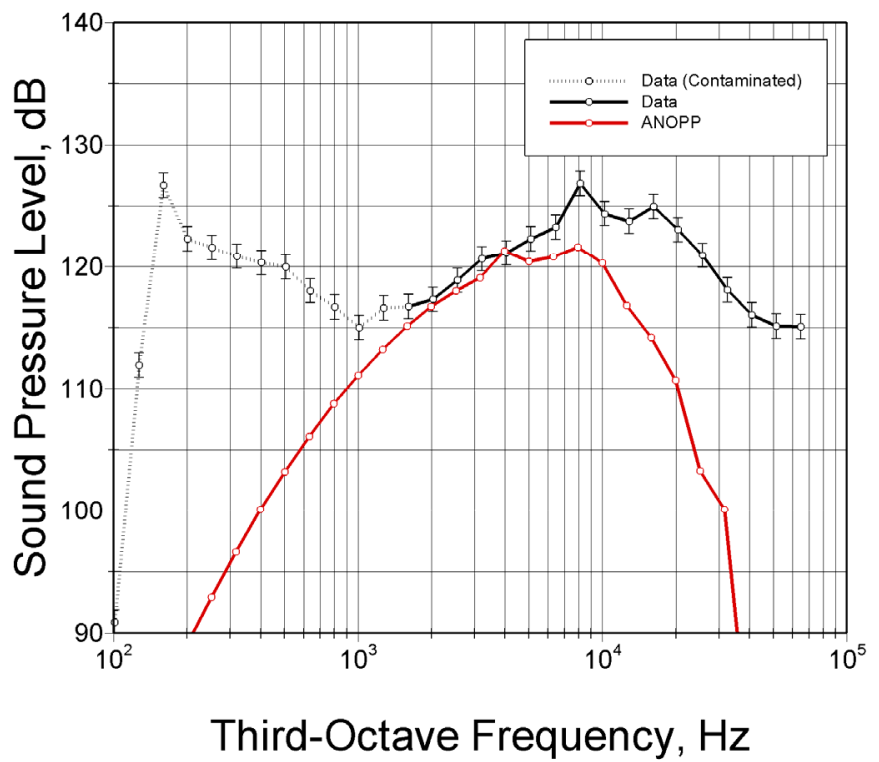

Figure A.14.-Comparison of predicted (ANOPP) and measured SPL for QHSF2 at 9,840 rpm. Results for a position in the exhaust quadrant are shown (emission angle of $136^{\circ}$ at Mach 0.1 ). 


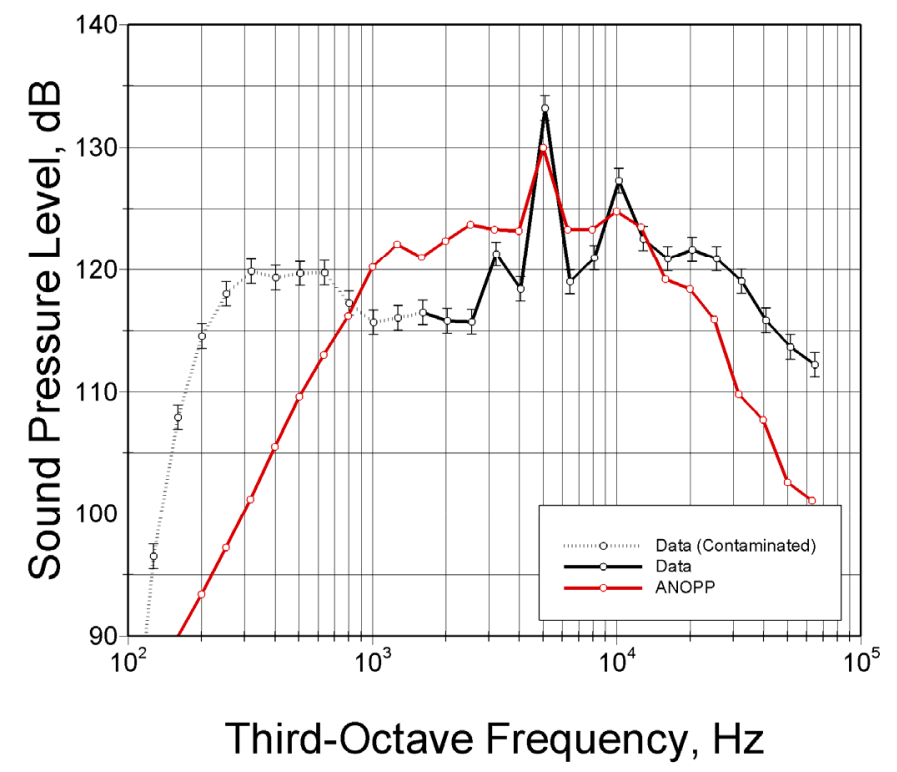

Figure A.15.-Comparison of predicted (ANOPP) and measured SPL for QHSF2 at 12,500 rpm. Results for a position in the inlet quadrant are shown (emission angle of $46^{\circ}$ at Mach 0.1).

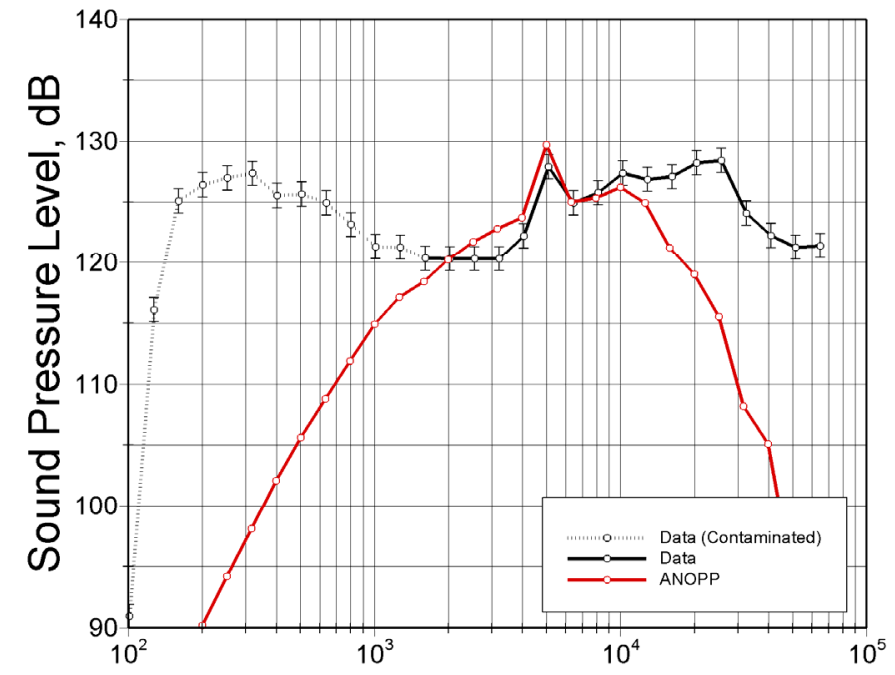

Third-Octave Frequency, $\mathrm{Hz}$

Figure A.16.-Comparison of predicted (ANOPP) and measured SPL for QHSF2 at 12,500 rpm. Results for a position in the exhaust quadrant are shown (emission angle of $136^{\circ}$ at Mach 0.1 ). 


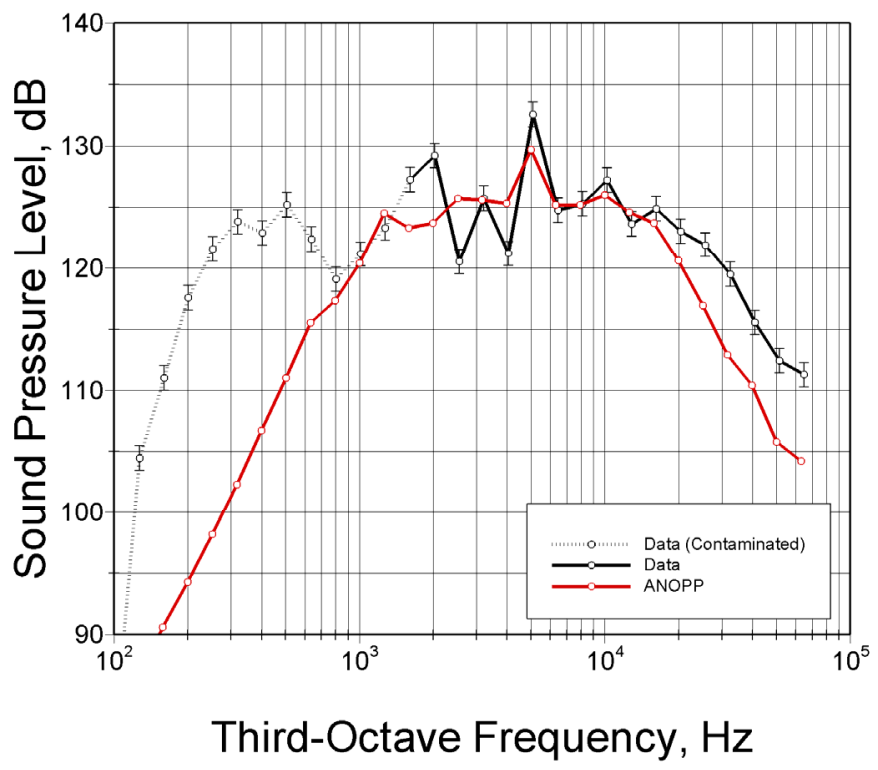

Figure A.17.-Comparison of predicted (ANOPP) and measured SPL for QHSF2 at 14,060 rpm. Results for a position in the inlet quadrant are shown (emission angle of $46^{\circ}$ at Mach 0.1).

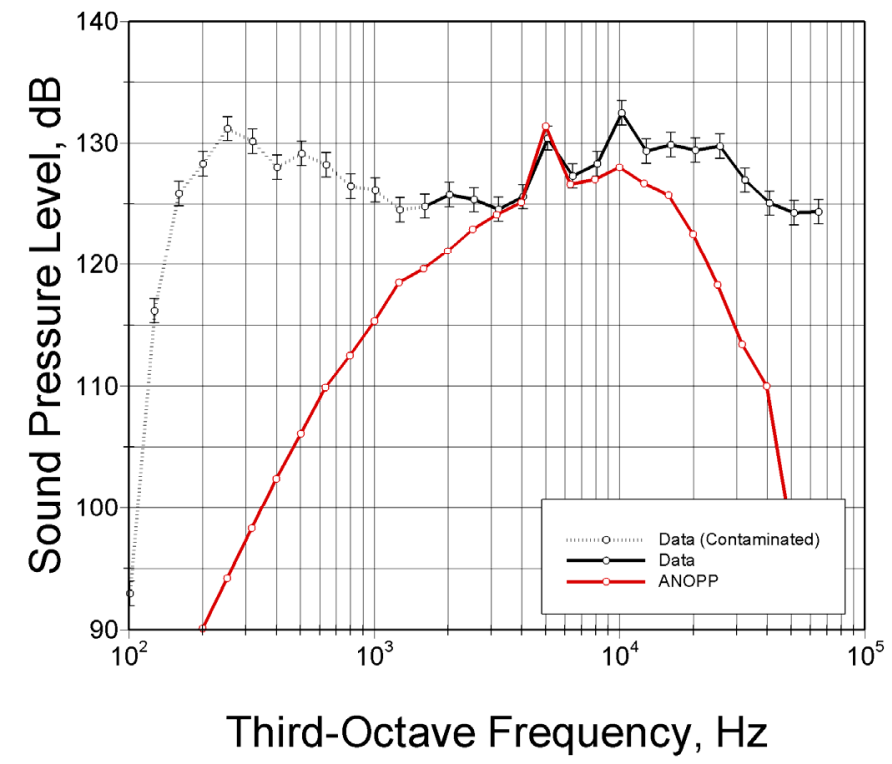

Figure A.18.-Comparison of predicted (ANOPP) and measured SPL for QHSF2 at 14,060 rpm. Results for a position in the exhaust quadrant are shown (emission angle of $136^{\circ}$ at Mach 0.1 ). 


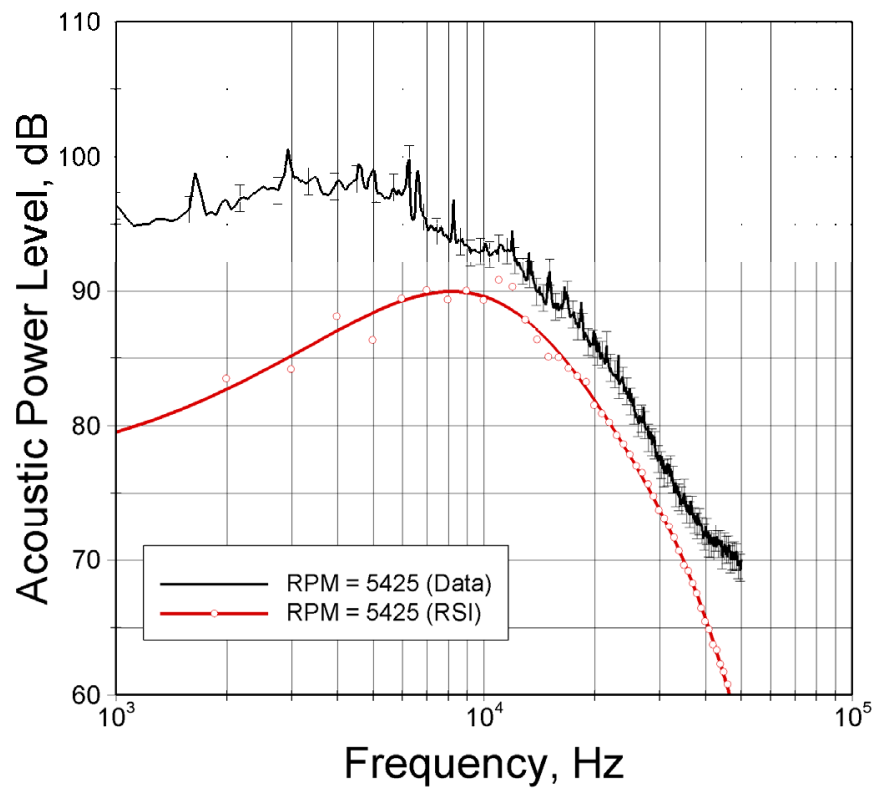

Figure A.19.-Comparisons of predicted (RSI) and measured narrowband sound power level for ADP at 5,425 rpm.

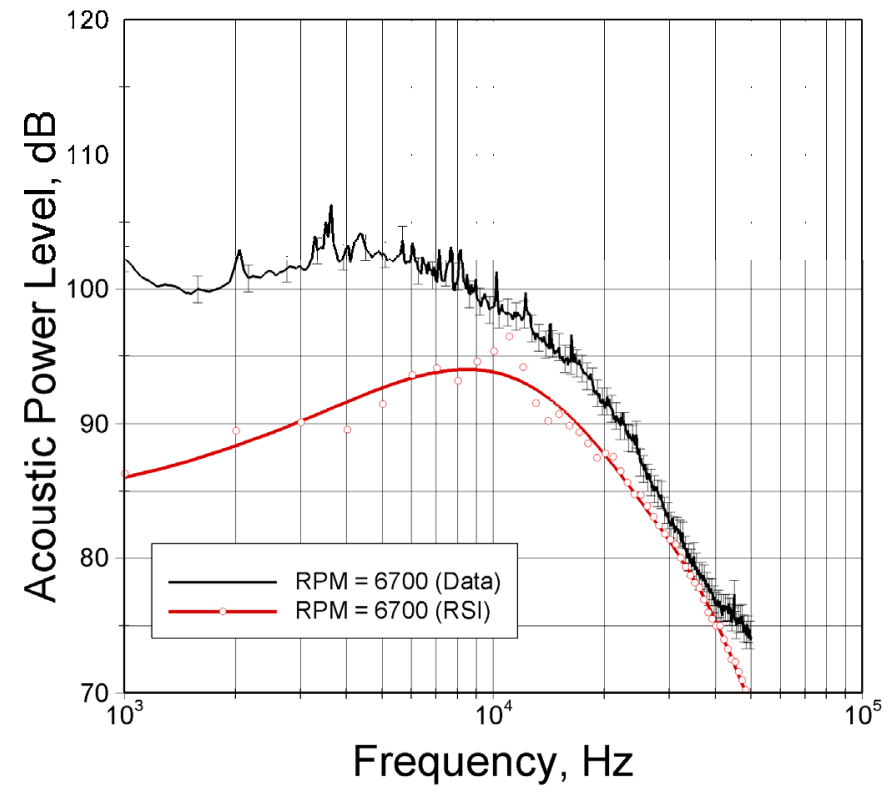

Figure A.20.-Comparisons of predicted (RSI) and measured narrowband sound power level for ADP at 6,700 rpm. 


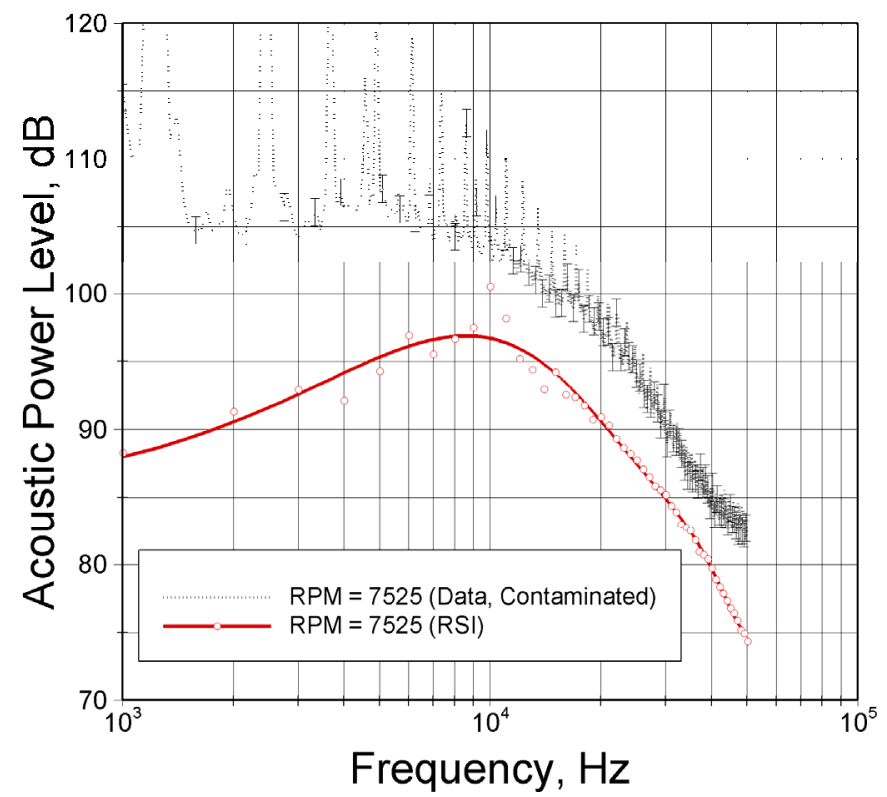

Figure A.21.-Comparisons of predicted (RSI) and measured narrowband sound power level for ADP at 7,525 rpm.

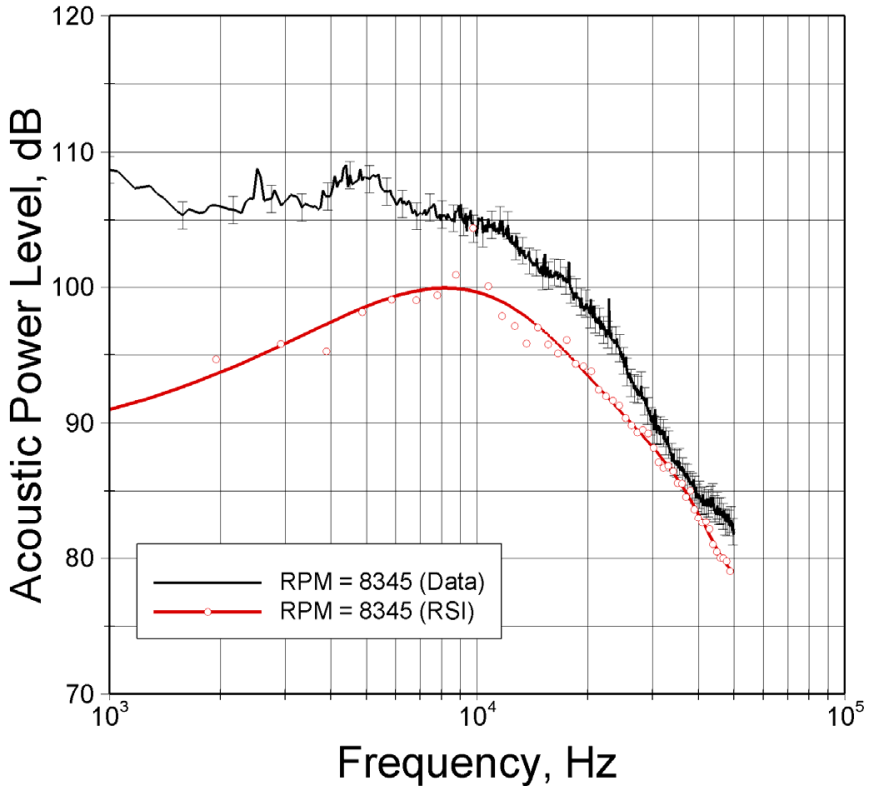

Figure A.22.-Comparisons of predicted (RSI) and measured narrowband sound power level for ADP at 8,345 rpm. 


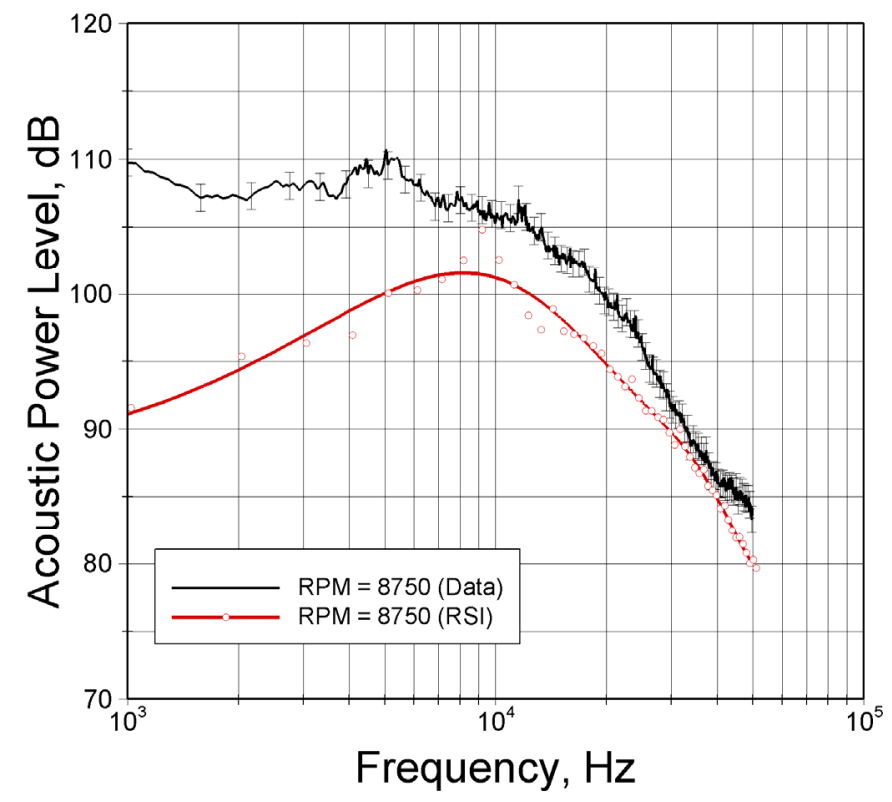

Figure A.23.-Comparisons of predicted (RSI) and measured narrowband sound power level for ADP at 8,750 rpm.

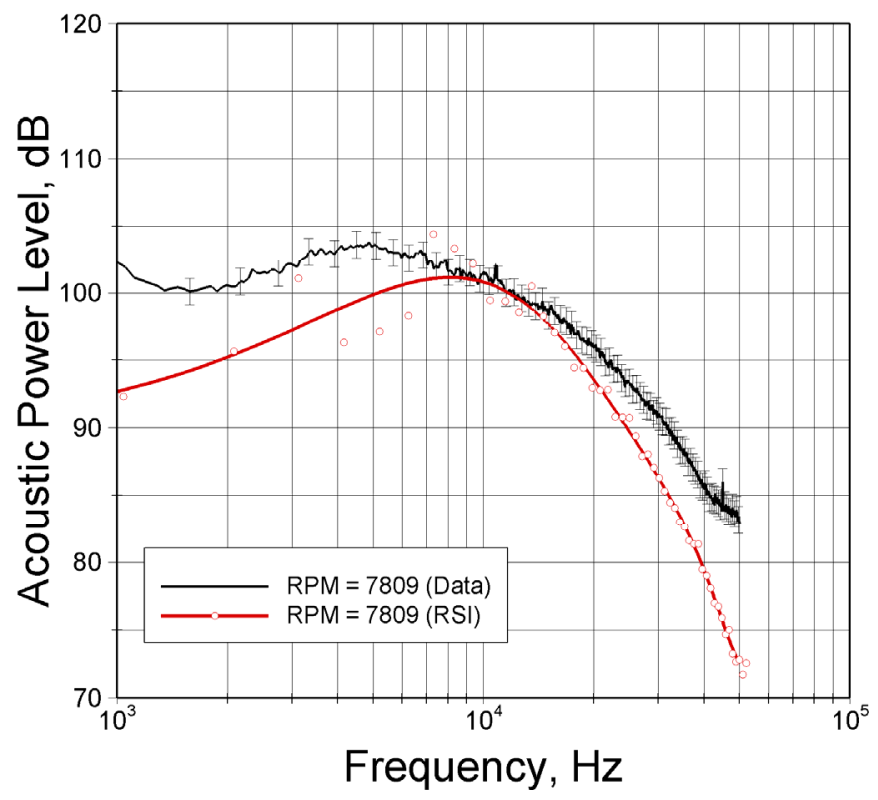

Figure A.24.-Comparisons of predicted (RSI) and measured narrowband sound power level for SDT at 7,809 rpm. 


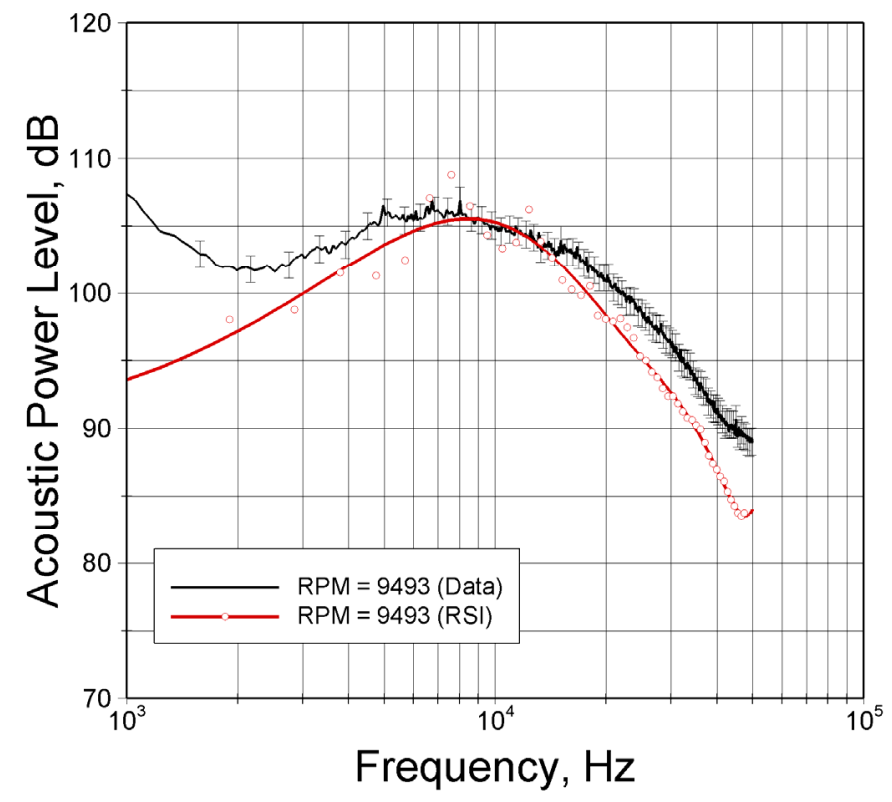

Figure A.25.-Comparisons of predicted (RSI) and measured narrowband sound power level for SDT at 9,493 rpm.

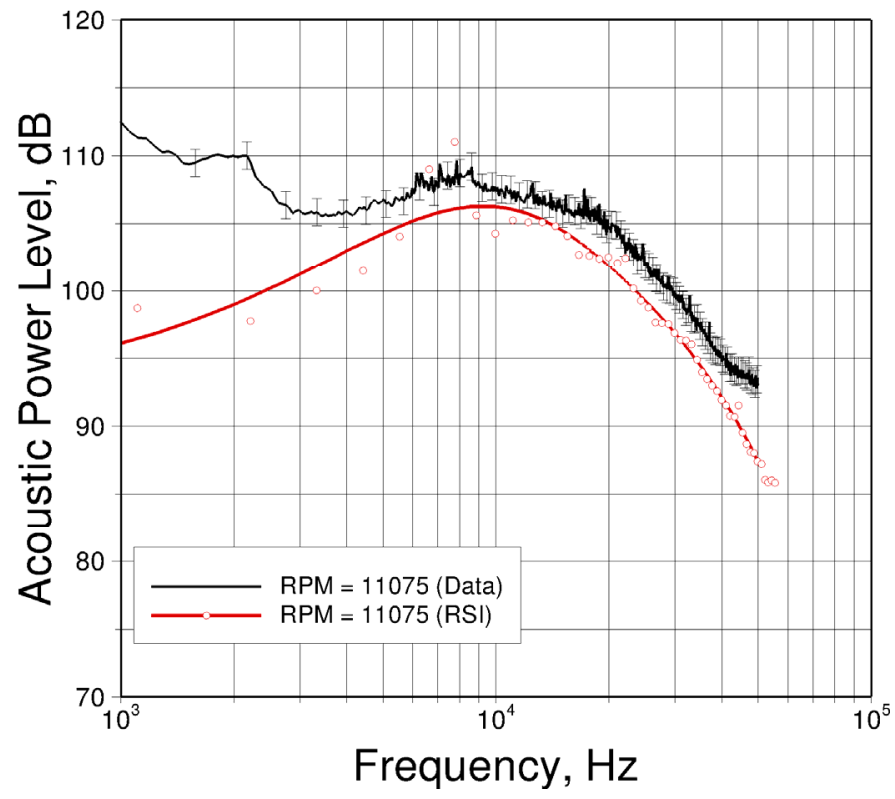

Figure A.26.-Comparisons of predicted (RSI) and measured narrowband sound power level for SDT at 11,075 rpm. 


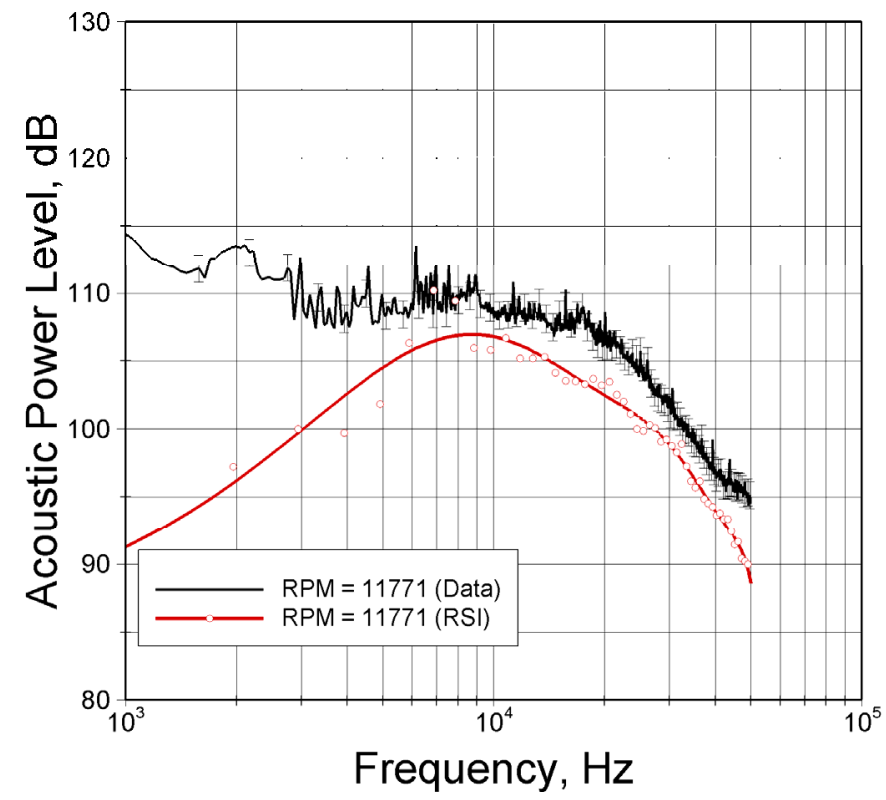

Figure A.27.-Comparisons of predicted (RSI) and measured narrowband sound power level for SDT at 11,771 rpm.

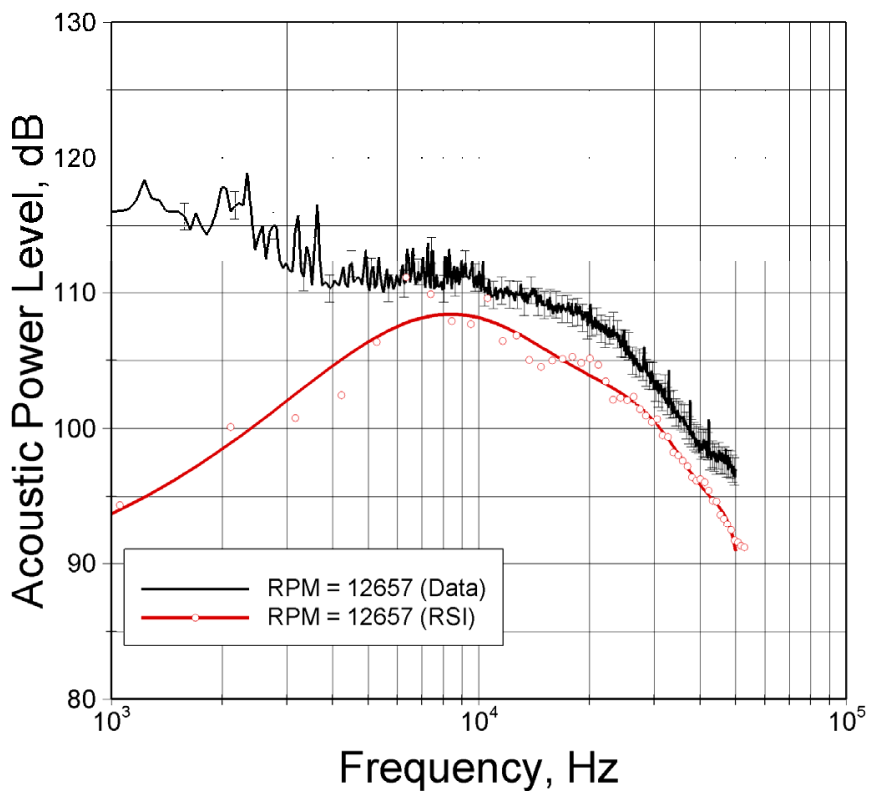

Figure A.28.-Comparisons of predicted (RSI) and measured narrowband sound power level for SDT at 12,675 rpm. 


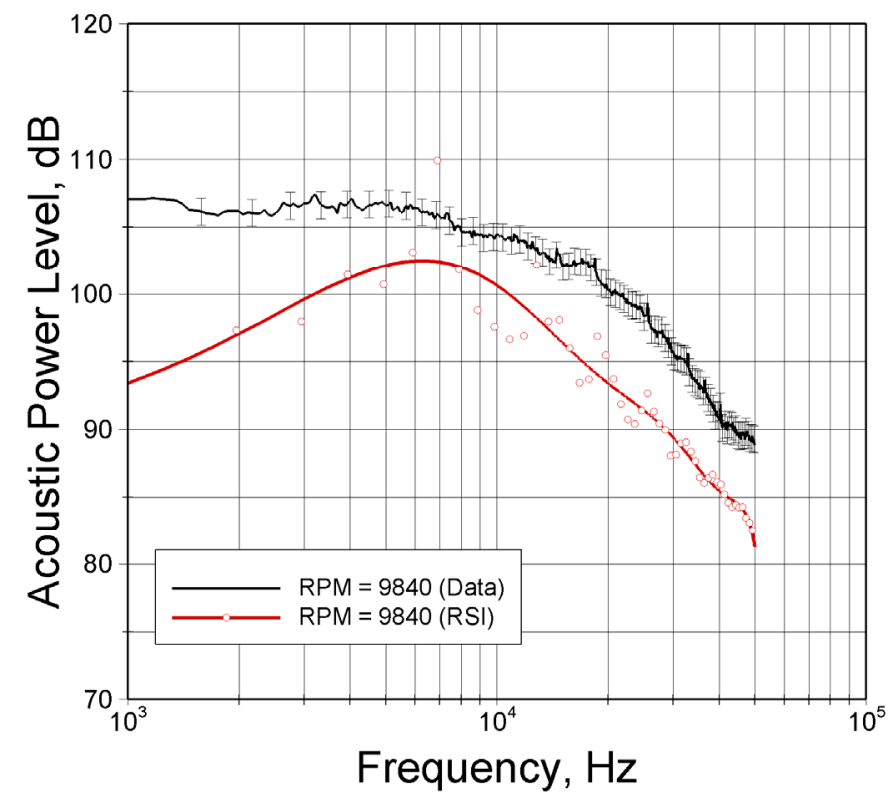

Figure A.29.-Comparisons of predicted (RSI) and measured narrowband sound power level for QHSF2 at 9,840 rpm.

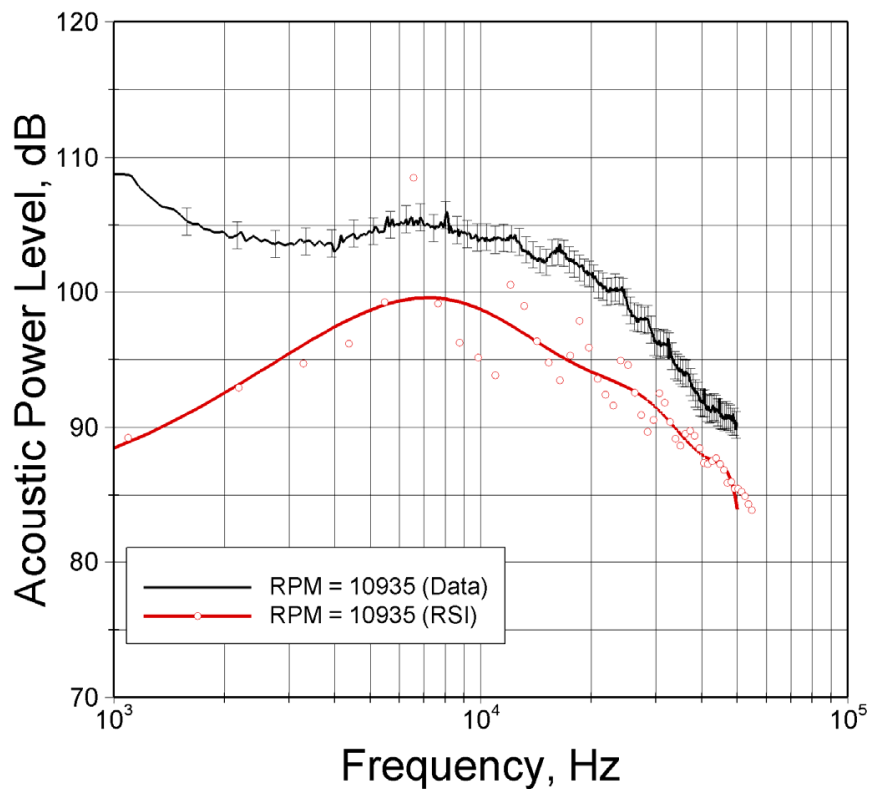

Figure A.30.-Comparisons of predicted (RSI) and measured narrowband sound power level for QHSF2 at 10,935 rpm. 


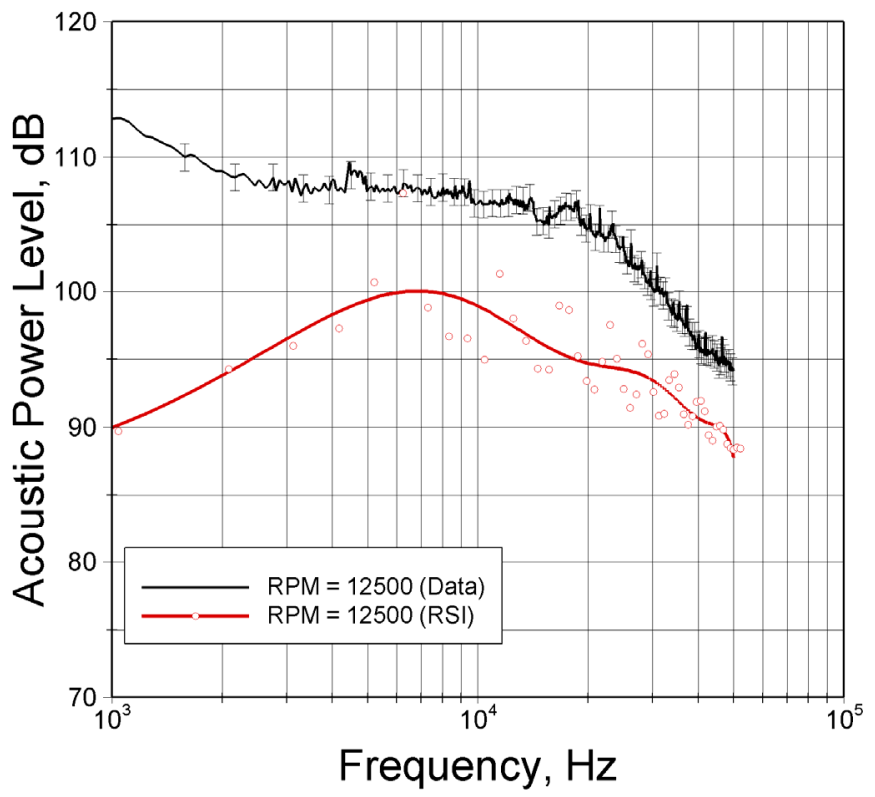

Figure A.31.-Comparisons of predicted (RSI) and measured narrowband sound power level for QHSF2 at 12,500 rpm.

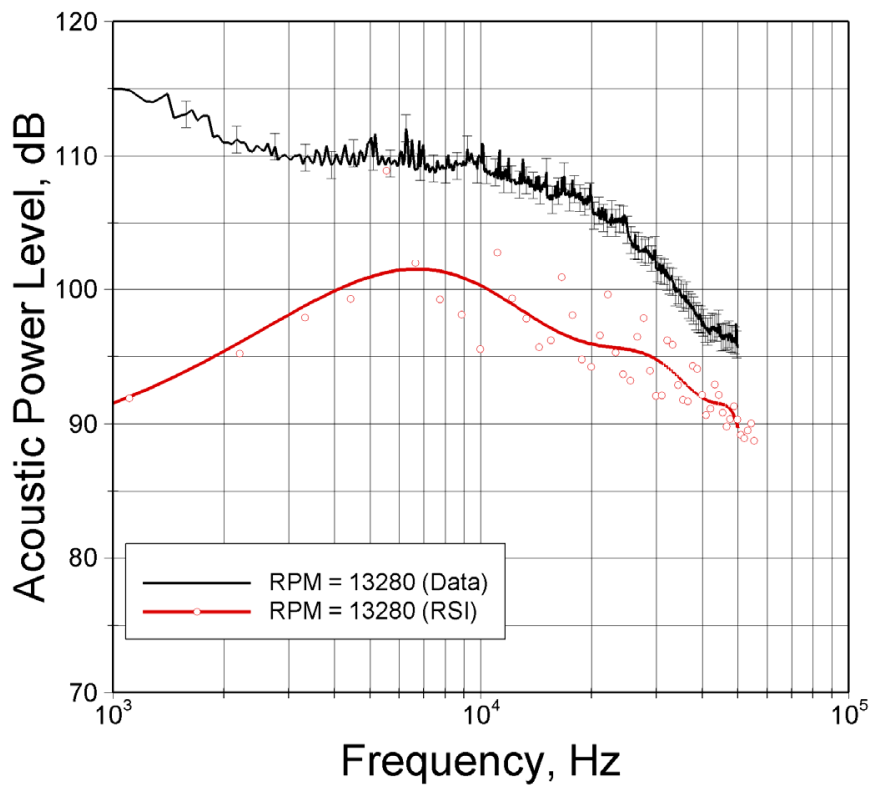

Figure A.32.-Comparisons of predicted (RSI) and measured narrowband sound power level for QHSF2 at 13,280 rpm. 


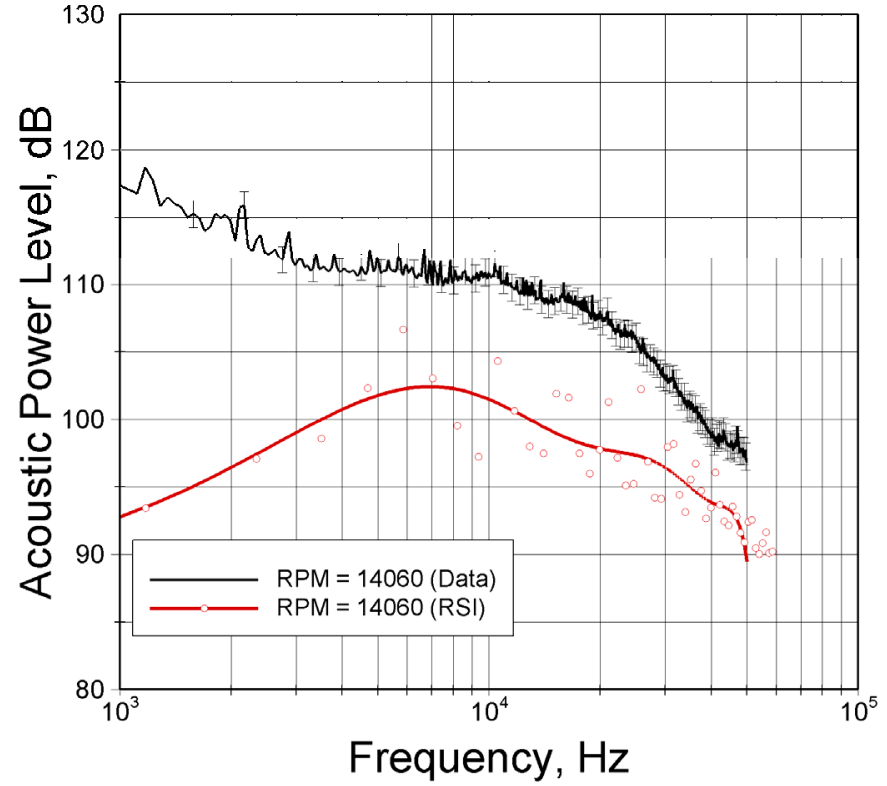

Figure A.33.-Comparisons of predicted (RSI) and measured narrowband sound power level for QHSF2 at 14,060 rpm. 


\section{References}

1. Jeracki, R.J., "Comprehensive Report of Fan Performance from Duct Rake Instrumentation on 1.294 Pressure Ratio, 8.06 $\mathrm{ft} / \mathrm{sec}$ Tip Speed Turbofan Simulator Models," NASA/TM-2006-213863.

2. Dittmar, J.H., Elliott, D.M, and Bock, L.A., "Some Acoustic Results from the Pratt and Whitney Advanced Ducted Propulsor-Fan 1," NASA/TM-1999-209049, 1999.

3. Woodward, R.P., Hughes, C.E., Jeracki, R.J., and Miller, C.J., "Fan Noise Source Diagnostic Test—Far Field Acoustic Results," ${ }^{\text {th }}$ AIAA/CEAS Aeroacoustics Conference, AIAA-2002-2427, 2002.

4. Hughes, C.E., "Aerodynamic Performance of Scale-Model Turbofan Outlet Guide Vanes Designed for Low Noise," $8^{\text {th }}$ AIAA/CEAS Aeroacoustics Conference, AIAA-2002-0374, 2002.

5. Dittmar, J.H., Elliott, D.M., and Fite, E.B., "The Noise of a Forward Swept Fan," NASA/TM-2003-212208, November 2003.

6. Weir, D., "Design and Test of Fan/Nacelle Models Quiet High-Speed Fan,” NASA/CR - 2003-212370, July 2003.

7. Yuska, J.A., Diedrich, J.H., and Nestor, C., "Lewis 9- by- 15-Foot V/STOL Wind Tunnel," NASA TM X-2305, 1971.

8. Arrington, A.E., and Gonsalez, J.C., "Flow Quality Improvements in the NASA Lewis Research Center 9- by 15-Foot Low Speed Wind Tunnel," NASA CR-195439, 1995.

9. Dahl, M.D., and Woodward, R.P., "Comparison Between Design and Installed Acoustic Characteristics of the NASA Lewis 9-by 15-Foot Low Speed Wind Tunnel Acoustic Treatment," NASA TP-2996, April 1990.

10. Dahl, M.D., and Woodward, R.P., "Background Noise Levels Measured I the NASA Lewis 9- by 15-Foot Low Speed Wind Tunnel," NASA TP-3274, November 1992.

11. Woodward, R.P., and Dittmar, J.H., "Background Noise Levels Measured in the NASA Lewis 9- by 15-Foot Low-Speed Wind Tunnel," NASA TM-106817, AIAA-95-0720, January 1995.

12. Chestnutt, D., "Flight Effects of Fan Noise," NASA CP-2242, January 1982

13. Sutliff, D.L., "Turbofan Duct Mode Measurements Using a Continuously Rotating Microphone Rake," International Journal of Aeroacoustics, vol. 6, no. 2, pp 147-170, 2007.

14. Sutliff, D.L., "Rotating Rake Mode Measurements Over Passive Treatment in a Ducted Fan," NASA/TM-2006-214493, 2006.

15. Dieck, R.H., Measurement Uncertainty; Methods and Applications, Fourth Edition, ISA, 2007.

16. Meyer, S.L., Data Analysis for Scientists and Engineers, John Wiley \& Sons, 1986.

17. Taylor, J.R., An Introduction to Error Analysis; The Study of Uncertainties in Physical Measurements, Second Edition, University Science Books, 1997.

18. Dahl, M.D., and Sutliff, D.L., "Numerical Technique for Analyzing Rotating Rake Mode Measurements in a Duct with Passive Treatment and Shear Flow", AIAA-2007-3679.

19. Gillian, R.E., "Aircraft Noise Prediction Program User's Manual," NASA TM-84486, 1982.

20. Zorumski, W.E., "Aircraft Noise Prediction Program Theoretical Manual,” NASA TM-83199 Part 1, February 1982.

21. Wilson, M.R., "An Introduction to High Speed Aircraft Noise Prediction," NASA Contractor Report 189592 (Contract NAS1-19000), February 1992, revised June 2005.

22. Kontos, K.B., Janardan, B.A., and Gliebe, P.R., "Improved NASA-ANOPP Noise Prediction Computer Code for Advanced Subsonic Propulsion Systems_-Volume 1: ANOPP Evaluation and Fan Noise Model Improvement," NASA CR-195480, April 1996.

23. Kontos, K.B., Kraft, R.E., and Gliebe, P.R., "Improved NASA-ANOPP Noise Prediction Computer Code for Advanced Subsonic Propulsion Systems_-Volume 2: Fan Suppression Model Development," NASA CR-202309, December 1996.

24. Chestnutt, D., "Flight Effects of Fan Noise," NASA CP-2242, January 1982.

25. Heidmann, M.F., "Interim Prediction Method for Fan and Compressor Source Noise," NASA TM X-71763, June 1979.

26. Brown, C.A., and Schifer, N.A., "Low Frequency Noise Contamination in Fan Model Testing," ASME Turbo Expo 2008 paper GT2008-50850, June 2008.

27. Nallasamy, N. and Envia, E., "Computation of Rotor Wake Turbulence Noise," Journal of Sound and Vibration, vol. 282, no. 3-5, pp. 649-678, April 22, 2005.

28. Chima, R.V., "Swift-Multiblock Analysis Code for Turbomachinery, User's Manual and Documentation," Version 300, August 2003 (Additional information found at URL: http://www.grc.nasa.gov/WWW/5810/rvc/docs.htm).

29. Hughes, C.E., Jeracki, R.J., Woodward, R.P., and Miller, C.J., "Fan Noise Source Diagnostic Test--Rotor Alone Aerodynamic Performance Results," AIAA-2002-2426, June 2002

30. Verdon, J.M., "Linearized Unsteady Aerodynamic Analysis of the Acoustic Response to Wake/Blade-Row Interaction," NASA/CR-2001-210713, January 2001. 


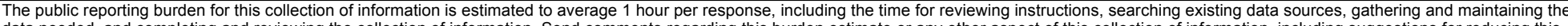

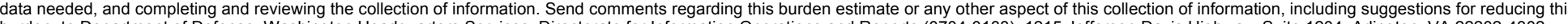

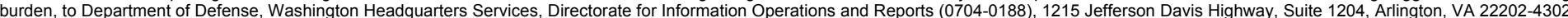

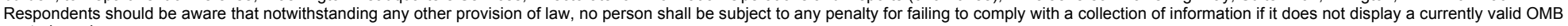
control number.

PLEASE DO NOT RETURN YOUR FORM TO THE ABOVE ADDRESS

\section{REPORT DATE (DD-MM-YYYY) \\ 2. REPORT TYPE \\ 3. DATES COVERED (From - To)}

01-10-2008

\section{TITLE AND SUBTITLE}

An Assessment of Current Fan Noise Prediction Capability

\section{5a. CONTRACT NUMBER}

5b. GRANT NUMBER

5c. PROGRAM ELEMENT NUMBER

\section{AUTHOR(S)}

Envia, Edmane; Tweedt, Daniel, L.; Woodward, Richard, P.; Elliott, David, M.; Fite, E.,

Brian; Hughes, Christopher, E.; Podboy, Gary, G.; Sutliff, Daniel, L.

\section{5d. PROJECT NUMBER}

5e. TASK NUMBER

5f. WORK UNIT NUMBER

WBS 561581.02.08.03.18.03

\section{PERFORMING ORGANIZATION NAME(S) AND ADDRESS(ES)}

National Aeronautics and Space Administration

8. PERFORMING ORGANIZATION

REPORT NUMBER

John H. Glenn Research Center at Lewis Field

E-16579

Cleveland, Ohio 44135-3191

\section{SPONSORING/MONITORING AGENCY NAME(S) AND ADDRESS(ES)}

National Aeronautics and Space Administration

Washington, DC 20546-0001

\section{SPONSORING/MONITORS ACRONYM(S) \\ NASA \\ 11. SPONSORING/MONITORING REPORT NUMBER \\ NASA/TM-2008-215415}

\section{DISTRIBUTION/AVAILABILITY STATEMENT}

Unclassified-Unlimited

Subject Categories: 01 and 64

Available electronically at http://gltrs.grc.nasa.gov

This publication is available from the NASA Center for AeroSpace Information, 301-621-0390

\section{SUPPLEMENTARY NOTES}

\section{ABSTRACT}

In this paper, the results of an extensive assessment exercise carried out to establish the current state of the art for predicting fan noise at NASA are presented. Representative codes in the empirical, analytical, and computational categories were exercised and assessed against a set of benchmark acoustic data obtained from wind tunnel tests of three model scale fans. The chosen codes were ANOPP, representing an empirical capability, RSI, representing an analytical capability, and LINFLUX, representing a computational aeroacoustics capability. The selected benchmark fans cover a wide range of fan pressure ratios and fan tip speeds, and are representative of modern turbofan engine designs. The assessment results indicate that the ANOPP code can predict fan noise spectrum to within $4 \mathrm{~dB}$ of the measurement uncertainty band on a third-octave basis for the low and moderate tip speed fans except at extreme aft emission angles. The RSI code can predict fan broadband noise spectrum to within $1.5 \mathrm{~dB}$ of experimental uncertainty band provided the rotor-only contribution is taken into account. The LINFLUX code can predict interaction tone power levels to within experimental uncertainties at low and moderate fan tip speeds, but could deviate by as much as $6.5 \mathrm{~dB}$ outside the experimental uncertainty band at the highest tip speeds in some case.

\section{SUBJECT TERMS}

Aeroacoustics; Aircraft noise; Noise prediction; Fan noise

\begin{tabular}{|c|c|c|c|c|}
\hline 16. SECURIT & ASSIFICATION & & 17. LIMITATION OF & 18. NUMBER \\
\hline $\begin{array}{l}\text { a. REPORT } \\
U\end{array}$ & $\begin{array}{l}\text { b. ABSTRACT } \\
\mathrm{U}\end{array}$ & $\begin{array}{l}\text { c. THIS } \\
\text { PAGE } \\
\text { U }\end{array}$ & UU & $\begin{array}{c}\text { PAGES } \\
52\end{array}$ \\
\hline
\end{tabular}

19a. NAME OF RESPONSIBLE PERSON
STI Help Desk (email:help@sti.nasa.gov)
19b. TELEPHONE NUMBER (include area code)
301-621-0390



